WAGNER DE CASTRO ANDRADE

\title{
Efeitos da administração de pentoxifilina e prednisolona na evolução da fibrose portal secundária à obstrução biliar : estudo experimental em animais em crescimento
}

Tese apresentada à Faculdade de Medicina da Universidade de São Paulo para obtenção do título de Doutor em Ciências

Área de concentração: Clínica Cirúrgica

Orientador: Prof. Dr. Uenis Tannuri

São Paulo

2008 


\section{Dados Internacionais de Catalogação na Publicação (CIP)}

Preparada pela Biblioteca da

Faculdade de Medicina da Universidade de São Paulo

Creprodução autorizada pelo autor

Andrade, Wagner de Castro

Efeitos da administração de pentoxifilina e prednisolona na evolução da fibrose portal secundária à obstrução biliar : estudo experimental em animais em crescimento / Wagner de Castro Andrade. -- São Paulo, 2008.

Tese(doutorado)--Faculdade de Medicina da Universidade de São Paulo. Departamento de Cirurgia.

Área de concentração: Clínica Cirúrgica.

Orientador: Uenis Tannuri.

Descritores: 1.Colestase extra-hepática 2.Cirrose hepática 3.Pentoxifilina 4.Corticosteróides 5.Animais de laboratório

USP/FM/SBD-270/08 
Esta pesquisa foi desenvolvida no Setor de Cirurgia Experimental do Instituto da Criança do Hospital das Clínicas e no Laboratório de Cirurgia Pediátrica (LIM-30) da Faculdade de Medicina da Universidade de São Paulo (FMUSP), com a colaboração do Laboratório de Investigação em Patologia Hepática (LIM-14).

O projeto do trabalho foi aprovado na Comissão de Ética para Análise de Projetos de Pesquisa da Diretoria Clínica do Hospital das Clínicas da FMUSP _ CAPPesq (protocolo $\mathrm{n}^{\circ}$ 0959/07) e realizado de acordo com as normas do Colégio Brasileiro de Experimentação Animal - COBEA ${ }^{1}$. 
Aos meus queridos pais, pela minha formação pré-acadêmica.

À minha esposa, pelo amor e apoio incondicionais. 


\section{AGRADECIMENTOS}

Ao Prof. Dr. João Gilberto Maksoud, pelo estímulo inicial para a realização desta tese.

Ao Prof. Dr. Uenis Tannuri, pela orientação efetiva e pelo estímulo constante. Por suas sugestões sempre preciosas e por sua objetividade invejável.

Ao Dr. Nelson Elias Mendes Gibelli, pela amizade e pelas importantes sugestões. Sua dedicação aos pacientes do Instituto da Criança tem sido exemplo constante para mim.

Ao Dr. Luiz Fernando Ferraz da Silva, pelo auxílio na avaliação histológica do material e na análise estatística dos dados.

Às Sras. Margarida Maria Damásio e Adriana Vasconcelos de Lacerda, pelo auxílio durante os procedimentos cirúrgicos no Laboratório de Cirurgia Experimental.

À Sra. Sandra Líria Adan Ogando, pelo preparo das soluções na Farmácia do Instituto da Criança.

Às Sras. Cássia Arruda e Neide Rosendo dos Santos, pelo preparo histológico do material. 
À Dra. Maria Mercês Santos, pela gentileza de dividir o espaço do Laboratório de Cirurgia Experimental e pelas sugestões no manejo dos animais.

Aos meus demais mestres da Disciplina de Cirurgia Pediátrica do Instituto da Criança do Hospital das Clínicas da FMUSP: Dr. Arthur Loghetti Mathias, Dr. Manoel Carlos Prieto Velhote, Dr. Ali Abdul Rahman Ayoub, Dr. Marcos Marques da Silva, Dr. João Gilberto Maksoud Filho e Dra. Maria Lúcia de Pinho-Apezzato, pela generosidade em compartilhar seus conhecimentos durante minha formação em cirurgia pediátrica e pelo apoio e estímulo durante a elaboração da tese. 
"Quando me aproximo de uma criança, ela me inspira dois sentimentos:

ternura pelo que ela é, e respeito pelo que ela pode se tornar."

Louis Pasteur

“Assim, pois, não é da vontade de vosso Pai celeste

que pereça um só destes pequeninos."

Mateus 18:14 
Esta tese está de acordo com as seguintes normas, em vigor no momento desta publicação:

Referências: adaptado de International Comitee of Medical Journals Editors (Vancouver)

Universidade de São Paulo. Faculdade de Medicina. Serviço de Biblioteca e Documentação. Guia de apresentação de dissertações, teses e monografias. Elaborado por Anneliese Carneiro da Cunha, Maria Júlia de A. L. Freddi, Maria F. Crestana, Marinalva de Souza Aragão, Suely C. Cardoso, Valéria Vilhena. 2a ed. São Paulo: Serviço de Biblioteca e Documentação; 2005.

Abreviaturas dos títulos dos periódicos de acordo com List of Journals Indexed in Index Medicus. 


\section{SUMÁRIO}

Lista de siglas e abreviaturas

Lista de figuras

Resumo

Summary

1. INTRODUÇÃO ....................................................................................... 1

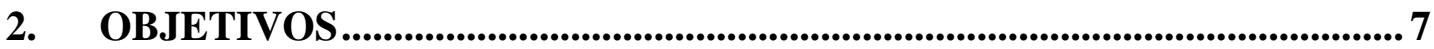

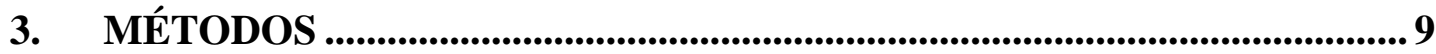

3.1 Animal de experimentação................................................................... 10

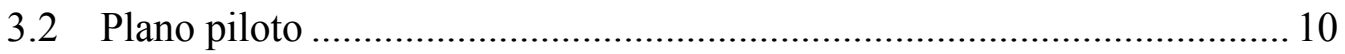

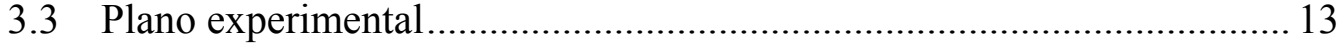

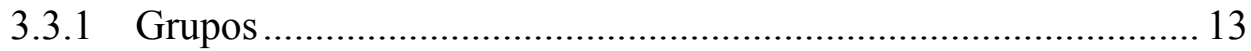

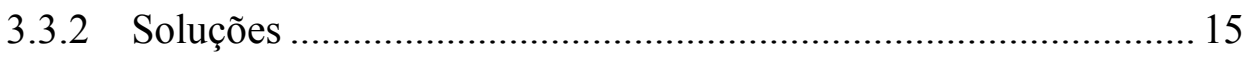

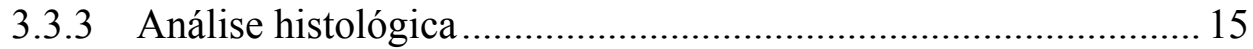

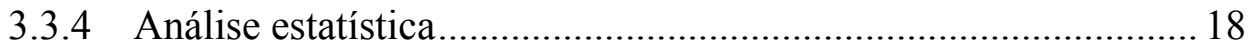

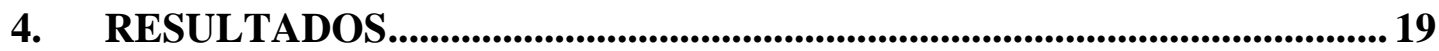

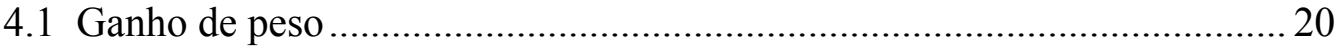

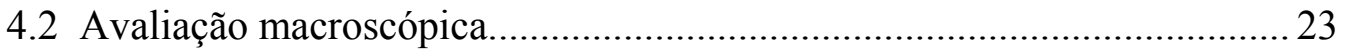

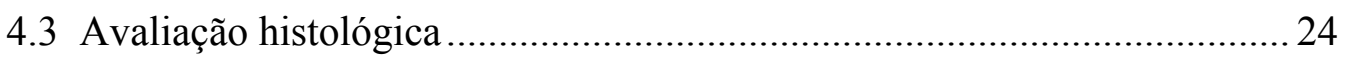

4.3.1 Hematoxilina-eosina .......................................................... 24

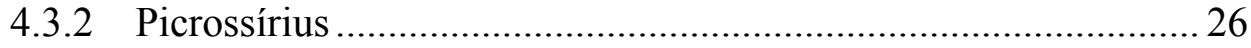

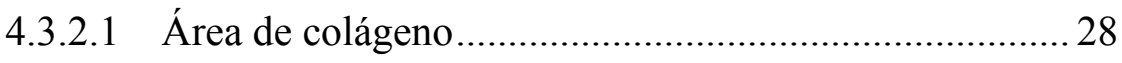

4.3.2.2 Área total............................................................... 30

4.3.2.3 Fração de área preenchida por colágeno ........................ 32

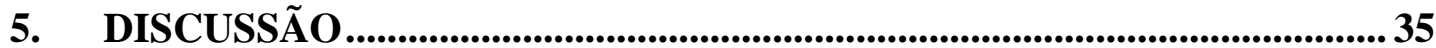

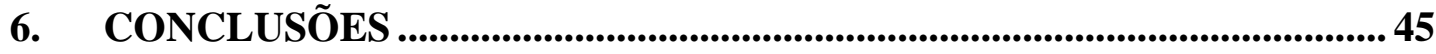

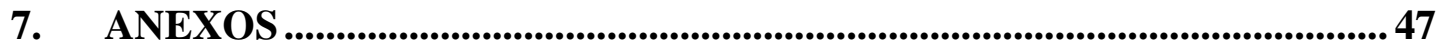

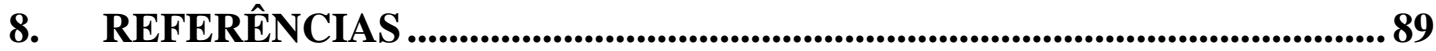


AVB atresia das vias biliares

$\mathrm{TNF} \alpha$ tumor necrosis factor alpha

TGF $\beta$ ..transforming growth factor beta

IL. interleucina

LIM laboratório de investigação médica

LDBC ligadura do ducto biliar comum

CS. cirurgia simulada PTX pentoxifilina

PRED .prednisolona

HE. hematoxilina-eosina $\mathrm{NF} \kappa \beta$. .nuclear factor kappa beta cAMP cyclic Adenosine MonoPhosphate cGMP cyclic Guanosine MonoPhosphate 


\section{LISTA DE FIGURAS}

Figura 1. Fotografia do ducto biliar comum dissecado e duplamente ligado rente ao duodeno - rato recém desmamado

Figura 2. Fotografia do procedimento de sondagem orogástrica para administração das medicações - rato jovem anestesiado.

Figura 3. Fotomicrografia digitalizada de espaço-porta para processamento no programa Image Pro-Plus ${ }^{\circledR}$ - coloração de picrossírius / aumento $200 x$

Figura 4. Fotomicrografia digitalizada com delimitação do espaço-porta e marcação da área preenchida por colágeno - programa Image Pro-Plus ${ }^{\circledR}$ coloração de picrossírius / aumento $200 \mathrm{x}$

Figura 5. Fotografia evidenciando diferença das dimensões dos animais ao final de 30 dias de tratamento: à esquerda - animal do grupo PTX; à direita animal do grupo PTX+PRED

Figura 6. Aspecto macroscópico do fígado e hilo hepático - animal do grupo LDBC 30 dias. Notar grande dilatação da via biliar extra-hepática (seta)....

Figura 7. Microfotografias de lâminas de fígado dos animais do grupo CS _à esquerda: 15 dias após laparotomia / à direita: 30 dias após laparotomia (coloração HE / aumento de 200x).

Figura 8. Microfotografias de lâminas de fígado dos animais do grupo LDBC à esquerda: 15 dias após ligadura biliar / à direita: 30 dias após ligadura biliar (coloração HE / aumento de 200x).

Figura 9. Microfotografias de lâminas de fígado dos animais do grupo PTX à̀ esquerda: 15 dias após ligadura biliar / à direita: 30 dias após ligadura biliar (coloração HE / aumento de 200x).

Figura 10. Microfotografias de lâminas de fígado dos animais do grupo PRED à esquerda: 15 dias após ligadura biliar / à direita: 30 dias após ligadura biliar (coloração HE / aumento de 200x). 
Figura 11. Microfotografias de lâminas de fígado dos animais do grupo PTX+PRED _ à esquerda: 15 dias após ligadura biliar / à direita: 30 dias após ligadura biliar (coloração HE / aumento de 200x)

Figura 12. Microfotografias de lâminas de fígado dos animais do grupo CS _à esquerda: 15 dias após laparotomia / à direita: 30 dias após laparotomia (coloração picrossírius / aumento de 200x)

Figura 13. Microfotografias de lâminas de fígado dos animais do grupo LDBC à esquerda: 15 dias após ligadura biliar / à direita: 30 dias após ligadura biliar (coloração picrossírius / aumento de 200x)

Figura 14. Microfotografias de lâminas de fígado dos animais do grupo PTX à esquerda: 15 dias após ligadura biliar / à direita: 30 dias após ligadura biliar (coloração picrossírius / aumento de 200x)

Figura 15. Microfotografias de lâminas de fígado dos animais do grupo PRED à esquerda: 15 dias após ligadura biliar / à direita: 30 dias após ligadura biliar (coloração picrossírius / aumento de 200x)

Figura 16. Microfotografias de lâminas de fígado dos animais do grupo PTX+PRED _à esquerda: 15 dias após ligadura biliar / à direita: 30 dias após ligadura biliar (coloração picrossírius / aumento de 200x). 


\section{RESUMO}

Andrade WC. Efeitos da administração de pentoxifilina e prednisolona na evolução da fibrose portal secundária à obstrução biliar - estudo experimental em animais em crescimento [tese]. São Paulo: Faculdade de Medicina, Universidade de São Paulo; 2008. 98p.

INTRODUÇÃO: Diversas doenças crônicas do fígado resultam em desenvolvimento de fibrose do parênquima, condição que pode culminar em perda de função do órgão e hipertensão portal grave com indicação de transplante. Nas últimas décadas, alguns estudos têm buscado demonstrar a possibilidade de modulação farmacológica do processo de fibrogênese hepática. Particularmente com relação às obstruções biliares, tem-se sugerido que a administração de corticosteróides pode promover melhora no prognóstico tardio das crianças portadoras de atresia das vias biliares submetidas a portoenterostomia (cirurgia de Kasai). Nenhum trabalho experimental foi realizado com o objetivo de verificar essa hipótese e os modelos descritos para estudo de outras drogas com potencial antifibrogênico, como a pentoxifilina, não incluíram animais jovens. MÉTODOS: Foram operados 119 ratos jovens $\left(21^{\circ}\right.$ ou $22^{\circ}$ dias de vida), submetidos a laparotomia com ligadura do ducto biliar comum (LDBC) ou cirurgia simulada (CS). Os animais foram divididos em 5 grupos, conforme o procedimento cirúrgico e a medicação administrada: 1. LDBC + água destilada; 2. CS + água destilada; 3. LDBC + pentoxifilina (PTX); 4. LDBC + prednisolona (PRED); 5. LDBC + pentoxifilina + prednisolona (PTX+PRED). Cada grupo foi dividido em 2 subgrupos conforme a duração do experimento (15 ou 30 dias). Ao final do período, os animais foram pesados e submetidos a retirada de um fragmento de fígado, coletado para análise histológica através das colorações de hematoxilina-eosina e de picrossírius. As lâminas coradas pelo picrossírius foram utilizadas para análise quantitativa (morfometria digital) da área preenchida por colágeno e da área total dos espaços-porta. Após a obtenção desses valores, foi calculada a fração de área de colágeno de cada grupo. RESULTADOS: Os animais do grupo PTX apresentaram maior ganho de peso do que os dos grupos PRED e PTX+PRED. Os animais dos 3 grupos terapêuticos (PTX, PRED e PTX+PRED) apresentaram diminuição da área preenchida por colágeno nos espaços-porta. A área total dos espaços-porta foi maior no grupo PTX. CONCLUSÕES: A evolução da fibrose hepática induzida pela ligadura biliar em ratos jovens pôde ser modificada com o uso de medicamentos. A administração de prednisolona e pentoxifilina, isoladamente ou em associação, resultou em diminuição da área preenchida por colágeno nos espaços-porta.

Descritores: 1.Colestase extra-hepática 2.Cirrose hepática 3.Pentoxifilina 4.Corticosteróides 5.Animais de laboratório 


\section{SUMMARY}

Andrade WC. Effects of administration of pentoxifylline and prednisolone on evolution of portal fibrosis secondary to biliary obstruction - experimental study in growing animals [thesis]. São Paulo: "Faculdade de Medicina, Universidade de São Paulo"; 2008. 98p.

INTRODUCTION: Many chronic liver diseases lead to progressive establishment of hepatic fibrosis, condition that can ultimately result in loss of organ function and severe portal hypertension demanding hepatic transplantation. Within the last decades, some studies have been conducted in order to demonstrate the possibility of drug modulation of hepatic fibrogenesis. Particularly related to biliary obstruction, it has been suggested that administration of corticosteroids could promote better late outcomes for biliary atresia children submitted to Kasai's portoenterostomy. There is no published experimental study related to that issue, and described models used to test potential antifibrogenic drugs, such as pentoxifylline, have not included growing animals. METHODS: In this experimental study, 119 young rats $\left(21^{\text {st }}\right.$ or $22^{\text {nd }}$ days $)$ were submitted to laparotomy and bile duct ligation (BDL) or sham surgery (SHAM). Animals were divided into 5 groups, according to surgical procedure and administered solution: 1 . BDL + distilled water; 2 . SHAM + distilled water; 3 . BDL + pentoxifylline (PTX); 4. BDL + prednisolone (PRED); 5. BDL + pentoxifylline + prednisolone (PTX+PRED). Each group was further divided into 2 subgroups according to the length of the experiment (15 or 30 days). At the end of the defined period, animals were weighed and one hepatic fragment was collected from each one for histological analysis using hematoxylin-eosin and Sirius red stains. Sirius red stained slides were examined for quantitative analysis (digital morphometry) of collagen-filled area and portal space total area. RESULTS: PTX group animals presented increased weight gain compared to PRED or PTX+PRED groups. Animals from the 3 therapeutic groups (PTX, PRED and PTX+PRED) showed diminished collagen-filled area in portal spaces. Total portal space area was increased in PTX group slides. CONCLUSIONS: Hepatic fibrosis induced by bile duct ligation in young rats could be modulated by pharmacologic interventions. Pentoxifylline and prednisolone administration, associated or not, resulted in diminished collagen-filled area in portal spaces.

Descriptors:1.Extrahepatic cholestasis 2.Hepatic cirrhosis 3.Pentoxifylline 4.Corticosteroids 5.Laboratory animals 
1. INTRODUÇÃO 
Diversas doenças crônicas do fígado apresentam, em sua história natural, desenvolvimento de fibrose do parênquima, definida como um acúmulo dos componentes da matriz extracelular ${ }^{2}$. Esse aumento de tecido conjuntivo determina distorções estruturais que resultam em perda da função do órgão e aumento da resistência ao fluxo sanguíneo. Embora a agressão hepática crônica que desencadeia a fibrose possa ser conseqüente a diversos agentes químicos, metabólicos e biológicos que atuam de maneiras distintas, a cicatriz fibrótica que se estabelece no fígado terá exatamente a mesma composição da matriz extracelular e as mesmas características da fibrose de outros tecidos ${ }^{3}$.

Na criança, do conjunto de doenças cuja via final comum é o estabelecimento de fibrose hepática, destacam-se as colestases (do grego cole $=$ bile e stasis $=$ parada). A causa mais freqüente de colestase neonatal é a atresia das vias biliares (AVB), condição que acomete 1:8000 a 1:12000 nascidos vivos ${ }^{4}$.

A etiopatogenia da AVB não se encontra totalmente esclarecida, sendo provável que a doença seja a manifestação fenotípica de diferentes mecanismos que podem atuar de forma isolada ou conjuntamente. Causas genéticas, agentes exógenos (vírus e toxinas), mecanismos imunológicos e malformação da placa ductal podem estar implicados no desenvolvimento dessa condição, que se não tratada, evolui rapidamente para insuficiência hepática por cirrose biliar, com sobrevida média inferior a 2 anos. No Brasil, a AVB é responsável por cerca de $60 \%$ das indicações de transplante hepático na criança ${ }^{5}$. 
O diagnóstico da AVB baseia-se na história clínica e exame físico característicos, associados à análise histológica de fragmento hepático obtido por meio de biópsia percutânea. Quando o diagnóstico é feito precocemente, ou seja, antes do estabelecimento de fibrose hepática grave e suas conseqüências, o tratamento cirúrgico inicial deve ser a realização de portoenterostomia hepática, conforme descrito por Kasai e Suzuki em 1959. Esse procedimento foi posteriormente modificado por diversos cirurgiões, porém manteve-se o princípio básico da anastomose do "porta hepatis" com um segmento de alça intestinal. O sucesso da cirurgia depende da obtenção de fluxo biliar através dos pequenos canalículos presentes na área de secção do resquício fibroso das vias biliares extrahepáticas. Infelizmente, apenas cerca de $20 \%$ dos pacientes têm sobrevida prolongada conservando o fígado original, sem que ocorra rápido desenvolvimento de insuficiência hepática e hipertensão portal. Nos demais casos, haverá necessidade de realização de transplante hepático nos primeiros anos de vida ${ }^{5,6}$.

Desde o final da década de 70, alguns pesquisadores têm sugerido que a utilização de corticosteróides poderia promover alguma melhora do prognóstico tardio dos portadores de AVB submetidos à cirurgia de Kasai. Inicialmente essa classe de drogas foi associada aos antibióticos durante o tratamento dos episódios de colangite, visando a reduzir o processo inflamatório secundário à infecção na placa biliar, o que supostamente diminuiria a permeabilidade dos pequenos ductos, afetando permanentemente o fluxo biliar $^{7}$. Posteriormente, ampliou-se empiricamente a utilização dos corticosteróides para o período perioperatório, segundo vários esquemas posológicos, sem padronização definida ${ }^{8}$. Nos últimos anos, alguns grupos têm publicado os resultados dessa nova abordagem, concluindo que foi possível obter uma 
porcentagem maior de crianças anictéricas após a portoenterostomia, embora o impacto a longo prazo_ sobrevida sem transplante_ainda não tenha sido demonstrado definitivamente ${ }^{9-11}$. Esses ensaios clínicos publicados apresentam amostras pequenas de pacientes e alguns não são controlados. Nenhum trabalho experimental específico nessa área foi publicado até o presente momento.

Em contrapartida, existem diversas publicações recentes que demonstram a busca dos pesquisadores por fármacos que modulem o processo de fibrogênese em diversos tecidos ${ }^{12-14}$. Culturas de células e diferentes modelos experimentais têm sido utilizados para testar o efeito antifibrogênico de algumas classes de drogas, frente a vários tipos de agressão tissular ${ }^{15,16}$.

Um dos medicamentos mais estudados a partir da década de 90 tem sido a pentoxifilina, um inibidor da fosfodiesterase derivado das metil-xantinas, habitualmente utilizado na prática clínica para o tratamento da insuficiência arterial periférica, pelo seu efeito de aumento do transporte de oxigênio aos territórios periféricos decorrente da ação vasodilatadora e de aumento da deformabilidade eritrocitária ${ }^{14,16,17}$.

Alguns estudos sugerem um efeito antifibrogênico "in vitro" e "in vivo" da pentoxifilina secundário à inibição da síntese de citocinas pró-inflamatórias como tumor necrosis factor alpha (TNF $\alpha)$, transforming growth factor beta (TGF $\beta$ ) e interleucina (IL) 1 , IL 6 e IL $8^{18,19}$. Outros trabalhos não demonstraram efeito antiinflamatório estatisticamente significativo em animais tratados com a medicação ${ }^{16,20}$. Diversos modelos experimentais foram descritos nessas publicações, incluindo porcos tratados com fósforo amarelo, ratos adultos submetidos a ligadura do ducto biliar, ratos tratados com tetracloreto de carbono e voluntários humanos ${ }^{21}$. 
Os resultados da administração de pentoxifilina nessas espécies foram controversos, não sendo possível estabelecer um consenso sobre a questão. Nenhum dos modelos estudados incluiu animais jovens.

Uma das principais características histológicas encontrada nos fígados de portadores de AVB e de outras formas de obstrução biliar é a proliferação ductular ${ }^{22}$. Alguns modelos experimentais foram descritos visando à obtenção de alterações estruturais hepáticas semelhantes às demonstradas nas atresias, possibilitando a realização de estudos para melhor compreensão dos mecanismos fisiopatológicos envolvidos na doença.

Riepenhoff-Talty et al descreveram um modelo experimental de indução de destruição inflamatória progressiva dos ductos biliares intra e extra-hepáticos através de inoculação de rotavírus em camundongos recém-nascidos ${ }^{23}$.

Cameron e Oakley descreveram em 1932 um método para obtenção de ratos com cirrose através de ligadura do ducto biliar comum ${ }^{24}$. Esse se tornou um dos modelos experimentais mais utilizados para o estudo das doenças colestáticas do adulto. Posteriormente, outros autores estudaram as diferenças histológicas obtidas com a mesma técnica aplicada em ratos jovens ${ }^{25,26}$.

Gibelli, em 2003, descreveu as alterações encontradas na aplicação do modelo de ligadura biliar em ratos jovens e adultos, demonstrando a evolução mais intensa da fibrose nos animais jovens ${ }^{27,28}$. Esse estudo foi desenvolvido no Laboratório de Cirurgia Pediátrica da Faculdade de Medicina da Universidade de São Paulo (LIM-30) e no Setor de Cirurgia Experimental do Instituto da Criança, constituindo o início de uma linha de pesquisa sobre o assunto. 
A proposta desta tese surgiu como continuidade desse trabalho inicial, utilizando o modelo experimental de cirrose em ratos jovens induzida pela ligadura biliar para estudar algumas possibilidades farmacológicas de modulação da evolução da fibrose hepática em condições mais semelhantes às que são encontradas durante a fisiopatogenia da cirrose decorrente da AVB. 


\section{OBJETIVOS}


Os objetivos da presente pesquisa foram:

1. Verificar a possibilidade de modulação da evolução da fibrose hepática promovida pela ligadura do ducto biliar comum em ratos jovens através de administração de medicamentos.

2. Comparar a evolução da fibrose portal secundária à obstrução biliar durante a administração de duas drogas usadas isoladamente e em associação: pentoxifilina e prednisolona. 
3. MÉTODOS 


\subsection{Animal de experimentação}

Foram utilizados ratos Wistar adultos de ambos os sexos, fornecidos pelo Centro de Bioterismo da FMUSP e transportados para o Setor de Cirurgia Experimental do Instituto da Criança. Os animais foram mantidos em gaiolas com água e ração "ad libitum" e acasalados para obtenção dos ratos jovens utilizados no experimento.

$\mathrm{O}$ número de filhotes de cada prole variou de 5 a 14 animais. $\mathrm{O}$ desmame ocorreu no $21^{\circ}$ dia de vida, quando os ratos pesavam de 31,4 a $83,2 \mathrm{~g}$.

\subsection{Plano piloto}

Todos os animais foram operados pelo mesmo cirurgião, auxiliado pelo técnico do laboratório. Inicialmente foram operados 10 ratos adultos (média dos pesos: $232 \mathrm{~g} \pm 13,21 \mathrm{~g}$ ), para padronização dos procedimentos anestésicos e da técnica cirúrgica.

Indução e manutenção do plano anestésico foram obtidas com administração de éter isopropílico por via inalatória em sistema aberto e ventilação espontânea. Os parâmetros utilizados para avaliar analgesia intra-operatória e profundidade da anestesia foram obtenção de imobilidade e relaxamento muscular dos animais.

Após a indução anestésica, cada animal foi pesado em balança de precisão, fixado à prancha cirúrgica com esparadrapo poroso nas quatro patas e submetido a 
tricotomia abdominal com lâmina de bisturi. O acesso à cavidade peritoneal foi obtido sem técnica asséptica, por incisão longitudinal mediana supra-umbilical, permitindo a visualização do hilo hepático após manobra de retração do fígado com afastador de Farabeuf pequeno e tração delicada do duodeno, em sentido caudal, aplicada com o auxílio de um cotonete. Dessa forma, facilitou-se a exposição da via biliar comum desde a junção dos ductos lobares até a inserção do ducto principal na alça intestinal. Utilizando material de microcirurgia, procedeu-se à dissecção do ducto biliar e ligadura dupla com fio inabsorvível de polipropileno 7.0, seguida de secção da via biliar (Figura 1). A síntese da parede abdominal foi realizada com fio de polipropileno 6.0 em plano único de sutura contínua. Assim que a anestesia inalatória era descontinuada, os ratos eram lavados em água morna e recolocados na maravalha.

Passando à fase seguinte, iniciaram-se as cirurgias nos animais jovens, quando algumas dificuldades técnicas foram descobertas. Segundo o protocolo previamente estabelecido, os ratos seriam operados com 3 dias de vida, porém a mortalidade intra e pós-operatória se mostrou muito alta, atingindo 59,5\% (22/37) dos recém-nascidos. Os óbitos foram ocasionados pelos seguintes fatores: depressão respiratória durante a anestesia, sangramentos incontroláveis durante a manipulação do fígado e alto índice de canibalismo praticado pela mãe após a reunião com a prole recém operada. Adicionalmente, verificou-se a impossibilidade de instalar sonda orogástrica em animais com dimensões tão reduzidas, o que inviabilizaria a administração diária das medicações em doses controladas. A partir dessas constatações, modificou-se a proposta inicial e passaram a ser operados animais recém-desmamados, com 21 ou 22 dias de vida. 


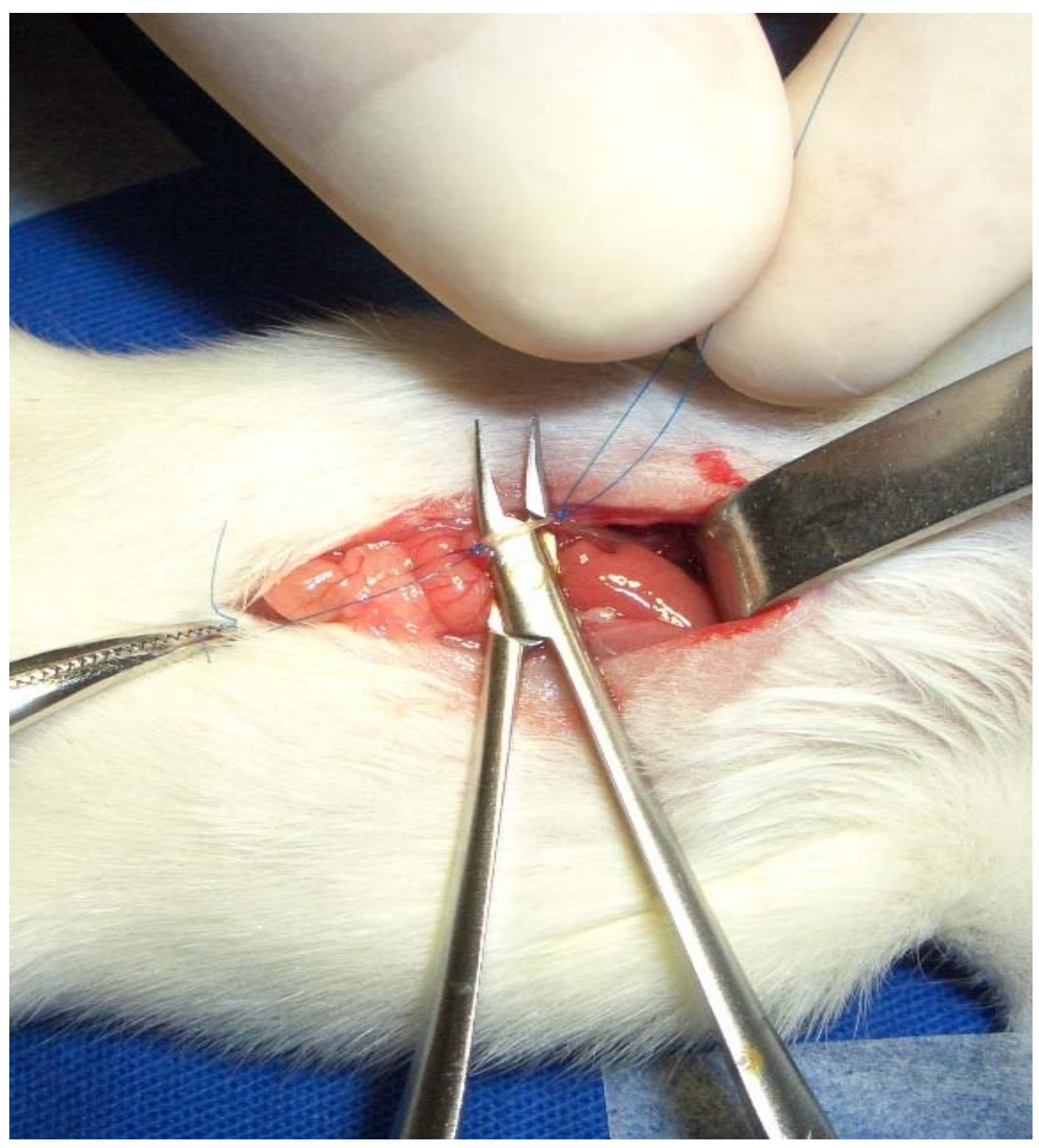

Figura 1. Fotografia do ducto biliar comum dissecado e duplamente ligado rente ao duodeno - rato recém desmamado 


\subsection{Plano experimental}

\subsubsection{Grupos}

Nesta fase, foram operados 119 ratos jovens, recém-desmamados, no $21^{\circ} \mathrm{ou}$ $22^{\circ}$ dias de vida, conforme padronização descrita na seção anterior. A sobrevida desse grupo foi de 92,4\% (110/119). Os animais foram divididos aleatoriamente em cinco grupos, conforme o procedimento cirúrgico e a solução administrada:
A. ligadura do ducto biliar comum (LDBC) + água destilada;
B. cirurgia simulada (CS) + água destilada;
C. $\mathrm{LDBC}+$ pentoxifilina $10 \mathrm{mg} / \mathrm{kg} / \mathrm{dia}(\mathrm{PTX})$;
D. LDBC + prednisolona $3 \mathrm{mg} / \mathrm{kg} /$ dia (PRED);
E. LDBC + pentoxifilina $10 \mathrm{mg} / \mathrm{kg} / \mathrm{dia}+$ prednisolona $3 \mathrm{mg} / \mathrm{kg} / \mathrm{dia}$ (PTX+PRED)

No grupo B, os animais foram submetidos ao mesmo procedimento anestésico, porém a cirurgia foi interrompida após a exposição do hilo hepático e procedeu-se ao fechamento da parede abdominal.

As doses das medicações corresponderam às habitualmente utilizadas na prática clínica em crianças e adultos. A duração máxima do tratamento (30 dias) foi determinada após a constatação da rápida evolução da cirrose biliar, indicando que a sobrevida média dos animais do grupo A não atingiria mais de 45 dias.

Imediatamente após o término do procedimento, todos os ratos receberam a primeira dose de água ou medicação através de sondagem orogástrica (sonda plástica 
$\mathrm{n}^{\circ} 4$ ou 6). A partir do dia seguinte, diariamente ao final da tarde, os animais foram novamente anestesiados, pesados e submetidos à sondagem gástrica para administração da solução correspondente (Figura 2).

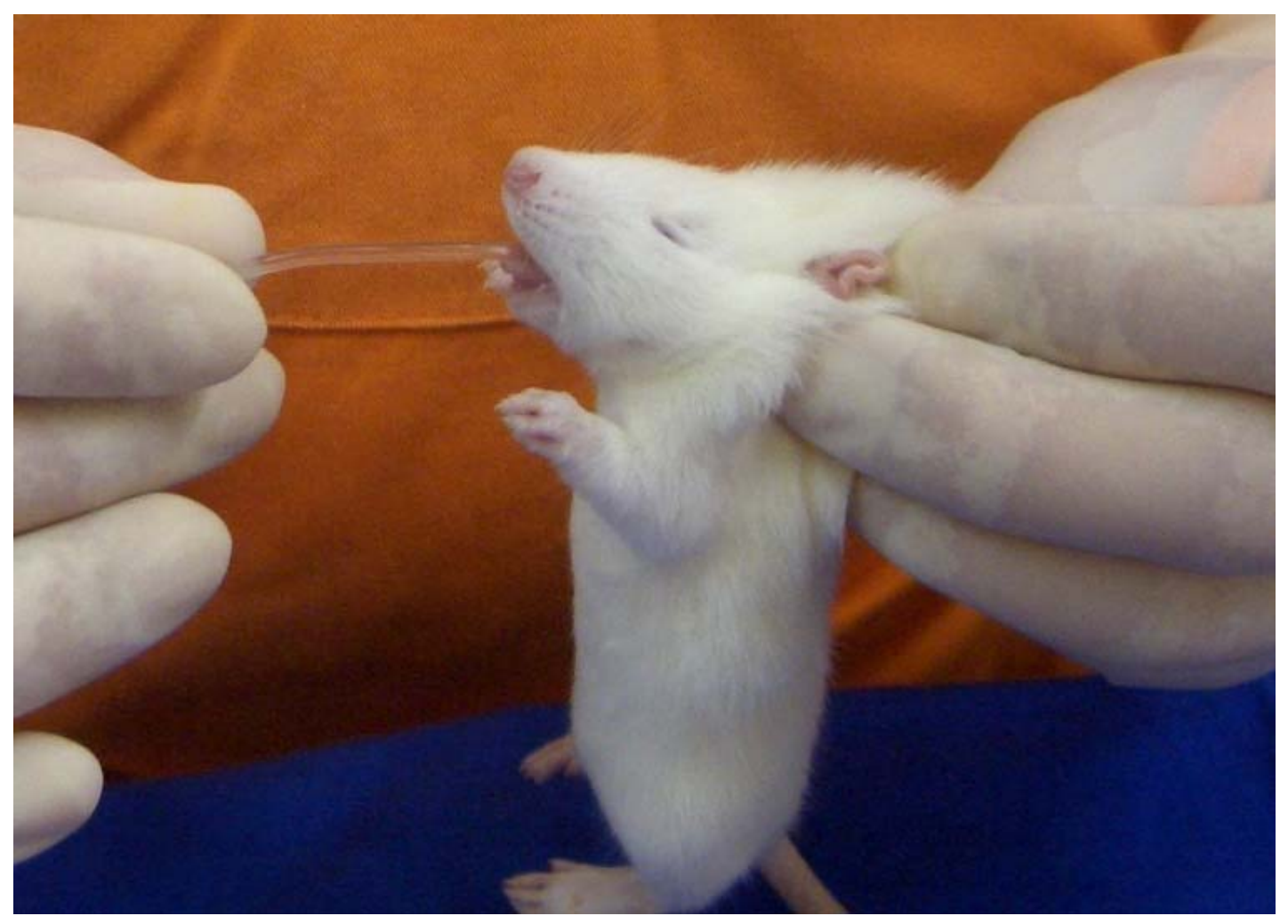

Figura 2. Fotografia do procedimento de sondagem orogástrica para administração das medicações - rato jovem anestesiado

Cada grupo foi posteriormente dividido, também aleatoriamente, em dois subgrupos conforme a duração do experimento: 10 animais receberam as soluções durante 15 dias e 10 durante 30 dias. Ao final do período determinado, os ratos foram anestesiados por meio de inalação de grande volume de éter até obtenção de parada cardiorrespiratória, pesados e submetidos rapidamente à laparotomia para retirada de fragmento do lobo hepático esquerdo em cunha, com dimensão aproximada de 0,5 a $1 \mathrm{~cm}^{3}$. 


\subsubsection{Soluções}

As soluções administradas foram preparadas na Farmácia do Instituto da Criança, com técnica habitual e após análise da estabilidade dos preparados.

A solução de prednisolona foi obtida através da diluição em água destilada da solução oral comercialmente disponível ( Prelone ${ }^{\circledR}$ - fosfato sódico de prednisolona $3 \mathrm{mg} / \mathrm{mL}$ ) até a concentração de $0,3 \mathrm{mg} / \mathrm{mL}$.

A solução de pentoxifilina foi obtida através da diluição do comprimido comercialmente disponível (Trental® - $400 \mathrm{mg}$ ) em água destilada até a concentração de $1 \mathrm{mg} / \mathrm{mL}$.

A estocagem das soluções foi realizada em frascos de vidro âmbar mantidos sob refrigeração no Setor de Cirurgia Experimental.

\subsubsection{Análise histológica}

Os fragmentos hepáticos foram fixados em solução tamponada de formaldeído a 10\% por período de 24 a 48 horas e transportados para o processamento do material no LIM 30. Após a inclusão em parafina, foram realizados cortes histológicos com espessura de $3 \mu \mathrm{m}$ e todo o material foi corado pela hematoxilina-eosina (HE) e pelo picrossírius, obtendo-se duas lâminas para cada animal. A coloração de picrossírius foi escolhida por ser específica para marcação tecidual de colágeno (técnica descrita no Anexo M). 
A análise histológica foi realizada em microscópio óptico Leica DMR ${ }^{\circledR}$, acoplado a sistema de aquisição de imagem através de câmera JVC TK C1380®. Após a avaliação inicial do parênquima na lâmina corada pela HE, onde confirmaram-se qualitativamente as alterações decorrentes da obstrução biliar, foram fotografados aleatoriamente 15 espaços-porta de cada lâmina corada pelo picrosírius com aumento de 200x (ocular de 10x e objetiva de 20x), correspondendo a mais de $75 \%$ do total de regiões portais representadas em cada lâmina. As imagens foram digitalizadas e processadas com auxílio do programa Image Pro-Plus ${ }^{\circledR}$ versão 4.5.0.29 para Windows $\mathrm{XP}{ }^{\circledR}$ (Media Cybernetics Inc ${ }^{\circledR}$ ), totalizando 1500 espaçosporta analisados (Figura 3).

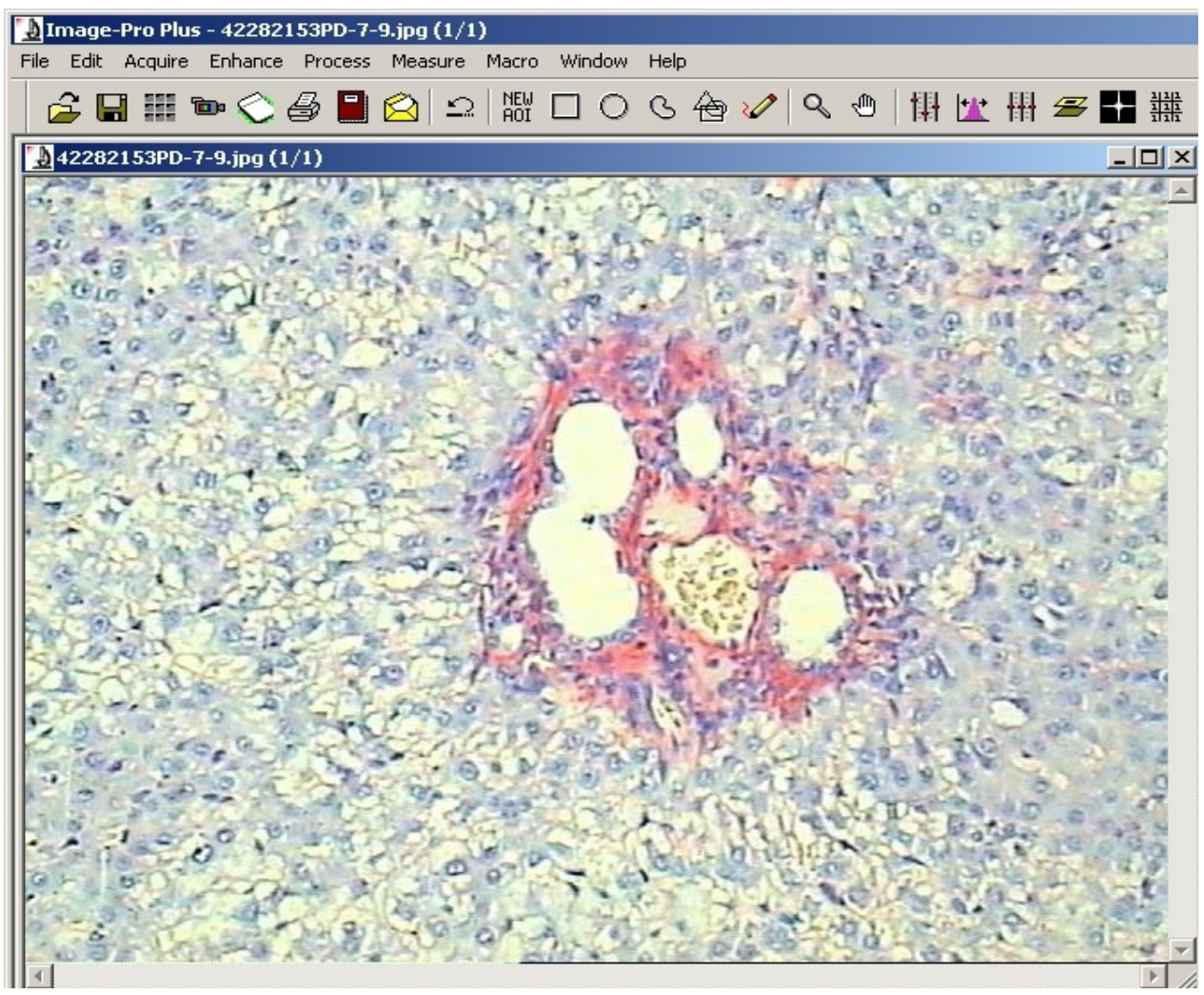

Figura 3. Fotomicrografia digitalizada de espaço-porta para processamento no programa Image Pro-Plus ${ }^{\circledR}$ - coloração de picrossírius / aumento 200x 
Após a aquisição das imagens, foi determinada uma calibração do programa para marcação do colágeno em todos os grupos, automatizando sua identificação. Cada espaço-porta foi delimitado com o auxílio do dispositivo apontador ("mouse"), obtendo-se os valores de área total do espaço-porta e área preenchida por colágeno, expressos em $\mu \mathrm{m}^{2}$ (figura 4). A fração de área de colágeno foi definida pela razão entre área de colágeno e área total.

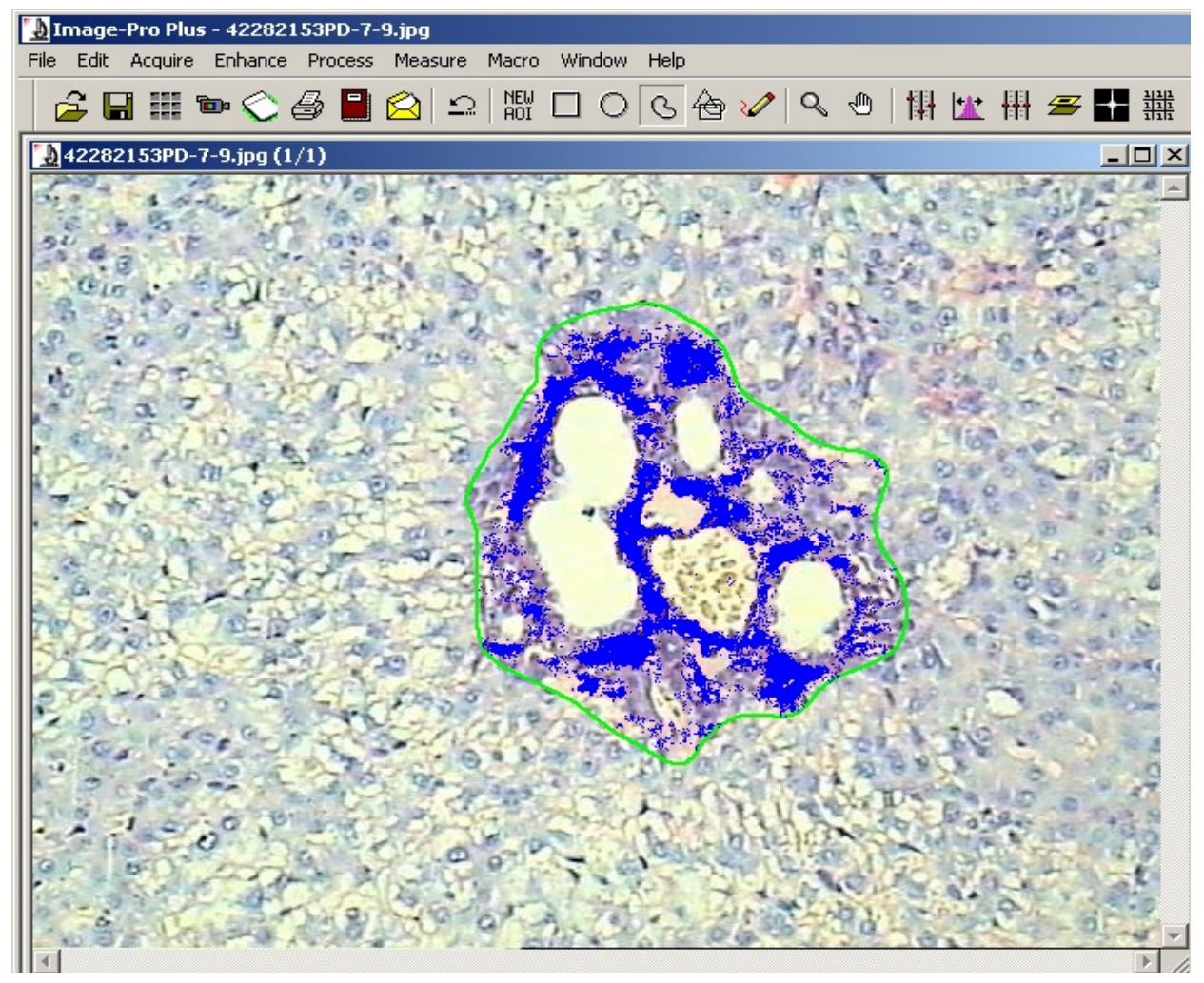

Figura 4. Fotomicrografia digitalizada com delimitação do espaço-porta e marcação da área preenchida por colágeno - programa Image Pro-Plus ${ }^{\circledR}$ - coloração de picrossírius / aumento 200x 


\subsubsection{Análise estatística}

A comparação dos valores obtidos para ganho de peso, área de colágeno, área total, fração de colágeno entre os 5 grupos foi realizada por meio do programa SPSS ${ }^{\circledR}$ versão 15.0 para Windows ${ }^{\circledR}$. Como os dados apresentaram distribuição normal, utilizou-se análise de variância (ANOVA) para verificar a existência de diferença entre os valores. Para testar a diferença entre os grupos, foi aplicado o teste post hoc de Tukey. A hipótese de igualdade entre os valores foi rejeitada para $\mathrm{p}<0,05$. 


\section{RESULTADOS}




\subsection{Ganho de peso}

As médias dos pesos iniciais (dia do desmame) e pesos finais $\left(15^{\circ}\right.$ ou $30^{\circ}$ dia $)$ de cada grupo estão apresentadas na Tabela 1.

Tabela 1 - Média dos pesos iniciais e finais dos animais $(\mathrm{g})$

\begin{tabular}{lcc}
\hline \multicolumn{1}{c}{ Grupos } & Peso inicial & Peso final \\
\hline LDBC 15 dias & 40,3 & 99,5 \\
\hline CS 15 dias & 73,6 & 143,6 \\
\hline PTX 15 dias & 63,4 & 133,8 \\
\hline PRED 15 dias & 48,1 & 82,4 \\
\hline PTX + PRED 15 dias & 49,2 & 73,5 \\
\hline LDBC 30 dias & 50,4 & 151,8 \\
\hline CS 30 dias & 50 & 190,1 \\
\hline PTX 30 dias & 55,2 & 181,7 \\
\hline PRED 30 dias & 60,2 & 107,3 \\
\hline PTX + PRED 30 dias & 62,3 & 92,3 \\
\hline
\end{tabular}

A análise do ganho de peso (diferença entre média do peso inicial e média do peso final) em 15 dias demonstrou melhor desempenho do grupo PTX e pior desempenho dos grupos PRED e PTX+PRED (Gráfico 1).

- PRED x LDBC: $p=0,08$

- PTX+PRED x LDBC: $p=0,005$

- $\quad$ PRED x CS: $p=0,004$

- $\quad$ PTX+PRED x CS: $p<0,001$

Após 30 dias, essa tendência se acentuou (Figura 5), demonstrando diferença estatística nos grupos PRED e PTX+PRED com relação aos grupos LDBC e $\mathrm{CS}(\mathrm{p}<0,001)$. Com relação ao grupo PTX, a comparação com o grupo LDBC revelou $\mathrm{p}=0,05$ (Gráfico 2). 
Gráfico 1 - Ganho de peso de cada grupo após 15 dias (g)

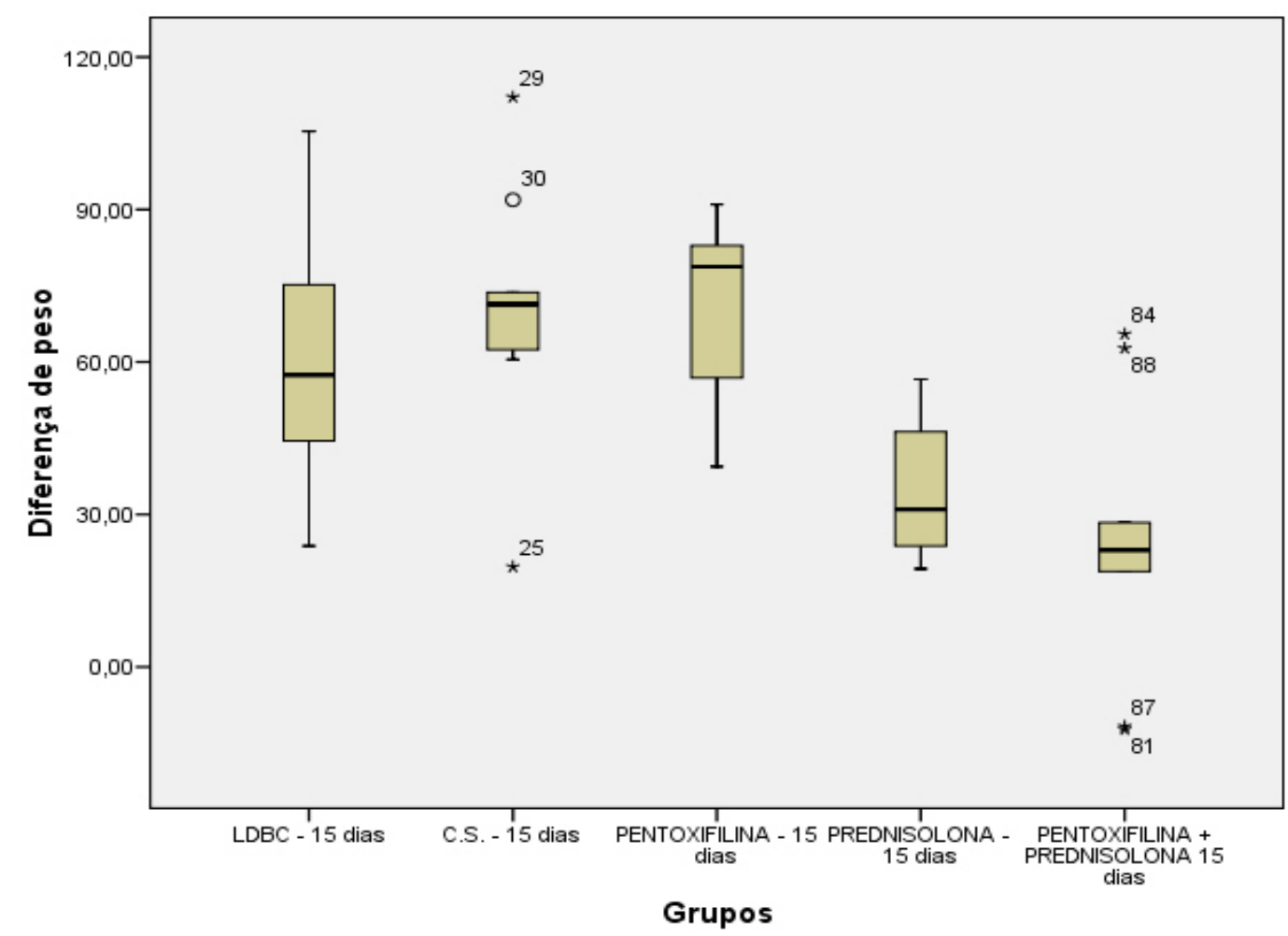

Gráfico 2 - Ganho de peso de cada grupo após 30 dias (g)

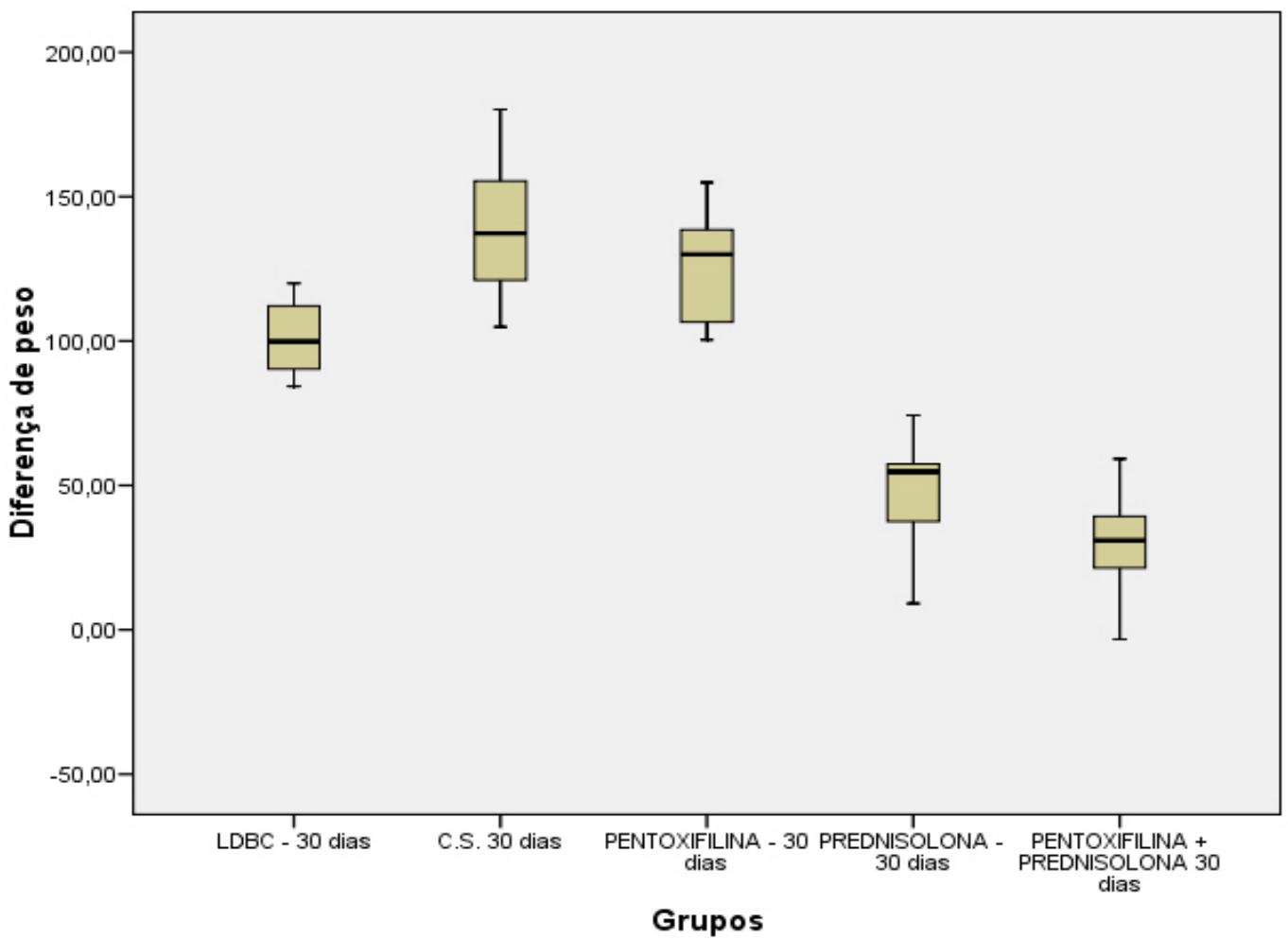




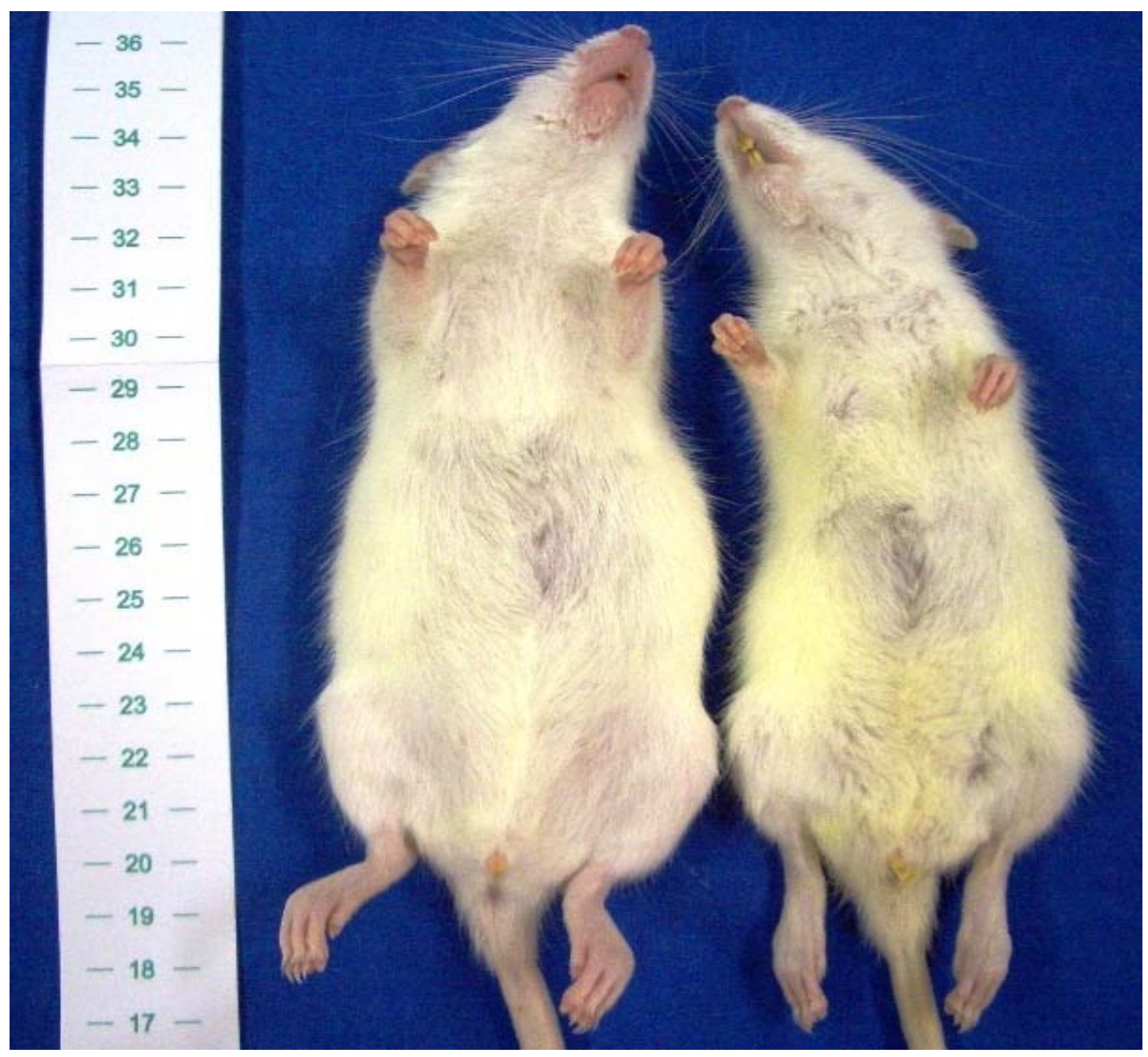

Figura 5. Fotografia evidenciando diferença das dimensões dos animais ao final de 30 dias de tratamento: à esquerda - animal do grupo PTX; à direita - animal do grupo PTX+PRED 


\subsection{Avaliação macroscópica}

Ao final do período de 15 dias, os animais estavam ictéricos e apresentavam colúria. As laparotomias revelaram dilatação da via biliar extra-hepática, com formação de grandes cistos na região do hilo. Os fígados apresentaram mudança de coloração, irregularidades na superfície e consistência endurecida. Após 30 dias, todas as alterações observadas encontraram-se exacerbadas (Figura 6).

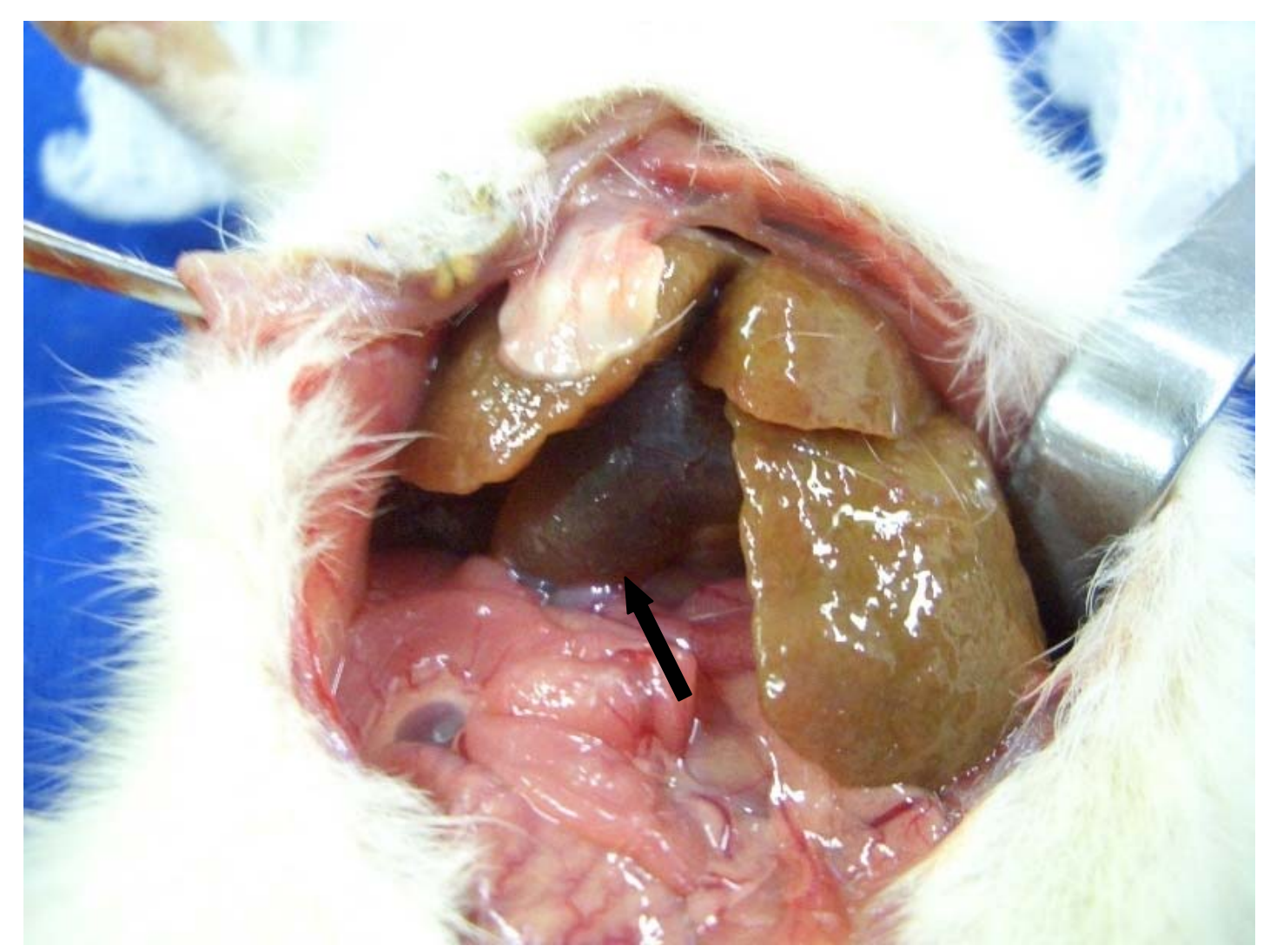

Figura 6. Aspecto macroscópico do fígado e hilo hepático - animal do grupo LDBC 30 dias. Notar grande dilatação da via biliar extra-hepática (seta) 


\subsection{Avaliação histológica}

\subsubsection{Hematoxilina-eosina}

$\mathrm{Na}$ análise das lâminas dos grupos LDBC, PTX, PRED e PTX+PRED coradas pela HE com 15 dias, verificou-se aumento da área dos espaços-porta às custas de proliferação ductular e aumento do tecido conjuntivo portal. Após 30 dias, exacerbaram-se as alterações, com formação de septos e desorganização do lóbulo hepático (Figuras 7 a 11).
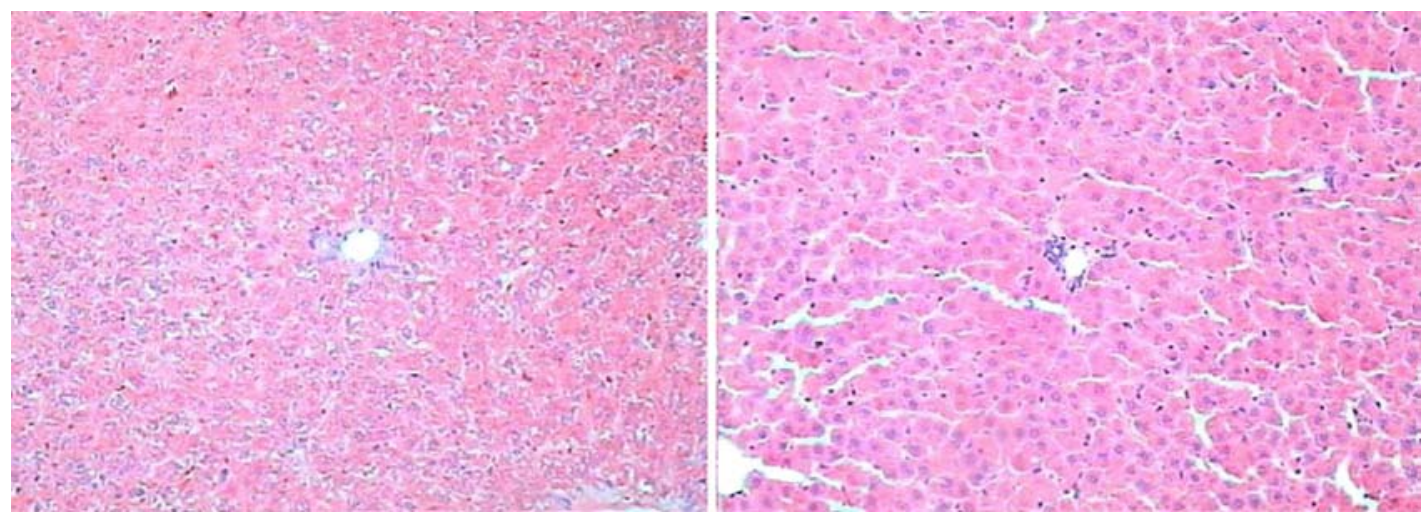

Figura 7. Microfotografias de lâminas de fígado dos animais do grupo CS _ à esquerda: 15 dias após laparotomia / à direita: 30 dias após laparotomia (coloração $\mathrm{HE} /$ aumento de 200x)
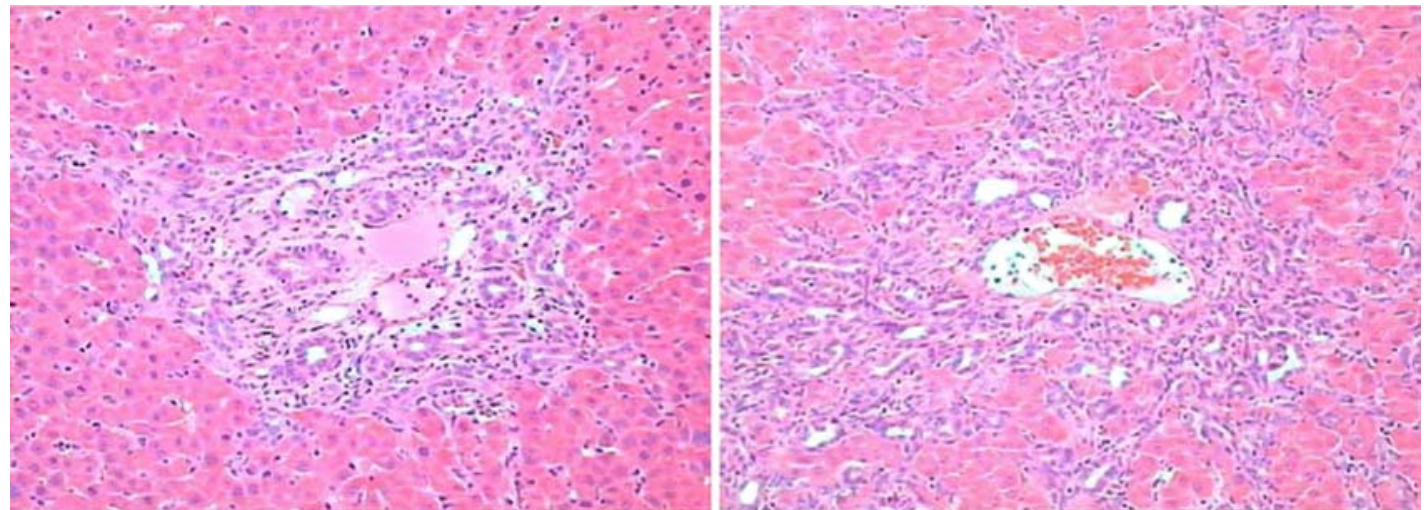

Figura 8. Microfotografias de lâminas de fígado dos animais do grupo LDBC à̀ esquerda: 15 dias após ligadura biliar / à direita: 30 dias após ligadura biliar (coloração HE / aumento de 200x) 

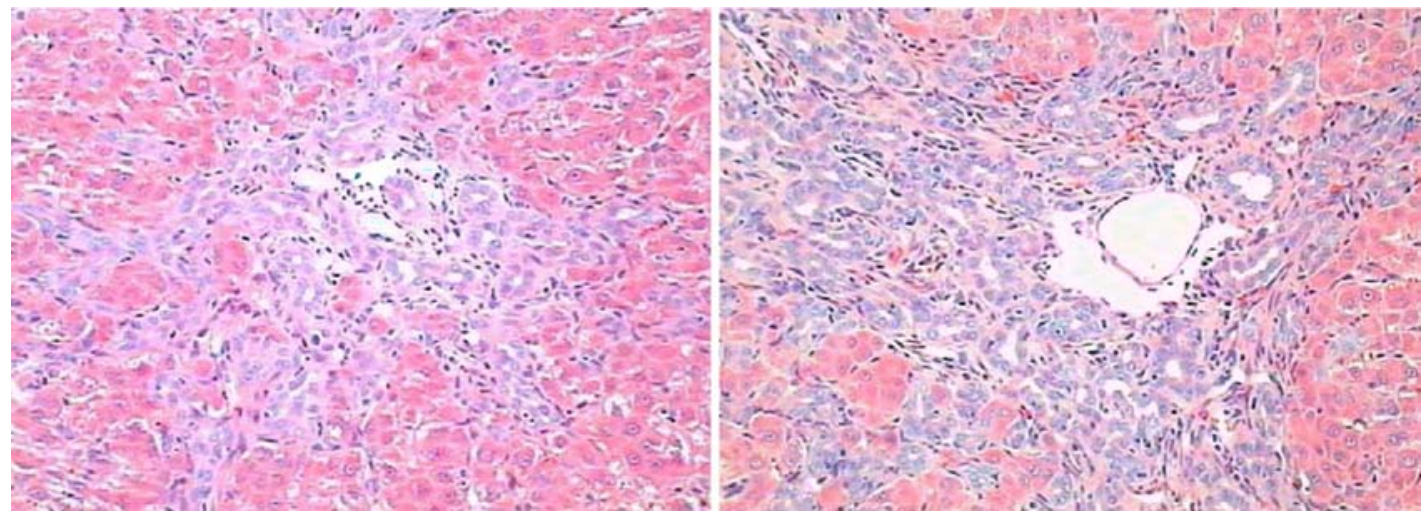

Figura 9. Microfotografias de lâminas de fígado dos animais do grupo PTX à esquerda: 15 dias após ligadura biliar / à direita: 30 dias após ligadura biliar (coloração HE / aumento de 200x)

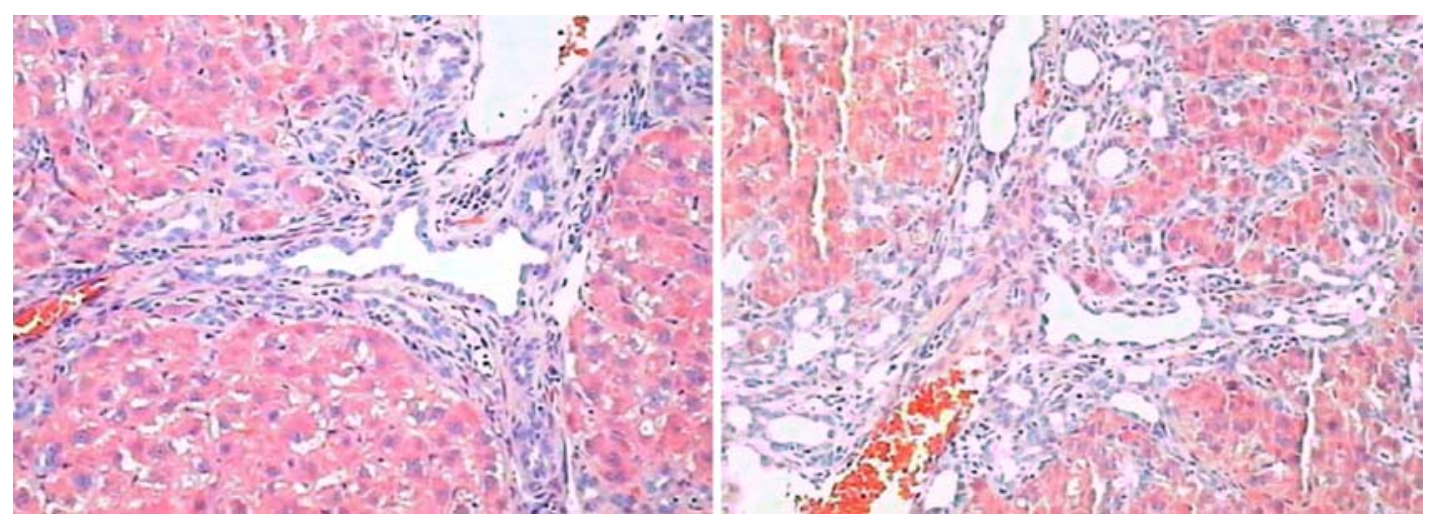

Figura 10. Microfotografias de lâminas de fígado dos animais do grupo PRED _à esquerda: 15 dias após ligadura biliar / à direita: 30 dias após ligadura biliar (coloração HE / aumento de 200x)
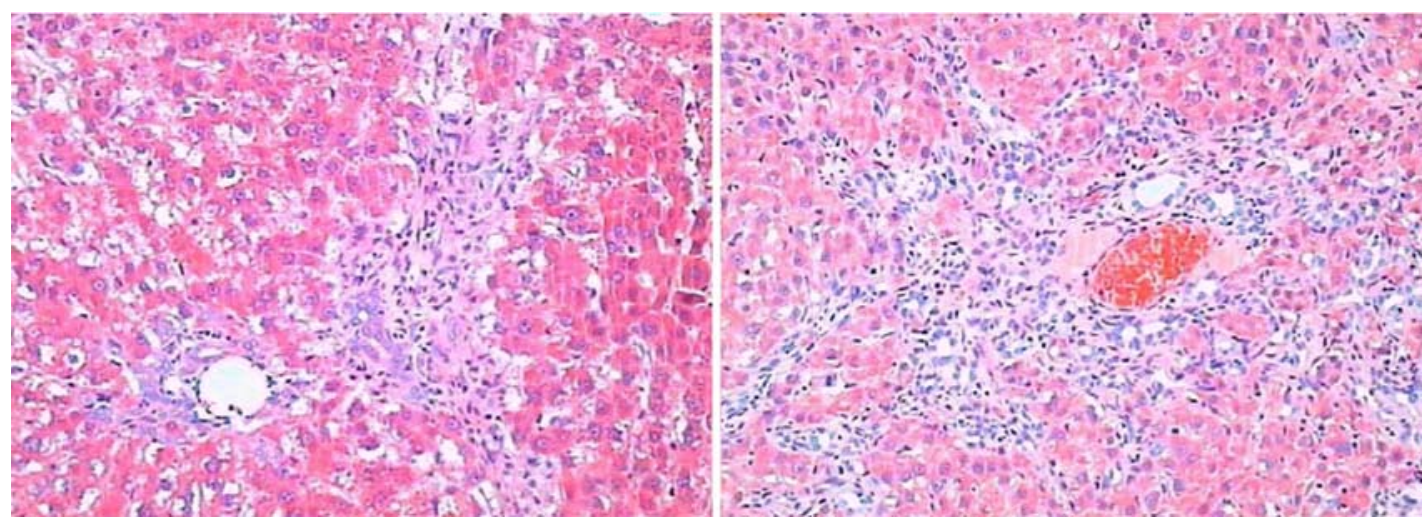

Figura 11. Microfotografias de lâminas de fígado dos animais do grupo PTX+PRED à esquerda: 15 dias após ligadura biliar / à direita: 30 dias após ligadura biliar (coloração HE / aumento de 200x) 


\subsubsection{Picrossírius}

Para melhor avaliação quantitativa, foram utilizadas as lâminas coradas pelo picrossírius (Figuras 12 a 16). Os valores obtidos nas medidas de área preenchida por colágeno e área total do espaço-porta, juntamente com as frações de área de colágeno calculadas para cada grupo estão apresentados sob forma de gráfico de caixa ("box plot"). Os valores individuais das medidas de cada espaço-porta estão descritos na seção Anexos.

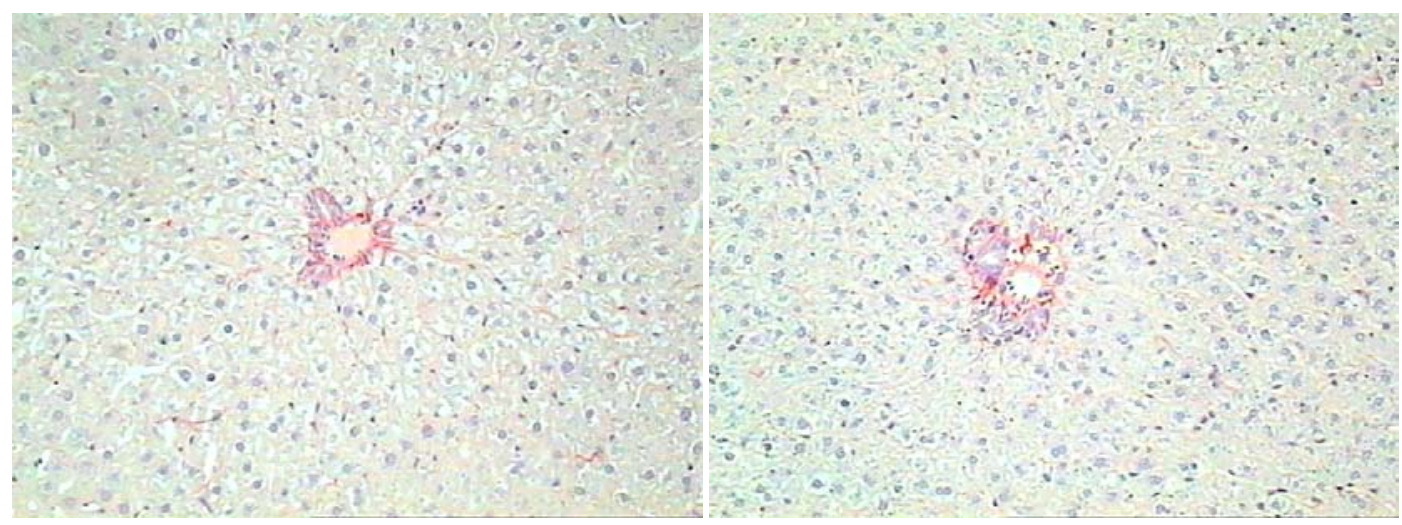

Figura 12. Microfotografias de lâminas de fígado dos animais do grupo CS _ à esquerda: 15 dias após laparotomia / à direita: 30 dias após laparotomia (coloração picrossírius / aumento de 200x)

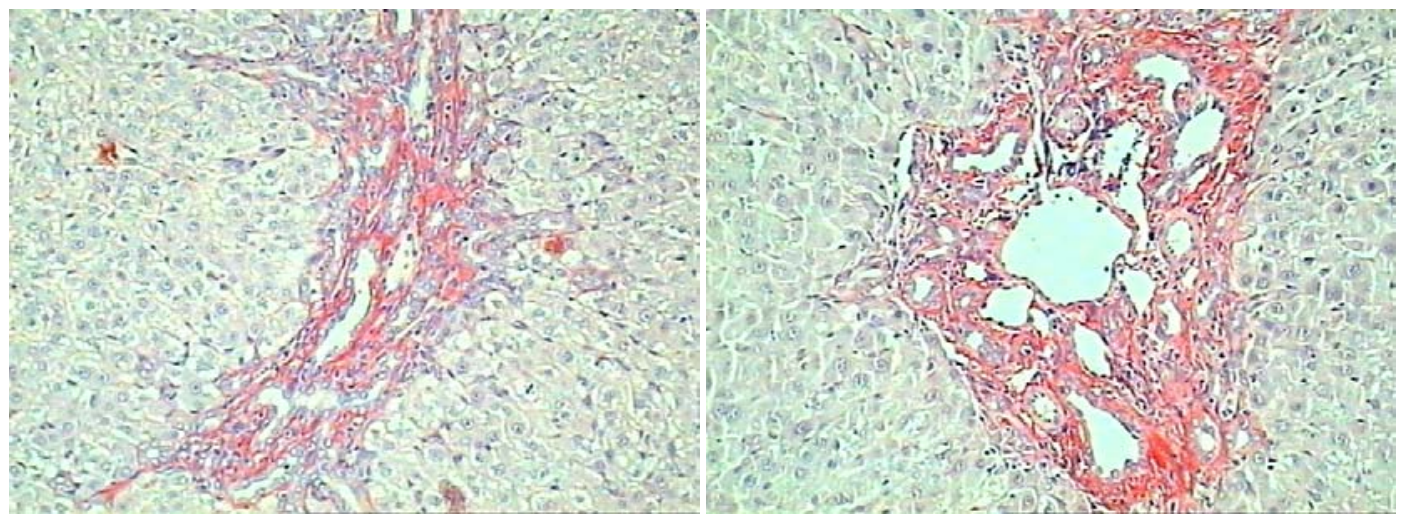

Figura 13. Microfotografias de lâminas de fígado dos animais do grupo LDBC à esquerda: 15 dias após ligadura biliar / à direita: 30 dias após ligadura biliar (coloração picrossírius / aumento de 200x) 


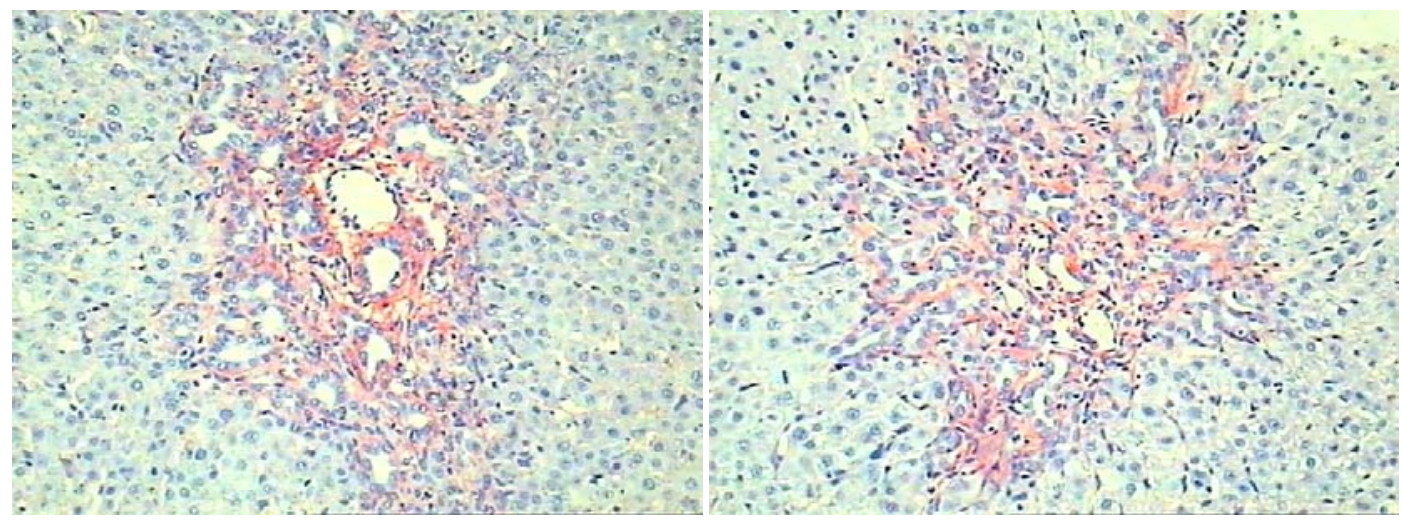

Figura 14. Microfotografias de lâminas de fígado dos animais do grupo PTX à esquerda: 15 dias após ligadura biliar / à direita: 30 dias após ligadura biliar (coloração picrossírius / aumento de 200x)

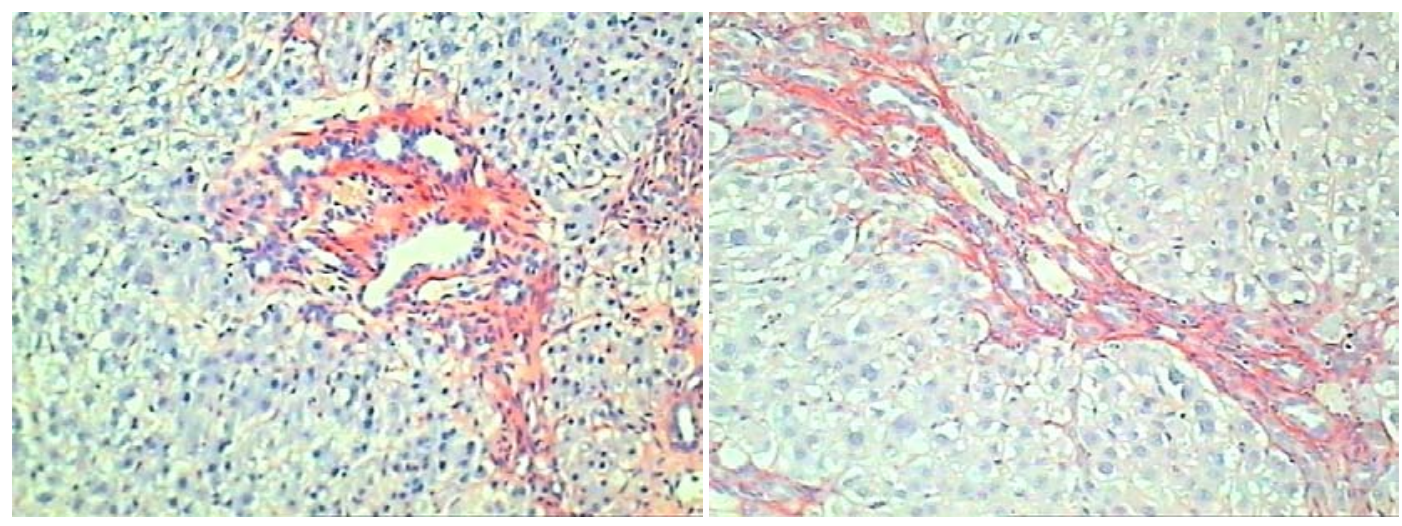

Figura 15. Microfotografias de lâminas de fígado dos animais do grupo PRED _à esquerda: 15 dias após ligadura biliar / à direita: 30 dias após ligadura biliar (coloração picrossírius / aumento de 200x)

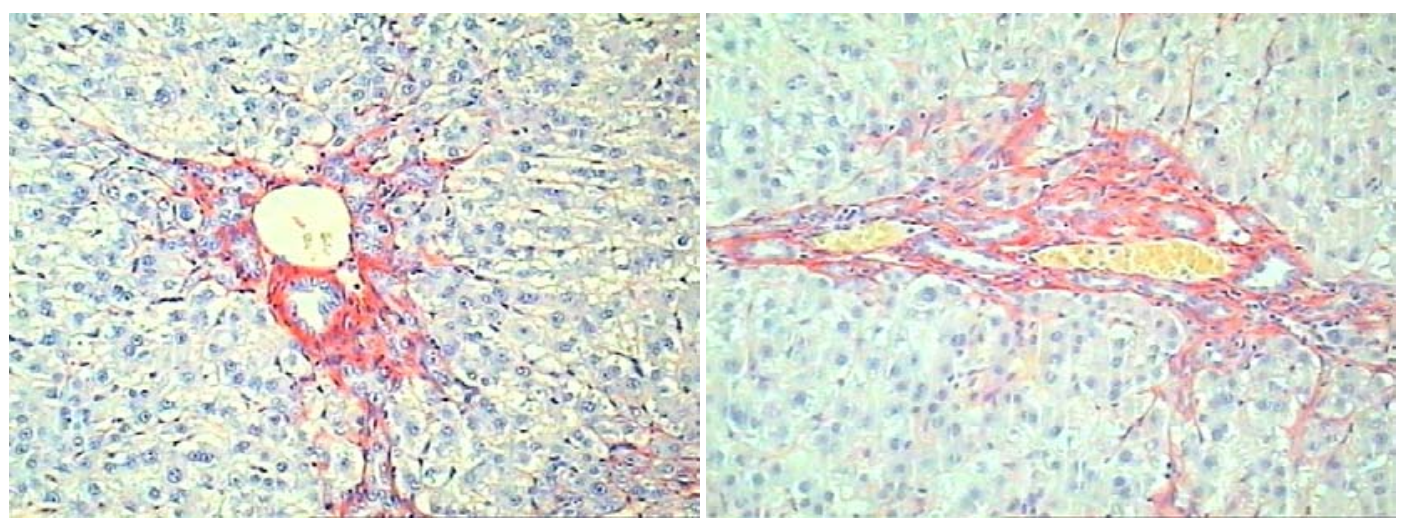

Figura 16. Microfotografias de lâminas de fígado dos animais do grupo PTX+PRED à esquerda: 15 dias após ligadura biliar / à direita: 30 dias após ligadura biliar (coloração picrossírius / aumento de 200x) 


\subsubsection{1 Área de colágeno}

Em 15 dias, demonstrou-se diferença significativa $(p<0,001)$ de cada um dos 3 grupos de tratamento (PTX, PRED e PTX+PRED) comparados tanto com o grupo LDBC quanto com o grupo CS. Entre os 3 grupos, não houve diferença estatística (Gráfico 3).

Gráfico 3 - Medidas das áreas preenchidas por colágeno $\left(\mu \mathrm{m}^{2}\right)$ - grupos 15 dias

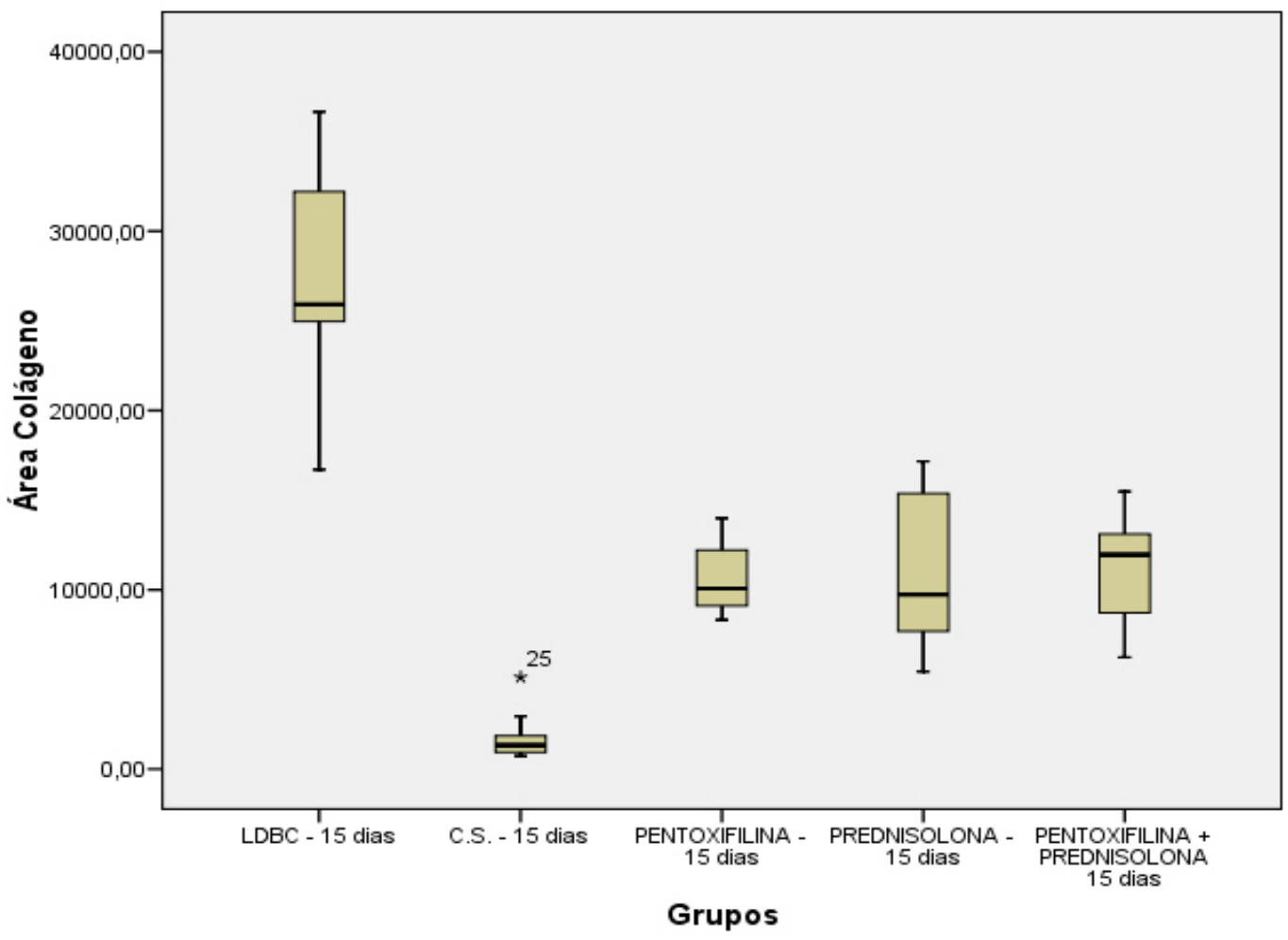


Gráfico 4 - Medidas das áreas preenchidas por colágeno $\left(\mu \mathrm{m}^{2}\right)$ - grupos 30 dias

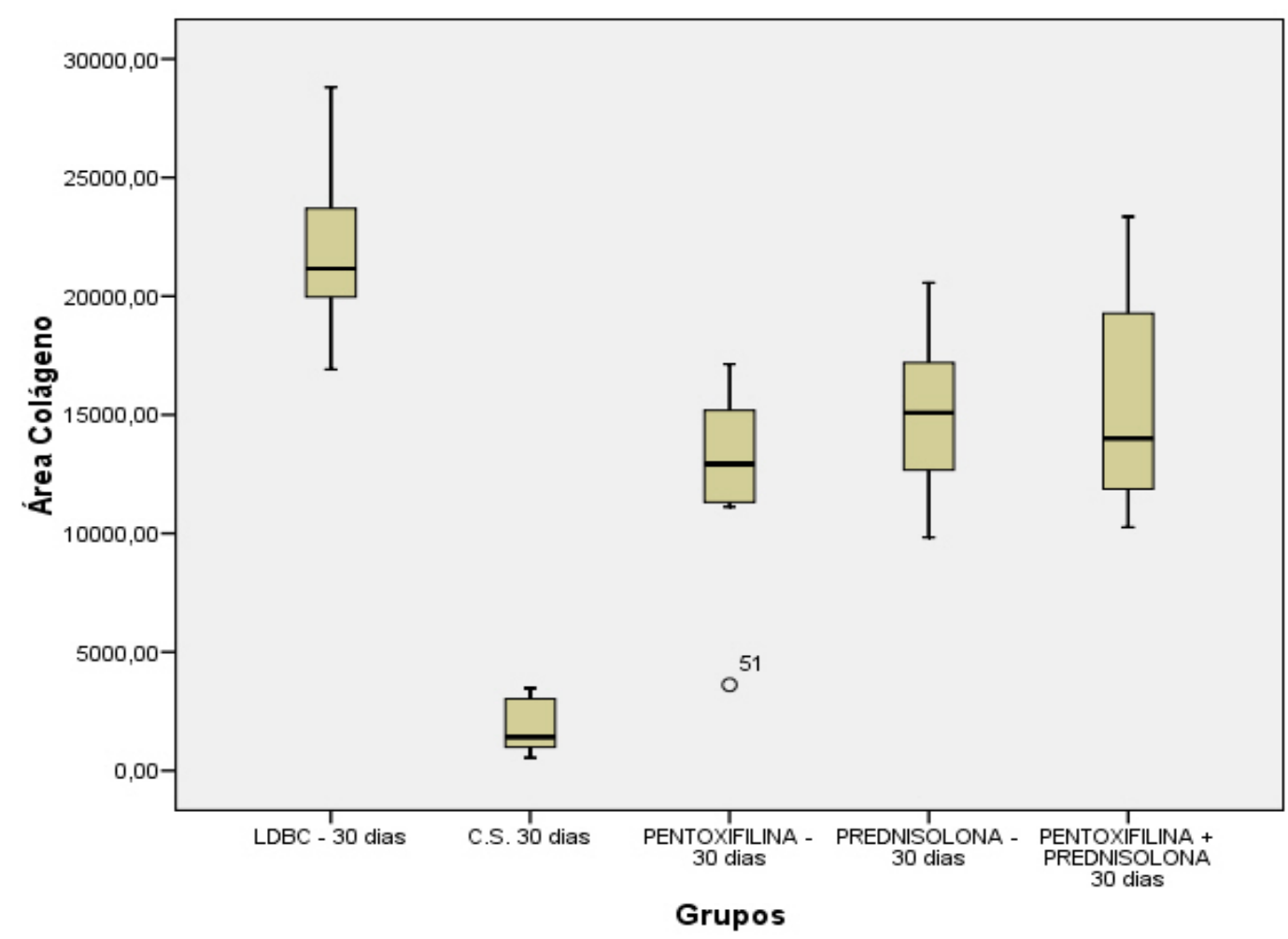

Nos grupos de 30 dias, o mesmo padrão foi observado (Gráfico 4):

- Grupos de tratamento x CS: $\mathrm{p}<0,001$

- PTX x LDBC: $\mathrm{p}<0,001$

- PRED x LDBC: $p=0,001$

- $\quad$ PTX+PRED x LDBC: $p=0,002$ 


\subsubsection{2 Área total}

Em 15 dias (Gráfico 5), os 3 grupos de tratamento apresentaram diferença com relação ao grupo $\mathrm{CS}(\mathrm{p}<0,001)$, porém somente os grupos PRED e PTX+PRED demonstraram diferença com relação ao grupo LDBC $(p<0,001)$.

Gráfico 5 - Medidas das áreas totais $\left(\mu \mathrm{m}^{2}\right)$ - grupos 15 dias

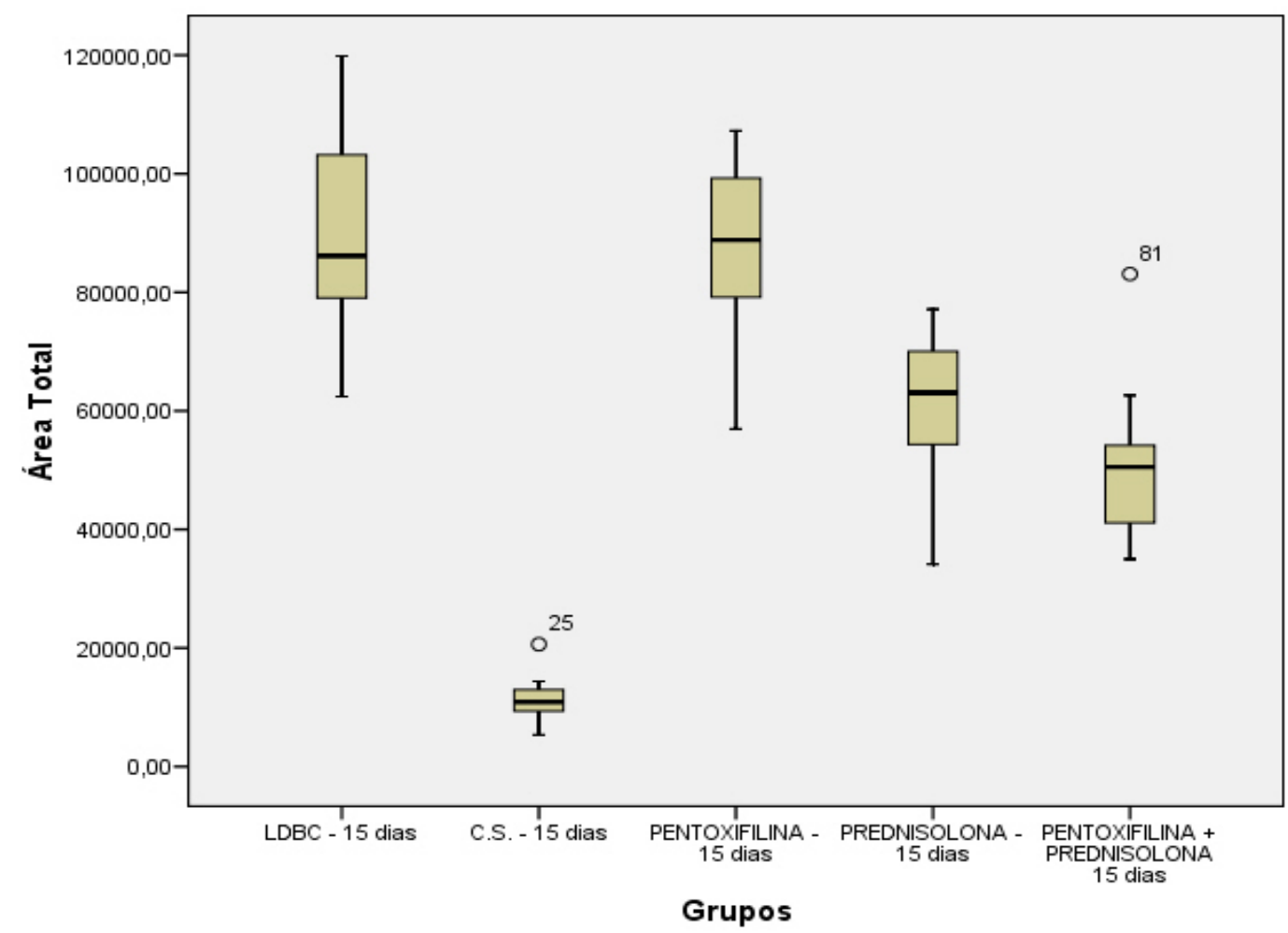


Em 30 dias, os 3 grupos de tratamento apresentaram diferença com relação ao grupo CS ( $\mathrm{p}<0,001)$, porém somente no grupo PTX houve diferença estatística com relação ao grupo LDBC $(\mathrm{p}=0,002)$ - área total maior (Gráfico 6).

Gráfico 6 - Medidas das áreas totais $\left(\mu \mathrm{m}^{2}\right)$ - grupos 30 dias

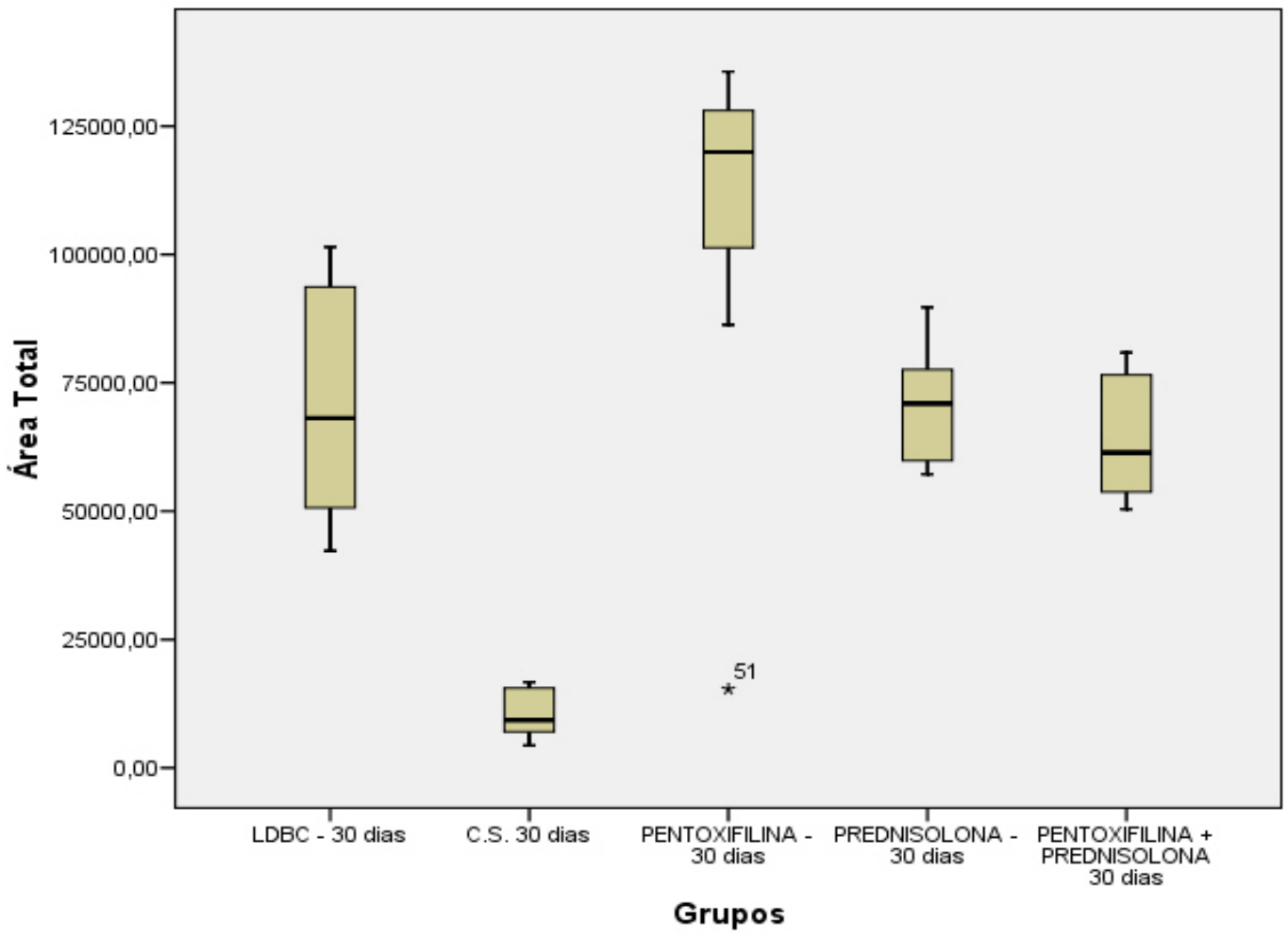




\subsubsection{Fração de área preenchida por colágeno}

Em 15 dias (Gráfico 7), os 3 grupos de tratamento apresentaram diferença com relação ao grupo $\operatorname{LDBC}(\mathrm{p}<0,001)$, porém somente o grupo $\mathrm{PTX}+\mathrm{PRED}$ demonstrou diferença significativa com relação ao grupo CS $(p<0,001)$.

Gráfico 7 - Medidas das frações de áreas de colágeno $\left(\mu \mathrm{m}^{2}\right)$ - grupos 15 dias

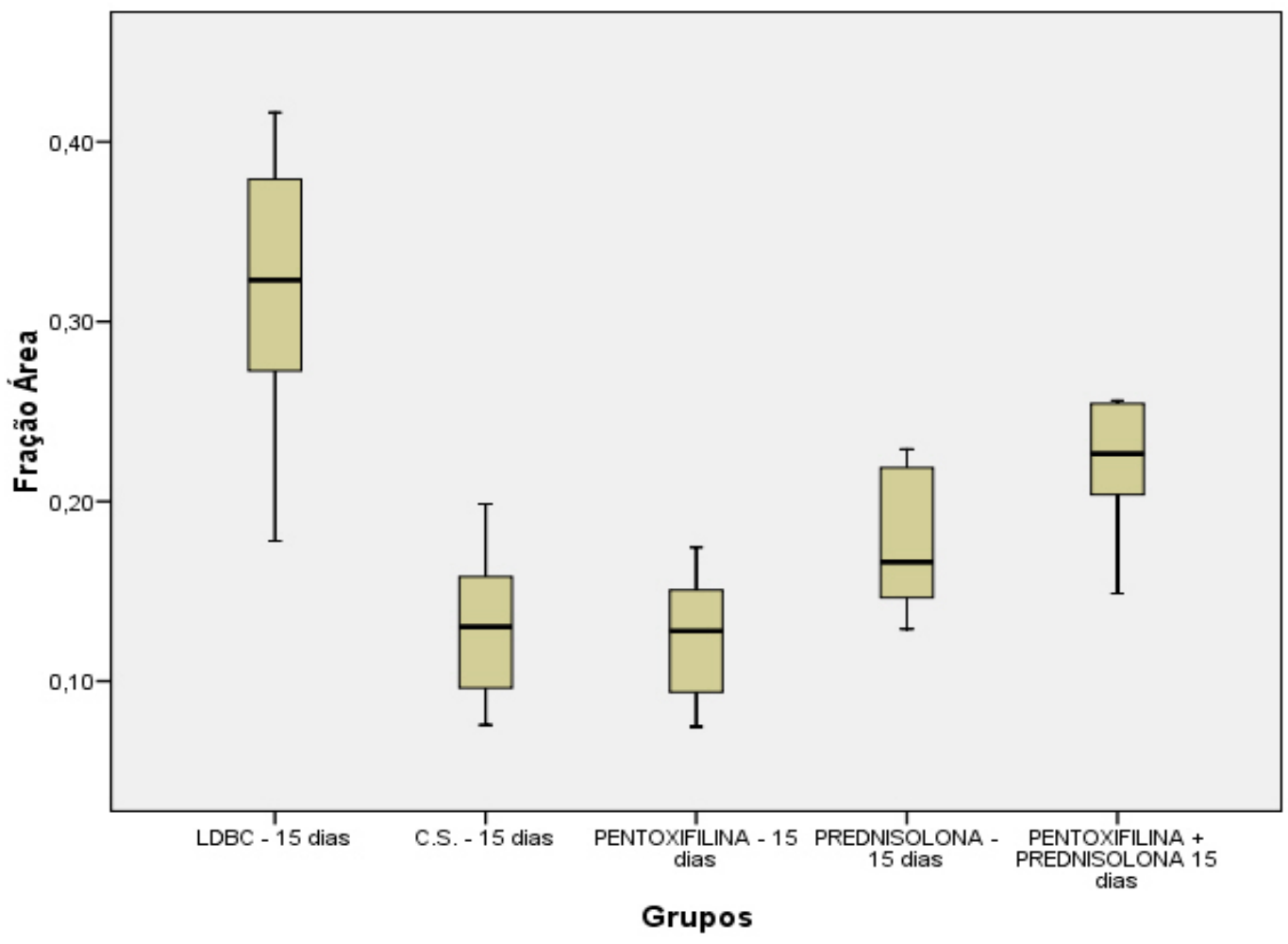


Gráfico 8 - Medidas das frações de áreas de colágeno $\left(\mu \mathrm{m}^{2}\right)$ - grupos 30 dias

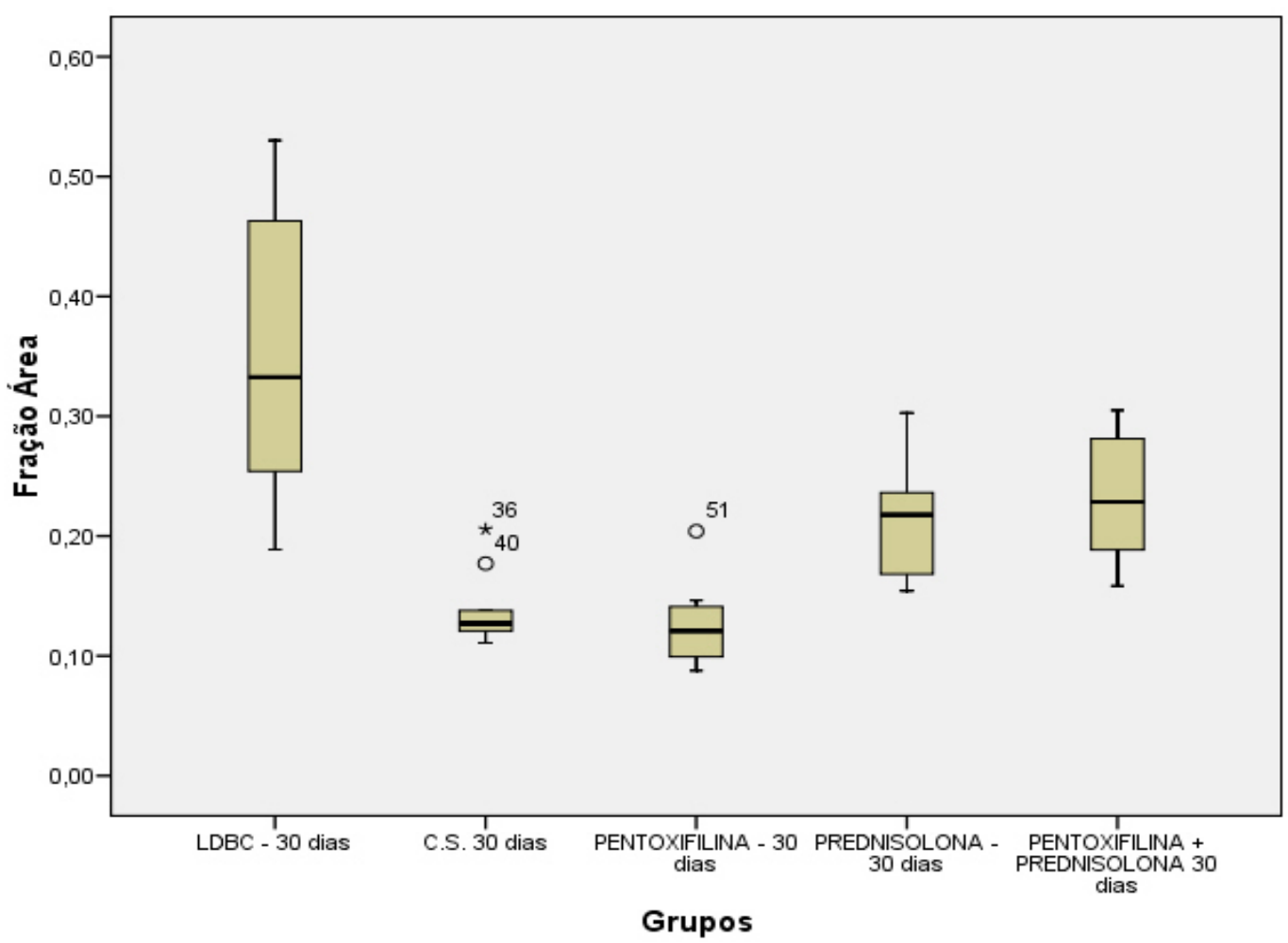

Em 30 dias (Gráfico 8), repetiu-se o mesmo padrão:

- PTX x LDBC: $\mathrm{p}<0,001$

- PRED x LDBC: $\mathrm{p}<0,001$

- PTX+ PRED x LDBC: $p=0,002$

- PRED x CS: $\mathrm{p}=0,084$

- PTX+ PRED x CS: $p=0,016$

Notavelmente, as frações de área de colágeno dos grupos PTX e CS foram estatisticamente iguais nos 2 períodos de observação (15 dias: $\mathrm{p}=1$ e 30 dias: $\mathrm{p}=0,992)$. 
Em resumo, notou-se que a administração das duas drogas, isoladamente ou em conjunto, resultou em diminuição significativa da produção de colágeno nos espaços-porta após ligadura biliar em relação ao ocorrido nos animais não tratados.

A administração de pentoxifilina implicou redução estatisticamente significativa na fração de área preenchida por colágeno, embora não tenha demonstrado diferença na área absoluta de colágeno, em comparação com os dois outros grupos de tratamento com corticóide. A área total dos espaços-porta foi significativamente maior no grupo PTX que nos outros grupos. 


\section{DISCUSSÃO}


A compreensão dos mecanismos envolvidos no desenvolvimento da fibrose observada em diversas doenças crônicas do fígado, a despeito dos avanços obtidos nas últimas décadas, ainda é parcial. O esclarecimento da fisiopatogenia da fibrogênese hepática frente aos diferentes estímulos lesivos implicaria possibilidades terapêuticas que modificariam a evolução de diversas condições patológicas que atualmente resultam em grande morbidade e alta letalidade ${ }^{29}$.

Nas crianças, o estudo das colestases e, particularmente, da atresia das vias biliares assume importância crucial pela prevalência dessas condições e pelo impacto que representam nos custos de Saúde Pública ${ }^{30}$.

Os modelos experimentais de colestase descritos na literatura podem reproduzir, ao menos parcialmente, as condições encontradas nos fígados de crianças com $\mathrm{AVB}^{31}$. A histologia hepática do modelo de ligadura do ducto biliar comum no rato apresenta aspectos semelhantes aos encontrados nas atresias, como a proliferação ductular e o acúmulo progressivo de matriz extra-celular, particularmente colágeno tipo I, ao redor dessas estruturas neoformadas e nas regiões peri-portais, com uma expansão radiada que culmina com formação de septos e, em sua fase final, desestruturação arquitetural do lóbulo hepático _ um padrão definido pelos patologistas como fibrose portal de padrão biliar $^{22}$.

Embora outros aspectos supostamente envolvidos na etiopatogenia da $\mathrm{AVB}^{32,33}$, tais como: processo inflamatório prévio induzido por agente microbiológico, destruição ductal imuno-mediada ou malformação da placa ductal, 
não estejam presentes nesse modelo exclusivo de obstrução mecânica da via biliar, as informações relacionadas à proliferação ductular e à fibrose secundária podem trazer algum esclarecimento com relação ao que parece ser a via final comum do estabelecimento da cirrose biliar ${ }^{34,35}$. Assim, justifica-se a utilização desse modelo de fibrose induzida por fator obstrutivo, também presente na evolução das atresias.

De acordo com as observações de vários autores, o modelo de LDBC aplicado no rato jovem, embora menos explorado e descrito na literatura, apresenta diferenças quando comparado ao modelo do rato adulto, com relação à velocidade de estabelecimento e à intensidade da inflamação, da proliferação ductular e do acúmulo de colágeno ${ }^{25-28}$. Portanto, como as alterações observadas na AVB iniciam-se precocemente (em alguns casos, no período antenatal), infere-se que, quanto mais jovem o animal de experimentação, mais semelhantes às ocorridas na criança são as alterações induzidas. Isso motivou a proposta inicial de utilização de ratos com 3 dias de vida no plano piloto do estudo. As dificuldades técnicas encontradas, relatadas na seção Métodos, impossibilitaram o êxito dessa abordagem. O rato recém-desmamado, entretanto, representou uma alternativa viável de utilização do animal jovem.

Existem evidências de que os mecanismos e mediadores responsáveis pelo estabelecimento da fibrose induzida por obstrução biliar incluam aumento do metabolismo oxidativo, a produção de espécies reativas de oxigênio e a peroxidação lipídica, desencadeados pelo estímulo tóxico da acumulação intra-hepática de sais biliares $^{29,31,36}$. Ocorre então uma cascata de eventos que promovem a liberação de citocinas pró-inflamatórias e pró-fibrogênicas (transforming growth factor beta TGF $\beta$, tumor necrosis alpha - TNF $\alpha$, interleucina 6 - IL6 e outras), o aumento da 
expressão de moléculas de adesão intercelular e a ativação de fatores de transcrição

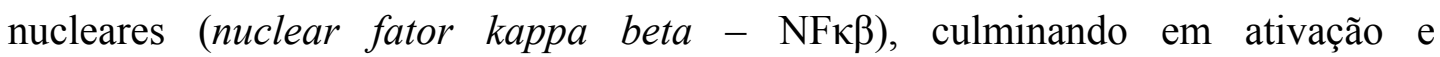
diferenciação das células miofibroblásticas presentes no espaço-porta e na zona de interface (células estreladas). Esses miofibroblastos ativados são os responsáveis pelo aumento da produção do colágeno que, depositado nas regiões portais e, posteriormente, entremeado no parênquima dos lóbulos hepáticos, ocasiona a fibrose/cirrose do órgão ${ }^{37}$.

Essa trama complexa, apenas parcialmente desvendada, apresenta alguns potenciais pontos de intervenção que têm sido explorados recentemente pelos pesquisadores, visando a descobrir possíveis abordagens terapêuticas ou modulatórias do processo de fibrogênese ${ }^{12}$.

Particularmente no tratamento das crianças com atresia das vias biliares, cirurgiões e hepatologistas têm prescrito, um tanto quanto empiricamente, corticosteróides no período pós-operatório imediato da portoenterostomia, associando essa classe de medicamentos aos classicamente utilizados ácido ursodesoxicólico e antibióticos $^{38}$. Tal conduta se iniciou na década de 80, após a publicação de alguns trabalhos que demonstravam aumento do fluxo biliar em modelo experimental após administração de metilprednisolona ${ }^{39}$. Esse efeito colerético, semelhante ao observado com a administração de fenobarbital ${ }^{40}$, é atribuído à estimulação do transporte de eletrólitos através da bomba $\mathrm{Na}^{+}-\mathrm{K}^{+}$-ATPase presente na superfície biliar dos hepatócitos. Portanto, embora o aumento do volume de bile não seja às custas de aumento da excreção de sais biliares, o favorecimento do fluxo biliar, ao menos teoricamente, diminuiria o risco de infecção decorrente da colestase. Esses novos conceitos, associados ao conhecimento prévio das 
propriedades anti-inflamatórias dos glicocorticóides, estimularam a utilização dessas drogas no tratamento dos pacientes portadores de AVB recém-operados ${ }^{41}$.

Assim, Karrer e Lilly (1985) publicaram um relato de 16 pacientes tratados com "pulsos" de metilprednisolona por colangites de repetição ou diminuição do fluxo biliar, observando diminuição dos níveis de fosfatase alcalina sérica e de linfócitos e aumento do volume de bile excretada ${ }^{7}$. A partir de então, outros autores ampliaram a indicação da utilização do corticosteróide, defendendo seu uso rotineiro no pós-operatório da cirurgia de Kasai ${ }^{42}$.

Nos últimos anos, foram publicados diversos relatos dessa nova abordagem, em estudos retrospectivos, não controlados e com tempos de seguimento curtos $^{8-11}$. Alguns sugeriram melhor evolução precoce, como diminuição dos níveis de bilirrubina sérica, porém falharam em demonstrar benefício real a longo prazo, traduzido por aumento da sobrevida livre de transplante. Recentemente, em dezembro de 2007, Davenport et al publicaram os resultados de um estudo prospectivo conduzido em 2 centros britânicos com metodologia mais adequada, embora apresentando um número total de casos relativamente pequeno ${ }^{43}$. Os autores acompanharam a evolução de 71 pacientes submetidos à portoenterostomia de Kasai divididos em 2 grupos (prednisolona oral administrada durante 21 dias x placebo) e observaram que o nível médio de bilirrubina sérica foi menor no grupo corticóide após 1 mês, porém sem diferença após 6 e 12 meses. A necessidade de transplante também não foi estatisticamente diferente nos 2 grupos após 6 e 12 meses.

Portanto, a eficácia dessa proposta terapêutica ainda não se encontra bem definida. Não há estudos experimentais publicados visando ao esclarecimento 
específico dessa questão e essa ausência deve suscitar algumas considerações éticas, já que a administração mais prolongada de corticosteróides pode incorrer em surgimento de efeitos colaterais potencialmente graves nas crianças, como déficits antropométricos, hipertensão, hiperglicemia, distúrbios gastrointestinais, risco de infecção e supressão adrenal ${ }^{43-45}$. Talvez os ensaios clínicos tenham sido antecipados sem que houvesse ênfase adequada na etapa de desenvolvimento de estudos experimentais, como seria conveniente antes de se postular uma nova indicação terapêutica para o medicamento. Assim, um dos objetivos propostos no presente estudo foi contribuir, através de um modelo experimental, para o entendimento de um dos aspectos envolvidos na evolução dos pacientes portadores de AVB: o estabelecimento da fibrose portal _ principal fator determinante da morbi-mortalidade relacionada à doença e da necessidade de substituição do fígado _ e como os depósitos de colágeno podem ser alterados com a administração de corticosteróides.

Paralelamente ao estudo com o corticóide, outra medicação incluída nessa pesquisa foi a pentoxifilina, droga já reconhecida por outros pesquisadores pelo potencial antifibrogênico ${ }^{16,18,19,46}$. Classificada como derivada das metilxantinas e inibidora inespecífica das fosfodiesterases, a pentoxifilina também já é utilizada na prática clínica, com indicação terapêutica nos distúrbios de perfusão arterial periférica e nas doenças cerebrovasculares, devido ao seu efeito potencializador do transporte de oxigênio para os tecidos periféricos, agindo primariamente por meio do aumento da deformabilidade eritrocitária, da diminuição da viscosidade sangüínea (diminuição da concentração de fibrinogênio plasmático) e da inibição da agregação plaquetária. É um medicamento bem tolerado, liberado para uso pediátrico, com 
incidência relatada de cerca de 3\% de efeitos adversos gastrointestinais (dispepsia, náuseas e diarréia) e menos de $0,25 \%$ de efeitos relacionados aos sistemas cardiovascular e nervoso central (palpitação, tontura ou vertigem, cefaléia) ${ }^{17,46}$.

As fosfodiesterases são enzimas envolvidas nos mecanismos de sinalização intracelular ${ }^{47}$. São responsáveis pela degradação dos nucleotídeos cíclicos (cAMP cyclic Adenosine MonoPhosphate e cGMP - cyclic Guanosine MonoPhosphate) por meio de hidrólise das pontes fosfodiéster presentes nessas duas moléculas. Portanto, as fosfodiesterases regulam os níveis intracelulares desses "segundos-mensageiros" sintetizados pelas proteínas ligadas aos receptores da membrana celular ${ }^{48}$. A inibição dessas enzimas, que compreendem pelo menos 11 famílias descritas, resulta em aumento da concentração dos nucleotídeos cíclicos, facilitando suas ligações às enzimas-alvo: Proteína Kinase A (PKA) e Proteína Kinase G (PKG). Essas enzimas ativadas pelas ligações com os nucleotídeos, por sua vez, promovem a fosforilação e ativação de substratos como canais iônicos, proteínas contráteis e fatores de transcrição que regulam as funções celulares. Assim, alterações na atividade das fosfodiesterases podem afetar diversos processos, incluindo apoptose, diferenciação e migração, proliferação celular, contração muscular e glicogenólise, entre outros. A multiplicidade de famílias e subtipos das fosfodiesterases exibe uma distribuição compartimentalizada nos diferentes tecidos, responsável pela regulação de mecanismos tão importantes quanto diversos ${ }^{47-49}$.

A pentoxifilina, como inibidora não seletiva das fosfodiesterases, apresenta teoricamente um potencial enorme de modulação desses processos celulares mencionados, o que justifica o interesse dos pesquisadores, nas últimas décadas, em identificar seus efeitos através de diversos modelos experimentais e ensaios clínicos. 
Entretanto, alguns autores sugerem que a droga bloqueie a ativação das células estreladas não por meio de seu efeito inibitório sobre as fosfodiesterases, e sim, pelo bloqueio do metabolismo oxidativo ${ }^{50}$. Com relação específica ao processo de fibrogênese hepática, desde 1993 os estudos têm demonstrado que a medicação diminui a ativação e proliferação das células estreladas e modula a produção de IL-1, IL-6 e TNF $\alpha$ (citocinas pró-inflamatórias) ${ }^{46,51}$.

Algumas publicações relatam os resultados de observações em culturas celulares $^{19,52}$ (modelos “in vitro") e talvez não revelem a complexidade das interações e dos mecanismos que resultam no estabelecimento da fibrose hepática "in vivo". Outros modelos utilizam agressão predominantemente hepatocelular (agentes como tetracloreto de carbono ${ }^{50}$ e acetaldeído ${ }^{53}$ ) e, portanto, revelam peculiaridades possivelmente não compartilhadas com os modelos de agressão inicialmente biliar. Dentre esses modelos de ligadura biliar, foram utilizados somente animais adultos (ratos e porcos) $)^{14,16,51}$, com apresentação de resultados controversos _ alguns não demonstraram redução da fibrose hepática com a administração de pentoxifilina ${ }^{14,16}$.

Com o objetivo de tentar obter informações mais aplicáveis ao tratamento das crianças portadoras de AVB, propôs-se, neste estudo, a verificação do efeito da administração de pentoxifilina na evolução da fibrose hepática induzida pela obstrução biliar em animais jovens.

Analisando os resultados obtidos, observou-se que, com relação ao ganho de peso dos animais durante o período de experimentação, os grupos que receberam corticosteróide (PRED e PTX + PRED) nitidamente apresentaram pior desempenho que os demais grupos (LDBC, CS e PTX). Os animais tratados com pentoxifilina, 
entretanto, apresentaram uma tendência de melhor desempenho com relação ao grupo LDBC e aos 2 grupos de animais tratados com corticóide. Esse fato ressalta o potencial efeito adverso no desenvolvimento pôndero-estatural da terapêutica com corticosteróides em animais e humanos, amplamente documentado na literatura ${ }^{44,54} \mathrm{e}$ sugere um benefício clinicamente identificável da utilização da pentoxifilina.

Com relação à análise histológica, verificou-se que os animais dos 3 grupos de tratamento (PTX, PRED e PTX+PRED) apresentaram diminuição da área absoluta de colágeno (sem diferença estatística entre os grupos), indicando um benéfico retardo no desenvolvimento da fibrose portal decorrente da obstrução biliar. Entretanto, são pertinentes mais algumas considerações a respeito da área total dos espaços-porta e da fração de área de colágeno nesses grupos, pois apresentaram evoluções diferentes. No grupo PTX, mensurou-se uma área total maior (e conseqüente diminuição da fração de área de colágeno) com relação ao grupos tratados com corticosteróide. Como a área total é resultante da soma da área preenchida por colágeno, da área ocupada pela proliferação ductular e da área ocupada pelas estruturas vasculares, teria o corticosteróide também um efeito inibitório sobre a proliferação ductular, paralelamente à redução da síntese de colágeno? Ou ainda inversamente, seria a pentoxifilina uma droga indutora da proliferação ductular? Essa segunda hipótese poderia explicar o aumento da área total mais pronunciado no grupo PTX do que no grupo não tratado (LDBC)? Não foram obtidas respostas para essas questões em consulta à literatura publicada até o presente momento. Portanto, abrem-se novas perspectivas de investigação nessa linha de pesquisa. A elucidação exata dos mecanismos envolvidos no retardo do desenvolvimento da fibrose portal de padrão biliar obtido com a administração do 
corticosteróide e da pentoxifilina também representa um desafio futuro. Finalmente, novos estudos experimentais e clínicos devem ser conduzidos no sentido de confirmar o benefício da utilização dessas drogas no tratamento dos pacientes portadores de AVB, objetivando melhora da sobrevida livre de transplante no pósoperatório da cirurgia de Kasai. 
6. CONCLUSÕES 
Nas condições do presente trabalho experimental, pôde-se concluir que:

1. A evolução da fibrose hepática induzida pela ligadura do ducto biliar comum em ratos jovens pode ser modulada com a administração de medicamentos.

2. A administração de prednisolona $3 \mathrm{mg} / \mathrm{kg} / \mathrm{dia}$ e pentoxifilina $10 \mathrm{mg} / \mathrm{kg} /$ dia, isoladamente ou em associação, durante 15 ou 30 dias após a ligadura biliar resultou em diminuição da área preenchida por colágeno nos espaços-porta. 
7. ANEXOS 
Anexo A - Medidas de área preenchida por colágeno $\left(\mu \mathrm{m}^{2}\right)$, área total dos espaços-porta $\left(\mu \mathrm{m}^{2}\right)$ e fração de área de colágeno - grupo LDBC 15 dias

\begin{tabular}{|c|c|c|c|c|}
\hline Lâmina & Espaço-porta & Área de colágeno & Área total & Fração de área de colágeno \\
\hline 1 & 1 & 29484,3 & 94653,5 & 0,311 \\
\hline 1 & 2 & 20996,5 & 103784,9 & 0,202 \\
\hline 1 & 3 & 30133,4 & 111054,2 & 0,271 \\
\hline 1 & 4 & 25610,4 & 128616,7 & 0,199 \\
\hline 1 & 5 & 7414,3 & 40424,4 & 0,183 \\
\hline 1 & 6 & 8989,9 & 38583,4 & 0,233 \\
\hline 1 & 7 & 30509,4 & 109314,8 & 0,279 \\
\hline 1 & 8 & 21940,4 & 69392,5 & 0,316 \\
\hline 1 & 9 & 47381,4 & 143732,4 & 0,330 \\
\hline 1 & 10 & 28935,3 & 104635,7 & 0,277 \\
\hline 1 & 11 & 34559,7 & 132013,6 & 0,262 \\
\hline 1 & 12 & 24216,2 & 80271 & 0,302 \\
\hline 1 & 13 & 25202,9 & 139539,9 & 0,181 \\
\hline 1 & 14 & 21235,9 & 109619,4 & 0,194 \\
\hline 1 & 15 & 21836,8 & 142095,9 & 0,154 \\
\hline 2 & 1 & 9776,3 & 57635,9 & 0,170 \\
\hline 2 & 2 & 18924,4 & 61102,9 & 0,310 \\
\hline 2 & 3 & 21575,6 & 47889,1 & 0,451 \\
\hline 2 & 4 & 26319,1 & 70349,1 & 0,374 \\
\hline 2 & 5 & 16458,1 & 50826,6 & 0,324 \\
\hline 2 & 6 & 47832,4 & 121438,3 & 0,394 \\
\hline 2 & 7 & 24004,8 & 71632,6 & 0,335 \\
\hline 2 & 8 & 22120,4 & 67566,9 & 0,327 \\
\hline 2 & 9 & 52872,8 & 123739,4 & 0,427 \\
\hline 2 & 10 & 49811,9 & 185352,1 & 0,269 \\
\hline 2 & 11 & 16067,4 & 57842,5 & 0,278 \\
\hline 2 & 12 & 11433,8 & 55054,8 & 0,208 \\
\hline 2 & 13 & 17076,4 & 42955,1 & 0,398 \\
\hline 2 & 14 & 37872,6 & 103901,1 & 0,365 \\
\hline 2 & 15 & 20179,3 & 71657,2 & 0,282 \\
\hline 3 & 1 & 18096,7 & 86447,3 & 0,209 \\
\hline 3 & 2 & 35512,1 & 126080,3 & 0,282 \\
\hline 3 & 3 & 22532,1 & 94623,4 & 0,238 \\
\hline 3 & 4 & 13764,9 & 69565,5 & 0,198 \\
\hline 3 & 5 & 73821,6 & 192447,7 & 0,384 \\
\hline 3 & 6 & 9852,6 & 47270,1 & 0,208 \\
\hline 3 & 7 & 74437,2 & 193809,7 & 0,384 \\
\hline 3 & 8 & 19287,1 & 132197,8 & 0,146 \\
\hline 3 & 9 & 23462,8 & 96957,4 & 0,242 \\
\hline
\end{tabular}


Anexo A - Medidas de área preenchida por colágeno $\left(\mu \mathrm{m}^{2}\right)$, área total dos espaços-porta $\left(\mu \mathrm{m}^{2}\right)$ e fração de área de colágeno - grupo LDBC 15 dias (continuação)

\begin{tabular}{|c|c|c|c|c|}
\hline Lâmina & Espaço-porta & Área de colágeno & Área total & Fração de área de colágeno \\
\hline 3 & 10 & 66686,7 & 144675,6 & 0,461 \\
\hline 3 & 11 & 16832 & 82361,3 & 0,204 \\
\hline 3 & 12 & 59886,6 & 144335,3 & 0,415 \\
\hline 3 & 13 & 21063,7 & 147516,6 & 0,143 \\
\hline 3 & 14 & 40577,7 & 124241,5 & 0,327 \\
\hline 3 & 15 & 28571,1 & 114967,3 & 0,249 \\
\hline 4 & 1 & 17252,2 & 98670,2 & 0,175 \\
\hline 4 & 2 & 16055,5 & 63933,3 & 0,251 \\
\hline 4 & 3 & 18978,3 & 65149,7 & 0,291 \\
\hline 4 & 4 & 8737,1 & 49182,4 & 0,178 \\
\hline 4 & 5 & 24535,6 & 66581 & 0,369 \\
\hline 4 & 6 & 25635,7 & 76145,1 & 0,337 \\
\hline 4 & 7 & 46411,5 & 137116,3 & 0,338 \\
\hline 4 & 8 & 14002,3 & 56068,8 & 0,250 \\
\hline 4 & 9 & 28871,5 & 80324,9 & 0,359 \\
\hline 4 & 10 & 39845,9 & 99142,9 & 0,402 \\
\hline 4 & 11 & 21059,5 & 86232,3 & 0,244 \\
\hline 4 & 12 & 44761,7 & 173594,8 & 0,258 \\
\hline 4 & 13 & 28174,1 & 74089,8 & 0,380 \\
\hline 4 & 14 & 18149,9 & 89395,3 & 0,203 \\
\hline 4 & 15 & 22111,3 & 68471,7 & 0,323 \\
\hline 5 & 1 & 42562,2 & 113559,7 & 0,375 \\
\hline 5 & 2 & 18690,5 & 59399,9 & 0,315 \\
\hline 5 & 3 & 28217,5 & 75545,7 & 0,374 \\
\hline 5 & 4 & 38897,1 & 98121,9 & 0,396 \\
\hline 5 & 5 & 23824,1 & 49368,7 & 0,483 \\
\hline 5 & 6 & 71509,4 & 170377,1 & 0,420 \\
\hline 5 & 7 & 24539,8 & 67867,4 & 0,362 \\
\hline 5 & 8 & 24051 & 72435,8 & 0,332 \\
\hline 5 & 9 & 24291,2 & 55399,3 & 0,438 \\
\hline 5 & 10 & 28069 & 96287,2 & 0,292 \\
\hline 5 & 11 & 41154 & 133332,2 & 0,309 \\
\hline 5 & 12 & 17610 & 44090,2 & 0,399 \\
\hline 5 & 13 & 45652,5 & 127756,7 & 0,357 \\
\hline 5 & 14 & 30688 & 89332,3 & 0,344 \\
\hline 5 & 15 & 23212,8 & 46928,3 & 0,495 \\
\hline 6 & 1 & 12155 & 83674,9 & 0,145 \\
\hline
\end{tabular}


Anexo A - Medidas de área preenchida por colágeno $\left(\mu \mathrm{m}^{2}\right)$, área total dos espaços-porta $\left(\mu \mathrm{m}^{2}\right)$ e fração de área de colágeno - grupo LDBC 15 dias (continuação)

\begin{tabular}{|c|c|c|c|c|}
\hline Lâmina & Espaço-porta & Área de colágeno & Área total & Fração de área de colágeno \\
\hline 6 & 2 & 14377,6 & 74445,6 & 0,193 \\
\hline 6 & 3 & 22380,9 & 93886,1 & 0,238 \\
\hline 6 & 4 & 19573,5 & 82069,3 & 0,238 \\
\hline 6 & 5 & 18768,3 & 127653,1 & 0,147 \\
\hline 6 & 6 & 17677,3 & 121878,1 & 0,145 \\
\hline 6 & 7 & 17834,1 & 114028,9 & 0,156 \\
\hline 6 & 8 & 23322,7 & 160238,8 & 0,146 \\
\hline 6 & 9 & 8430,4 & 79791,3 & 0,106 \\
\hline 6 & 10 & 17539,3 & 99497,9 & 0,176 \\
\hline 6 & 11 & 15741,7 & 103766 & 0,152 \\
\hline 6 & 12 & 11251 & 58018,3 & 0,194 \\
\hline 6 & 13 & 21871,8 & 72054,2 & 0,304 \\
\hline 6 & 14 & 20170,2 & 121248,6 & 0,166 \\
\hline 6 & 15 & 9455,6 & 57953,9 & 0,163 \\
\hline 7 & 1 & 15572,3 & 47503,9 & 0,328 \\
\hline 7 & 2 & 17564,5 & 50158,6 & 0,350 \\
\hline 7 & 3 & 30302,2 & 61849,4 & 0,490 \\
\hline 7 & 4 & 19755,6 & 53675,3 & 0,368 \\
\hline 7 & 5 & 44574,1 & 103238,7 & 0,432 \\
\hline 7 & 6 & 18753,5 & 52985,5 & 0,354 \\
\hline 7 & 7 & 18237,5 & 45676,3 & 0,399 \\
\hline 7 & 8 & 26553 & 77853,8 & 0,341 \\
\hline 7 & 9 & 21674,3 & 43533,5 & 0,498 \\
\hline 7 & 10 & 14485,5 & 44852,1 & 0,323 \\
\hline 7 & 11 & 50199,9 & 124267,4 & 0,404 \\
\hline 7 & 12 & 31485,6 & 87359,7 & 0,360 \\
\hline 7 & 13 & 22875,3 & 47768,6 & 0,479 \\
\hline 7 & 14 & 17393,6 & 46105,5 & 0,377 \\
\hline 7 & 15 & 22461,4 & 49228 & 0,456 \\
\hline 8 & 1 & 33764,2 & 71360,9 & 0,473 \\
\hline 8 & 2 & 19765,4 & 40418,8 & 0,489 \\
\hline 8 & 3 & 27034,1 & 76384,6 & 0,354 \\
\hline 8 & 4 & 35989,6 & 61747,8 & 0,583 \\
\hline 8 & 5 & 20750,7 & 64002,7 & 0,324 \\
\hline 8 & 6 & 30444,3 & 58275,3 & 0,522 \\
\hline 8 & 7 & 11118 & 21402,6 & 0,519 \\
\hline 8 & 8 & 21165,9 & 45190,3 & 0,468 \\
\hline
\end{tabular}


Anexo A - Medidas de área preenchida por colágeno $\left(\mu \mathrm{m}^{2}\right)$, área total dos espaços-porta $\left(\mu \mathrm{m}^{2}\right)$ e fração de área de colágeno - grupo LDBC 15 dias (conclusão)

\begin{tabular}{|c|c|c|c|c|}
\hline Lâmina & Espaço-porta & Área de colágeno & Área total & Fração de área de colágeno \\
\hline 8 & 9 & 24764,5 & 74166,9 & 0,334 \\
\hline 8 & 10 & 39459,4 & 113239,7 & 0,348 \\
\hline 8 & 11 & 34529,6 & 100007,7 & 0,345 \\
\hline 8 & 12 & 25868,1 & 62997,1 & 0,411 \\
\hline 8 & 13 & 58645 & 132820,3 & 0,442 \\
\hline 8 & 14 & 32296,5 & 101889,3 & 0,317 \\
\hline 8 & 15 & 47289,7 & 150384,8 & 0,314 \\
\hline 9 & 1 & 23026,5 & 48328,1 & 0,476 \\
\hline 9 & 2 & 28797,3 & 108779,8 & 0,265 \\
\hline 9 & 3 & 27584,5 & 100904,7 & 0,273 \\
\hline 9 & 4 & 49063,4 & 124829,7 & 0,393 \\
\hline 9 & 5 & 26140,5 & 79487,4 & 0,329 \\
\hline 9 & 6 & 25534,1 & 89425,4 & 0,286 \\
\hline 9 & 7 & 17370,5 & 47186 & 0,368 \\
\hline 9 & 8 & 11815,4 & 44545,4 & 0,265 \\
\hline 9 & 9 & 31045,8 & 111483,5 & 0,278 \\
\hline 9 & 10 & 12292,3 & 34363,6 & 0,358 \\
\hline 9 & 11 & 24302,4 & 68375,1 & 0,355 \\
\hline 9 & 12 & 18864,9 & 56497,3 & 0,334 \\
\hline 9 & 13 & 20508,4 & 88270,7 & 0,232 \\
\hline 9 & 14 & 31418,4 & 75428,7 & 0,417 \\
\hline 9 & 15 & 37342,5 & 108031,1 & 0,346 \\
\hline 10 & 1 & 39264 & 109082,3 & 0,360 \\
\hline 10 & 2 & 22209,3 & 81972,6 & 0,271 \\
\hline 10 & 3 & 29332,3 & 153126,3 & 0,192 \\
\hline 10 & 4 & 46729,5 & 128037,5 & 0,365 \\
\hline 10 & 5 & 31372,2 & 116151,4 & 0,270 \\
\hline 10 & 6 & 20071,4 & 77448,3 & 0,259 \\
\hline 10 & 7 & 32223 & 110910 & 0,291 \\
\hline 10 & 8 & 35601 & 150889,7 & 0,236 \\
\hline 10 & 9 & 33524,7 & 77316,6 & 0,434 \\
\hline 10 & 10 & 37993,8 & 123474 & 0,308 \\
\hline 10 & 11 & 15420 & 63732,4 & 0,242 \\
\hline 10 & 12 & 58762,6 & 137473,5 & 0,427 \\
\hline 10 & 13 & 55852,4 & 134036,6 & 0,417 \\
\hline 10 & 14 & 49072,5 & 134141,7 & 0,366 \\
\hline 10 & 15 & 42245 & 121741,5 & 0,347 \\
\hline
\end{tabular}


Anexo B - Medidas de área preenchida por colágeno $\left(\mu \mathrm{m}^{2}\right)$, área total dos espaços-porta $\left(\mu \mathrm{m}^{2}\right)$ e fração de área de colágeno - grupo LDBC 30 dias

\begin{tabular}{|c|c|c|c|c|}
\hline Lâmina & Espaço-porta & Área de colágeno & Área total & Fração de área de colágeno \\
\hline 1 & 1 & 14293,6 & 84587,4 & 0,169 \\
\hline 1 & 2 & 30402,3 & 114290,1 & 0,266 \\
\hline 1 & 3 & 27943 & 133678,8 & 0,209 \\
\hline 1 & 4 & 26146,1 & 153948,4 & 0,170 \\
\hline 1 & 5 & 16580,7 & 96362,9 & 0,172 \\
\hline 1 & 6 & 15787,3 & 87372,3 & 0,181 \\
\hline 1 & 7 & 10382 & 80105,7 & 0,130 \\
\hline 1 & 8 & 11926,1 & 80430,7 & 0,148 \\
\hline 1 & 9 & 12359,5 & 69453,4 & 0,178 \\
\hline 1 & 10 & 46137,7 & 171095,6 & 0,270 \\
\hline 1 & 11 & 13463,8 & 81439,7 & 0,165 \\
\hline 1 & 12 & 12269,2 & 71612,3 & 0,171 \\
\hline 1 & 13 & 29062 & 129099,8 & 0,225 \\
\hline 1 & 14 & 9181,8 & 53929,5 & 0,170 \\
\hline 1 & 15 & 23541,9 & 114023,3 & 0,206 \\
\hline 2 & 1 & 14810,4 & 74077,2 & 0,200 \\
\hline 2 & 2 & 16772,5 & 107134,9 & 0,157 \\
\hline 2 & 3 & 12324,5 & 76091,2 & 0,162 \\
\hline 2 & 4 & 20756,3 & 94929,4 & 0,219 \\
\hline 2 & 5 & 19590,4 & 83498,5 & 0,235 \\
\hline 2 & 6 & 33032,5 & 132981,3 & 0,248 \\
\hline 2 & 7 & 22051,7 & 97713,7 & 0,226 \\
\hline 2 & 8 & 29104 & 113284,6 & 0,257 \\
\hline 2 & 9 & 30336,5 & 122710,7 & 0,247 \\
\hline 2 & 10 & 13041,6 & 68154,5 & 0,191 \\
\hline 2 & 11 & 19772,4 & 111531,8 & 0,177 \\
\hline 2 & 12 & 11663,5 & 60547,6 & 0,193 \\
\hline 2 & 13 & 20668 & 118897,8 & 0,174 \\
\hline 2 & 14 & 14145,2 & 86598,5 & 0,163 \\
\hline 2 & 15 & 29028,4 & 111327,3 & 0,261 \\
\hline 3 & 1 & 43547,5 & 131926,8 & 0,330 \\
\hline 3 & 2 & 17762,7 & 64287,7 & 0,276 \\
\hline 3 & 3 & 26275 & 115118,5 & 0,228 \\
\hline 3 & 4 & 28239,9 & 117349,5 & 0,241 \\
\hline 3 & 5 & 25354,2 & 91241,9 & 0,278 \\
\hline 3 & 6 & 9279,8 & 33787,3 & 0,275 \\
\hline 3 & 7 & 32468,8 & 103490,8 & 0,314 \\
\hline 3 & 8 & 12279,7 & 50493,3 & 0,243 \\
\hline 3 & 9 & 28160,8 & 107551,6 & 0,262 \\
\hline
\end{tabular}


Anexo B - Medidas de área preenchida por colágeno $\left(\mu \mathrm{m}^{2}\right)$, área total dos espaços-porta $\left(\mu \mathrm{m}^{2}\right)$ e fração de área de colágeno - grupo LDBC 30 dias (continuação)

\begin{tabular}{|c|c|c|c|c|}
\hline Lâmina & Espaço-porta & Área de colágeno & Área total & Fração de área de colágeno \\
\hline 3 & 10 & 18274,6 & 103297,5 & 0,177 \\
\hline 3 & 11 & 18598,1 & 85445,9 & 0,218 \\
\hline 3 & 12 & 24545,4 & 93602,5 & 0,262 \\
\hline 3 & 13 & 19999,3 & 86202,2 & 0,232 \\
\hline 3 & 14 & 27966,8 & 93130,5 & 0,300 \\
\hline 3 & 15 & 22604,9 & 128069 & 0,177 \\
\hline 4 & 1 & 23158,2 & 49277 & 0,470 \\
\hline 4 & 2 & 38147,8 & 108598,4 & 0,351 \\
\hline 4 & 3 & 20715 & 61287,8 & 0,338 \\
\hline 4 & 4 & 6833,1 & 27639,8 & 0,247 \\
\hline 4 & 5 & 40303,2 & 153048,6 & 0,263 \\
\hline 4 & 6 & 32893,8 & 96597,5 & 0,341 \\
\hline 4 & 7 & 34457,5 & 96754,3 & 0,356 \\
\hline 4 & 8 & 31602,5 & 94012,1 & 0,336 \\
\hline 4 & 9 & 39561 & 111466,7 & 0,355 \\
\hline 4 & 10 & 34370,6 & 122725,4 & 0,280 \\
\hline 4 & 11 & 15505,8 & 50386,9 & 0,308 \\
\hline 4 & 12 & 40263,3 & 122816,4 & 0,328 \\
\hline 4 & 13 & 44863,3 & 131393,9 & 0,341 \\
\hline 4 & 14 & 11266,4 & 42187,6 & 0,267 \\
\hline 4 & 15 & 18086,2 & 40827,7 & 0,443 \\
\hline 5 & 1 & 8839,3 & 15333,5 & 0,576 \\
\hline 5 & 2 & 30889 & 52028,3 & 0,594 \\
\hline 5 & 3 & 21766,7 & 39170,9 & 0,556 \\
\hline 5 & 4 & 46165,8 & 79161,1 & 0,583 \\
\hline 5 & 5 & 18198,2 & 28724,5 & 0,634 \\
\hline 5 & 6 & 24784,8 & 63300,3 & 0,392 \\
\hline 5 & 7 & 18717,1 & 42439,7 & 0,441 \\
\hline 5 & 8 & 13241,1 & 24338,1 & 0,544 \\
\hline 5 & 9 & 11709,7 & 23435,5 & 0,500 \\
\hline 5 & 10 & 34213,1 & 73497,4 & 0,466 \\
\hline 5 & 11 & 50797,2 & 89660,7 & 0,567 \\
\hline 5 & 12 & 32401,5 & 72885,4 & 0,445 \\
\hline 5 & 13 & 5140,6 & 9342,8 & 0,550 \\
\hline 5 & 14 & 65347,9 & 121953 & 0,536 \\
\hline 5 & 15 & 13884,7 & 24415,8 & 0,569 \\
\hline 6 & 1 & 27560,7 & 71901,5 & 0,383 \\
\hline
\end{tabular}


Anexo B - Medidas de área preenchida por colágeno $\left(\mu \mathrm{m}^{2}\right)$, área total dos espaços-porta $\left(\mu \mathrm{m}^{2}\right)$ e fração de área de colágeno - grupo LDBC 30 dias (continuação)

\begin{tabular}{|c|c|c|c|c|}
\hline Lâmina & Espaço-porta & Área de colágeno & Área total & Fração de área de colágeno \\
\hline 6 & 2 & 11066,8 & 24102,1 & 0,459 \\
\hline 6 & 3 & 25747,7 & 53038,1 & 0,485 \\
\hline 6 & 4 & 12545,8 & 26413,6 & 0,475 \\
\hline 6 & 5 & 17770,4 & 42215,6 & 0,421 \\
\hline 6 & 6 & 7777 & 14905,6 & 0,522 \\
\hline 6 & 7 & 25666,5 & 50577,4 & 0,507 \\
\hline 6 & 8 & 4873,8 & 10069,7 & 0,484 \\
\hline 6 & 9 & 48608,2 & 123311,5 & 0,394 \\
\hline 6 & 10 & 43191,8 & 84651,1 & 0,510 \\
\hline 6 & 11 & 34710,3 & 58458,7 & 0,594 \\
\hline 6 & 12 & 8291,7 & 15423,8 & 0,538 \\
\hline 6 & 13 & 10303,6 & 19454,5 & 0,530 \\
\hline 6 & 14 & 7454,9 & 19056,8 & 0,391 \\
\hline 6 & 15 & 15906,3 & 30745,4 & 0,517 \\
\hline 7 & 1 & 24574,8 & 92305,6 & 0,266 \\
\hline 7 & 2 & 25978,8 & 79728,3 & 0,326 \\
\hline 7 & 3 & 7395,4 & 14897,9 & 0,496 \\
\hline 7 & 4 & 19664,6 & 54717,3 & 0,359 \\
\hline 7 & 5 & 14555,5 & 41439,7 & 0,351 \\
\hline 7 & 6 & 26817 & 92148 & 0,291 \\
\hline 7 & 7 & 15931,5 & 49058,5 & 0,325 \\
\hline 7 & 8 & 32138,2 & 107197,2 & 0,300 \\
\hline 7 & 9 & 31062,6 & 107632,1 & 0,289 \\
\hline 7 & 10 & 16722,1 & 48214,7 & 0,347 \\
\hline 7 & 11 & 26077,5 & 72181,6 & 0,361 \\
\hline 7 & 12 & 35938,5 & 102105,7 & 0,352 \\
\hline 7 & 13 & 17138,8 & 39215,7 & 0,437 \\
\hline 7 & 14 & 20410,4 & 50833,7 & 0,402 \\
\hline 7 & 15 & 13437,2 & 42812,2 & 0,314 \\
\hline 8 & 1 & 7310 & 24418,6 & 0,299 \\
\hline 8 & 2 & 20392,8 & 71550 & 0,285 \\
\hline 8 & 3 & 28681,1 & 122688,3 & 0,234 \\
\hline 8 & 4 & 3949,4 & 15373,4 & 0,257 \\
\hline 8 & 5 & 13323,1 & 50208,3 & 0,265 \\
\hline 8 & 6 & 26591,5 & 70984,9 & 0,375 \\
\hline 8 & 7 & 17867 & 41812,3 & 0,427 \\
\hline 8 & 8 & 12696,3 & 33588,5 & 0,378 \\
\hline
\end{tabular}


Anexo B - Medidas de área preenchida por colágeno $\left(\mu \mathrm{m}^{2}\right)$, área total dos espaços-porta $\left(\mu \mathrm{m}^{2}\right)$ e fração de área de colágeno - grupo LDBC 30 dias (conclusão)

\begin{tabular}{|c|c|c|c|c|}
\hline Lâmina & Espaço-porta & Área de colágeno & Área total & Fração de área de colágeno \\
\hline 8 & 9 & 4271,6 & 16450,4 & 0,260 \\
\hline 8 & 10 & 22072,1 & 45768 & 0,482 \\
\hline 8 & 11 & 21949,5 & 106153,8 & 0,207 \\
\hline 8 & 12 & 18056,8 & 56791,4 & 0,318 \\
\hline 8 & 13 & 18846 & 103628,7 & 0,182 \\
\hline 8 & 14 & 12707,5 & 50182,4 & 0,253 \\
\hline 8 & 15 & 24996,3 & 75812,5 & 0,330 \\
\hline 9 & 1 & 12673,9 & 48961,8 & 0,259 \\
\hline 9 & 2 & 21190,4 & 68791,7 & 0,308 \\
\hline 9 & 3 & 33907,8 & 129141,1 & 0,263 \\
\hline 9 & 4 & 13894,5 & 39841 & 0,349 \\
\hline 9 & 5 & 21840,3 & 80205,2 & 0,272 \\
\hline 9 & 6 & 16746,6 & 41476,1 & 0,404 \\
\hline 9 & 7 & 9193,7 & 21876,7 & 0,420 \\
\hline 9 & 8 & 27380 & 94050 & 0,291 \\
\hline 9 & 9 & 18285,8 & 52592 & 0,348 \\
\hline 9 & 10 & 21150,5 & 59647,8 & 0,355 \\
\hline 9 & 11 & 33082,2 & 75150,7 & 0,440 \\
\hline 9 & 12 & 15227,1 & 39019,7 & 0,390 \\
\hline 9 & 13 & 32696,3 & 120845,2 & 0,271 \\
\hline 9 & 14 & 29585,8 & 94369,2 & 0,314 \\
\hline 9 & 15 & 22315 & 83767,4 & 0,266 \\
\hline 10 & 1 & 4756,8 & 10449,2 & 0,455 \\
\hline 10 & 2 & 8854,7 & 18257,8 & 0,485 \\
\hline 10 & 3 & 24071,3 & 61407,5 & 0,392 \\
\hline 10 & 4 & 23303,8 & 44845,1 & 0,520 \\
\hline 10 & 5 & 22321,3 & 40887,9 & 0,546 \\
\hline 10 & 6 & 38829,9 & 89545,9 & 0,434 \\
\hline 10 & 7 & 17766,2 & 36157,7 & 0,491 \\
\hline 10 & 8 & 6925,5 & 23730,3 & 0,292 \\
\hline 10 & 9 & 7307,2 & 15487,6 & 0,472 \\
\hline 10 & 10 & 10023,5 & 21921,5 & 0,457 \\
\hline 10 & 11 & 24739,3 & 46144,7 & 0,536 \\
\hline 10 & 12 & 17507,8 & 30440,1 & 0,575 \\
\hline 10 & 13 & 33741,8 & 83482,4 & 0,404 \\
\hline 10 & 14 & 46132,1 & 100013,3 & 0,461 \\
\hline 10 & 15 & 4905,3 & 11587,1 & 0,423 \\
\hline
\end{tabular}


Anexo C - Medidas de área preenchida por colágeno $\left(\mu \mathrm{m}^{2}\right)$, área total dos espaços-porta $\left(\mu \mathrm{m}^{2}\right)$ e fração de área de colágeno - grupo SHAM 15 dias

\begin{tabular}{|c|c|c|c|c|}
\hline Lâmina & Espaço-porta & Área de colágeno & Área total & Fração de área de colágeno \\
\hline 1 & 1 & 376 & 3621,7 & 0,104 \\
\hline 1 & 2 & 1261,2 & 12505,9 & 0,101 \\
\hline 1 & 3 & 195,4 & 3418,6 & 0,057 \\
\hline 1 & 4 & 10713,2 & 37933,5 & 0,282 \\
\hline 1 & 5 & 573,5 & 4476 & 0,128 \\
\hline 1 & 6 & 566,5 & 4241,4 & 0,134 \\
\hline 1 & 7 & 609,9 & 3913,7 & 0,156 \\
\hline 1 & 8 & 3789,8 & 15561,8 & 0,244 \\
\hline 1 & 9 & 700,3 & 8109,7 & 0,086 \\
\hline 1 & 10 & 399,8 & 5067,7 & 0,079 \\
\hline 1 & 11 & 3855,6 & 23291,9 & 0,166 \\
\hline 1 & 12 & 5057,9 & 19431,4 & 0,260 \\
\hline 1 & 13 & 1172,2 & 7417,8 & 0,158 \\
\hline 1 & 14 & 7457 & 35760,7 & 0,209 \\
\hline 1 & 15 & 7466,1 & 30798,6 & 0,242 \\
\hline 2 & 1 & 357,1 & 3328,3 & 0,107 \\
\hline 2 & 2 & 8286,1 & 27719,6 & 0,299 \\
\hline 2 & 3 & 876 & 4524,4 & 0,194 \\
\hline 2 & 4 & 2583,9 & 13845,5 & 0,187 \\
\hline 2 & 5 & 568,6 & 5578,9 & 0,102 \\
\hline 2 & 6 & 1219,8 & 4916,5 & 0,248 \\
\hline 2 & 7 & 394,2 & 3897,6 & 0,101 \\
\hline 2 & 8 & 3132,9 & 23254,1 & 0,135 \\
\hline 2 & 9 & 3650,4 & 32143,1 & 0,114 \\
\hline 2 & 10 & 600,8 & 4583,2 & 0,131 \\
\hline 2 & 11 & 1844,5 & 8475,2 & 0,218 \\
\hline 2 & 12 & 1216,3 & 7775,6 & 0,156 \\
\hline 2 & 13 & 2165,2 & 14117,9 & 0,153 \\
\hline 2 & 14 & 422,3 & 2814,3 & 0,150 \\
\hline 2 & 15 & 463,6 & 6214,8 & 0,075 \\
\hline 3 & 1 & 2607,8 & 24759,6 & 0,105 \\
\hline 3 & 2 & 931,3 & 14173,9 & 0,066 \\
\hline 3 & 3 & 418,8 & 4761,7 & 0,088 \\
\hline 3 & 4 & 1436,9 & 19393,6 & 0,074 \\
\hline 3 & 5 & 729,7 & 9961,1 & 0,073 \\
\hline 3 & 6 & 1976,8 & 17134,6 & 0,115 \\
\hline 3 & 7 & 540,6 & 4969 & 0,109 \\
\hline 3 & 8 & 390,7 & 4242,8 & 0,092 \\
\hline 3 & 9 & 178,6 & 2633 & 0,068 \\
\hline
\end{tabular}


Anexo C - Medidas de área preenchida por colágeno $\left(\mu \mathrm{m}^{2}\right)$, área total dos espaços-porta $\left(\mu \mathrm{m}^{2}\right)$ e fração de área de colágeno - grupo SHAM 15 dias (continuação)

\begin{tabular}{|c|c|c|c|c|}
\hline Lâmina & Espaço-porta & Área de colágeno & Área total & Fração de área de colágeno \\
\hline 3 & 10 & 1778,6 & 15802,7 & 0,113 \\
\hline 3 & 11 & 593,8 & 7709,8 & 0,077 \\
\hline 3 & 12 & 1543,4 & 12892,4 & 0,120 \\
\hline 3 & 13 & 198,9 & 2728,9 & 0,073 \\
\hline 3 & 14 & 588,9 & 20507,7 & 0,029 \\
\hline 3 & 15 & 51,8 & 3297,5 & 0,016 \\
\hline 4 & 1 & 939,7 & 8467,5 & 0,111 \\
\hline 4 & 2 & 231,8 & 5396,2 & 0,043 \\
\hline 4 & 3 & 444,7 & 7084,5 & 0,063 \\
\hline 4 & 4 & 1346,6 & 12637,5 & 0,107 \\
\hline 4 & 5 & 141,5 & 2336,8 & 0,061 \\
\hline 4 & 6 & 378,1 & 9529,1 & 0,040 \\
\hline 4 & 7 & 3797,5 & 32632,6 & 0,116 \\
\hline 4 & 8 & 795,5 & 10981,4 & 0,072 \\
\hline 4 & 9 & 266,8 & 3462,1 & 0,077 \\
\hline 4 & 10 & 1566,5 & 20486,7 & 0,076 \\
\hline 4 & 11 & 435,6 & 13735,5 & 0,032 \\
\hline 4 & 12 & 787,8 & 6951,4 & 0,113 \\
\hline 4 & 13 & 625,3 & 7324 & 0,085 \\
\hline 4 & 14 & 628,1 & 9596,3 & 0,065 \\
\hline 4 & 15 & 488,8 & 6710,5 & 0,073 \\
\hline 5 & 1 & 2376 & 13829,3 & 0,172 \\
\hline 5 & 2 & 796,9 & 5090,9 & 0,157 \\
\hline 5 & 3 & 5511,7 & 27757,4 & 0,199 \\
\hline 5 & 4 & 1177,1 & 12072,4 & 0,098 \\
\hline 5 & 5 & 12355,3 & 34713,8 & 0,356 \\
\hline 5 & 6 & 10328,1 & 20724,1 & 0,498 \\
\hline 5 & 7 & 486 & 11779 & 0,041 \\
\hline 5 & 8 & 5453,6 & 29997,5 & 0,182 \\
\hline 5 & 9 & 10111,7 & 41382,3 & 0,244 \\
\hline 5 & 10 & 342,4 & 3179,9 & 0,108 \\
\hline 5 & 11 & 12726,4 & 37646,4 & 0,338 \\
\hline 5 & 12 & 12582,9 & 40258,4 & 0,313 \\
\hline 5 & 13 & 874,6 & 5644,8 & 0,155 \\
\hline 5 & 14 & 1560,2 & 18944 & 0,082 \\
\hline 5 & 15 & 230,4 & 6356,9 & 0,036 \\
\hline 6 & 1 & 5245,6 & 32842,7 & 0,160 \\
\hline
\end{tabular}


Anexo C - Medidas de área preenchida por colágeno $\left(\mu \mathrm{m}^{2}\right)$, área total dos espaços-porta $\left(\mu \mathrm{m}^{2}\right)$ e fração de área de colágeno - grupo SHAM 15 dias (continuação)

\begin{tabular}{|c|c|c|c|c|}
\hline Lâmina & Espaço-porta & Área de colágeno & Área total & Fração de área de colágeno \\
\hline 6 & 2 & 931,3 & 7360,4 & 0,127 \\
\hline 6 & 3 & 236 & 6135,6 & 0,038 \\
\hline 6 & 4 & 3932,5 & 29379,9 & 0,134 \\
\hline 6 & 5 & 222 & 3046,1 & 0,073 \\
\hline 6 & 6 & 2121,8 & 13797,8 & 0,154 \\
\hline 6 & 7 & 1039,2 & 8033,3 & 0,129 \\
\hline 6 & 8 & 3133,6 & 16283 & 0,192 \\
\hline 6 & 9 & 245,8 & 11225,1 & 0,022 \\
\hline 6 & 10 & 243 & 1979,6 & 0,123 \\
\hline 6 & 11 & 838,9 & 9784,7 & 0,086 \\
\hline 6 & 12 & 586,1 & 8607,5 & 0,068 \\
\hline 6 & 13 & 380,9 & 4107 & 0,093 \\
\hline 6 & 14 & 530,1 & 7876,5 & 0,067 \\
\hline 6 & 15 & 163,2 & 2787 & 0,059 \\
\hline 7 & 1 & 310,2 & 3670 & 0,085 \\
\hline 7 & 2 & 394,9 & 6380 & 0,062 \\
\hline 7 & 3 & 782,9 & 8232,2 & 0,095 \\
\hline 7 & 4 & 585,4 & 5253,3 & 0,111 \\
\hline 7 & 5 & 301,8 & 2355 & 0,128 \\
\hline 7 & 6 & 2742,9 & 30242,3 & 0,091 \\
\hline 7 & 7 & 3302,4 & 24250,5 & 0,136 \\
\hline 7 & 8 & 341 & 2766,7 & 0,123 \\
\hline 7 & 9 & 3629,4 & 24266,7 & 0,150 \\
\hline 7 & 10 & 810,2 & 5593,6 & 0,145 \\
\hline 7 & 11 & 1252,8 & 9099,8 & 0,138 \\
\hline 7 & 12 & 219,9 & 2198,8 & 0,100 \\
\hline 7 & 13 & 808,8 & 4345,8 & 0,186 \\
\hline 7 & 14 & 460,1 & 3897,6 & 0,118 \\
\hline 7 & 15 & 287,1 & 4808 & 0,060 \\
\hline 8 & 1 & 993,7 & 9069 & 0,110 \\
\hline 8 & 2 & 533,6 & 3583,2 & 0,149 \\
\hline 8 & 3 & 1020,3 & 6607,6 & 0,154 \\
\hline 8 & 4 & 841 & 4627,3 & 0,182 \\
\hline 8 & 5 & 1554,6 & 9652,3 & 0,161 \\
\hline 8 & 6 & 922,9 & 5831 & 0,158 \\
\hline 8 & 7 & 371,1 & 4328,3 & 0,086 \\
\hline 8 & 8 & 4781,3 & 20467,1 & 0,234 \\
\hline
\end{tabular}


Anexo C - Medidas de área preenchida por colágeno $\left(\mu \mathrm{m}^{2}\right)$, área total dos espaços-porta $\left(\mu \mathrm{m}^{2}\right)$ e fração de área de colágeno - grupo SHAM 15 dias (conclusão)

\begin{tabular}{|c|c|c|c|c|}
\hline Lâmina & Espaço-porta & Área de colágeno & Área total & Fração de área de colágeno \\
\hline 8 & 9 & 704,5 & 5779,2 & 0,122 \\
\hline 8 & 10 & 693,3 & 4293,3 & 0,161 \\
\hline 8 & 11 & 1285 & 6334,5 & 0,203 \\
\hline 8 & 12 & 1079,8 & 8170,6 & 0,132 \\
\hline 8 & 13 & 7450,7 & 33020,6 & 0,226 \\
\hline 8 & 14 & 2764,6 & 13554,1 & 0,204 \\
\hline 8 & 15 & 422,3 & 4648,3 & 0,091 \\
\hline 9 & 1 & 1186,2 & 10625,7 & 0,112 \\
\hline 9 & 2 & 549,7 & 5799,5 & 0,095 \\
\hline 9 & 3 & 322,8 & 3951,6 & 0,082 \\
\hline 9 & 4 & 171,6 & 2339,6 & 0,073 \\
\hline 9 & 5 & 621,1 & 7422 & 0,084 \\
\hline 9 & 6 & 889,3 & 1150,6 & 0,773 \\
\hline 9 & 7 & 455,9 & 4444,5 & 0,103 \\
\hline 9 & 8 & 530,8 & 3877,3 & 0,137 \\
\hline 9 & 9 & 424,4 & 3909,5 & 0,109 \\
\hline 9 & 10 & 395,6 & 3845,1 & 0,103 \\
\hline 9 & 11 & 502,1 & 6525,7 & 0,077 \\
\hline 9 & 12 & 4401,8 & 18790,7 & 0,234 \\
\hline 9 & 13 & 107,1 & 2488,7 & 0,043 \\
\hline 9 & 14 & 291,3 & 3238 & 0,090 \\
\hline 9 & 15 & 108,5 & 1628,1 & 0,067 \\
\hline 10 & 1 & 261,9 & 4046,8 & 0,065 \\
\hline 10 & 2 & 334,7 & 4915,8 & 0,068 \\
\hline 10 & 3 & 171,6 & 4166,5 & 0,041 \\
\hline 10 & 4 & 500,7 & 4994,9 & 0,100 \\
\hline 10 & 5 & 1619,7 & 21981 & 0,074 \\
\hline 10 & 6 & 2406,8 & 22460 & 0,107 \\
\hline 10 & 7 & 2053,8 & 21072,8 & 0,097 \\
\hline 10 & 8 & 1815,1 & 14421,1 & 0,126 \\
\hline 10 & 9 & 938,3 & 7160,1 & 0,131 \\
\hline 10 & 10 & 1014 & 7050,9 & 0,144 \\
\hline 10 & 11 & 3025,8 & 30407,9 & 0,100 \\
\hline 10 & 12 & 736,7 & 5072 & 0,145 \\
\hline 10 & 13 & 512,6 & 8795,2 & 0,058 \\
\hline 10 & 14 & 322,1 & 5654,6 & 0,057 \\
\hline 10 & 15 & 4135 & 32062,6 & 0,129 \\
\hline
\end{tabular}


Anexo D - Medidas de área preenchida por colágeno $\left(\mu \mathrm{m}^{2}\right)$, área total dos espaços-porta $\left(\mu \mathrm{m}^{2}\right)$ e fração de área de colágeno - grupo SHAM 30 dias

\begin{tabular}{|c|c|c|c|c|}
\hline Lâmina & Espaço-porta & Área de colágeno & Área total & Fração de área de colágeno \\
\hline 1 & 1 & 1745 & 15517 & 0,112 \\
\hline 1 & 2 & 755,6 & 4261,7 & 0,177 \\
\hline 1 & 3 & 328,4 & 6329,6 & 0,052 \\
\hline 1 & 4 & 813 & 4721,1 & 0,172 \\
\hline 1 & 5 & 972,7 & 7125,8 & 0,137 \\
\hline 1 & 6 & 19,6 & 2346,5 & 0,008 \\
\hline 1 & 7 & 95,2 & 3724 & 0,026 \\
\hline 1 & 8 & 163,9 & 3353,5 & 0,049 \\
\hline 1 & 9 & 7972,4 & 26949,3 & 0,296 \\
\hline 1 & 10 & 2110,6 & 17415,4 & 0,121 \\
\hline 1 & 11 & 194 & 2317,1 & 0,084 \\
\hline 1 & 12 & 375,3 & 4274,4 & 0,088 \\
\hline 1 & 13 & 510,5 & 3250,6 & 0,157 \\
\hline 1 & 14 & 159,7 & 2834,6 & 0,056 \\
\hline 1 & 15 & 1081,2 & 3908,1 & 0,277 \\
\hline 2 & 1 & 590,3 & 3922,1 & 0,151 \\
\hline 2 & 2 & 2238,7 & 11480,7 & 0,195 \\
\hline 2 & 3 & 221,3 & 3061,5 & 0,072 \\
\hline 2 & 4 & 696,1 & 2062,3 & 0,338 \\
\hline 2 & 5 & 745,8 & 4340,9 & 0,172 \\
\hline 2 & 6 & 283,6 & 5711,3 & 0,050 \\
\hline 2 & 7 & 43,4 & 1845,2 & 0,024 \\
\hline 2 & 8 & 206,6 & 2081,9 & 0,099 \\
\hline 2 & 9 & 586,8 & 7237,1 & 0,081 \\
\hline 2 & 10 & 328,4 & 5362,6 & 0,061 \\
\hline 2 & 11 & 91,7 & 2594,4 & 0,035 \\
\hline 2 & 12 & 351,5 & 2275,1 & 0,154 \\
\hline 2 & 13 & 217,8 & 770,3 & 0,283 \\
\hline 2 & 14 & 706,6 & 6502,6 & 0,109 \\
\hline 2 & 15 & 836,8 & 6555,1 & 0,128 \\
\hline 3 & 1 & 3810,1 & 25343 & 0,150 \\
\hline 3 & 2 & 1159,6 & 10111,7 & 0,115 \\
\hline 3 & 3 & 955,8 & 5973,9 & 0,160 \\
\hline 3 & 4 & 74,9 & 2972,6 & 0,025 \\
\hline 3 & 5 & 88,9 & 2017,4 & 0,044 \\
\hline 3 & 6 & 59,5 & 1346,6 & 0,044 \\
\hline 3 & 7 & 6778,5 & 28330,9 & 0,239 \\
\hline 3 & 8 & 2075,6 & 8387 & 0,247 \\
\hline 3 & 9 & 6986,4 & 31757,3 & 0,220 \\
\hline
\end{tabular}


Anexo D - Medidas de área preenchida por colágeno $\left(\mu \mathrm{m}^{2}\right)$, área total dos espaços-porta $\left(\mu \mathrm{m}^{2}\right)$ e fração de área de colágeno - grupo SHAM 30 dias (continuação)

\begin{tabular}{|c|c|c|c|c|}
\hline Lâmina & Espaço-porta & Área de colágeno & Área total & Fração de área de colágeno \\
\hline 3 & 10 & 205,9 & 1611,3 & 0,128 \\
\hline 3 & 11 & 82,6 & 2276,5 & 0,036 \\
\hline 3 & 12 & 3906 & 26638,4 & 0,147 \\
\hline 3 & 13 & 4857 & 19184,9 & 0,253 \\
\hline 3 & 14 & 53,9 & 4565 & 0,012 \\
\hline 3 & 15 & 946 & 8644 & 0,109 \\
\hline 4 & 1 & 1210 & 4980,2 & 0,243 \\
\hline 4 & 2 & 431,4 & 6964,7 & 0,062 \\
\hline 4 & 3 & 577,7 & 11741,9 & 0,049 \\
\hline 4 & 4 & 188,4 & 5399 & 0,035 \\
\hline 4 & 5 & 442,6 & 3961,3 & 0,112 \\
\hline 4 & 6 & 832,6 & 4420 & 0,188 \\
\hline 4 & 7 & 824,9 & 5582,4 & 0,148 \\
\hline 4 & 8 & 13789,4 & 42570,6 & 0,324 \\
\hline 4 & 9 & 88,9 & 6118,8 & 0,015 \\
\hline 4 & 10 & 165,3 & 4670,7 & 0,035 \\
\hline 4 & 11 & 79,8 & 1284,3 & 0,062 \\
\hline 4 & 12 & 422,3 & 7461,9 & 0,057 \\
\hline 4 & 13 & 2371,8 & 13810,4 & 0,172 \\
\hline 4 & 14 & 979 & 6802,3 & 0,144 \\
\hline 4 & 15 & 2708,6 & 11312,6 & 0,239 \\
\hline 5 & 1 & 3964,1 & 13124,9 & 0,302 \\
\hline 5 & 2 & 787,1 & 10073,9 & 0,078 \\
\hline 5 & 3 & 948,1 & 7069,1 & 0,134 \\
\hline 5 & 4 & 181,4 & 2865,4 & 0,063 \\
\hline 5 & 5 & 1084 & 8082,3 & 0,134 \\
\hline 5 & 6 & 3896,9 & 18007,8 & 0,216 \\
\hline 5 & 7 & 543,4 & 6416,4 & 0,085 \\
\hline 5 & 8 & 448,2 & 3976,1 & 0,113 \\
\hline 5 & 9 & 1484,5 & 13622,1 & 0,109 \\
\hline 5 & 10 & 64,4 & 2202,3 & 0,029 \\
\hline 5 & 11 & 273,1 & 2608,5 & 0,105 \\
\hline 5 & 12 & 167,4 & 1922,2 & 0,087 \\
\hline 5 & 13 & 499,3 & 3955 & 0,126 \\
\hline 5 & 14 & 234,6 & 3225,4 & 0,073 \\
\hline 5 & 15 & 1031,5 & 8223,8 & 0,125 \\
\hline 6 & 1 & 5221,1 & 19110 & 0,273 \\
\hline
\end{tabular}


Anexo D - Medidas de área preenchida por colágeno $\left(\mu \mathrm{m}^{2}\right)$, área total dos espaços-porta $\left(\mu \mathrm{m}^{2}\right)$ e fração de área de colágeno - grupo SHAM 30 dias (continuação)

\begin{tabular}{|c|c|c|c|c|}
\hline Lâmina & Espaço-porta & Área de colágeno & Área total & Fração de área de colágeno \\
\hline 6 & 2 & 5035,5 & 23934,7 & 0,210 \\
\hline 6 & 3 & 2296,1 & 13601,1 & 0,169 \\
\hline 6 & 4 & 5525 & 27403,8 & 0,202 \\
\hline 6 & 5 & 1065,8 & 5972,5 & 0,178 \\
\hline 6 & 6 & 10148,8 & 44280 & 0,229 \\
\hline 6 & 7 & 432,1 & 2589,5 & 0,167 \\
\hline 6 & 8 & 2335,4 & 9174,7 & 0,255 \\
\hline 6 & 9 & 2907,5 & 10492,6 & 0,277 \\
\hline 6 & 10 & 2618,3 & 21211,4 & 0,123 \\
\hline 6 & 11 & 535 & 3541,9 & 0,151 \\
\hline 6 & 12 & 4310,8 & 22481 & 0,192 \\
\hline 6 & 13 & 3165,9 & 15816,7 & 0,200 \\
\hline 6 & 14 & 1282,2 & 5086 & 0,252 \\
\hline 6 & 15 & 5291,8 & 25608,3 & 0,207 \\
\hline 7 & 1 & 607,8 & 4329,7 & 0,140 \\
\hline 7 & 2 & 4087,4 & 14080,7 & 0,290 \\
\hline 7 & 3 & 116,2 & 1926,4 & 0,060 \\
\hline 7 & 4 & 3970,4 & 21707,2 & 0,183 \\
\hline 7 & 5 & 1349,4 & 5282,7 & 0,255 \\
\hline 7 & 6 & 675,7 & 4118,2 & 0,164 \\
\hline 7 & 7 & 500,7 & 5031,3 & 0,100 \\
\hline 7 & 8 & 352,9 & 7174,8 & 0,049 \\
\hline 7 & 9 & 151,3 & 3104,9 & 0,049 \\
\hline 7 & 10 & 2726,8 & 37444,8 & 0,073 \\
\hline 7 & 11 & 22425,7 & 74415,5 & 0,301 \\
\hline 7 & 12 & 8507,4 & 42271,6 & 0,201 \\
\hline 7 & 13 & 1126,7 & 10866,6 & 0,104 \\
\hline 7 & 14 & 74,9 & 3454,4 & 0,022 \\
\hline 7 & 15 & 443,3 & 5894,1 & 0,075 \\
\hline 8 & 1 & 440,5 & 5349,3 & 0,082 \\
\hline 8 & 2 & 1157,5 & 1540,5 & 0,751 \\
\hline 8 & 3 & 183,5 & 5027,1 & 0,037 \\
\hline 8 & 4 & 154,1 & 5219,7 & 0,030 \\
\hline 8 & 5 & 834 & 8891,8 & 0,094 \\
\hline 8 & 6 & 7228,1 & 42849,3 & 0,169 \\
\hline 8 & 7 & 705,9 & 6905,2 & 0,102 \\
\hline 8 & 8 & 142,9 & 2947,4 & 0,048 \\
\hline
\end{tabular}


Anexo D - Medidas de área preenchida por colágeno $\left(\mu \mathrm{m}^{2}\right)$, área total dos espaços-porta $\left(\mu \mathrm{m}^{2}\right)$ e fração de área de colágeno - grupo SHAM 30 dias (conclusão)

\begin{tabular}{|c|c|c|c|c|}
\hline Lâmina & Espaço-porta & Área de colágeno & Área total & Fração de área de colágeno \\
\hline 8 & 9 & 110,6 & 2890 & 0,038 \\
\hline 8 & 10 & 322,1 & 3687,5 & 0,087 \\
\hline 8 & 11 & 163,2 & 5372,4 & 0,030 \\
\hline 8 & 12 & 1584 & 32635,4 & 0,049 \\
\hline 8 & 13 & 413,9 & 6967,5 & 0,059 \\
\hline 8 & 14 & 392,8 & 6974,5 & 0,056 \\
\hline 8 & 15 & 128,8 & 4158,8 & 0,031 \\
\hline 9 & 1 & 3149,7 & 25787,6 & 0,122 \\
\hline 9 & 2 & 345,2 & 4658,8 & 0,074 \\
\hline 9 & 3 & 159 & 3889,2 & 0,041 \\
\hline 9 & 4 & 989,5 & 5913,7 & 0,167 \\
\hline 9 & 5 & 9961,1 & 40448,9 & 0,246 \\
\hline 9 & 6 & 1672,2 & 7838,7 & 0,213 \\
\hline 9 & 7 & 1621,1 & 6500,5 & 0,249 \\
\hline 9 & 8 & 21686,9 & 76235,4 & 0,284 \\
\hline 9 & 9 & 78,4 & 2220,5 & 0,035 \\
\hline 9 & 10 & 242,3 & 6807,9 & 0,036 \\
\hline 9 & 11 & 512,6 & 10031,9 & 0,051 \\
\hline 9 & 12 & 1198,8 & 8597,7 & 0,139 \\
\hline 9 & 13 & 3495,7 & 27416,4 & 0,128 \\
\hline 9 & 14 & 85,4 & 4136,4 & 0,021 \\
\hline 9 & 15 & 168,8 & 3053,1 & 0,055 \\
\hline 10 & 1 & 724,1 & 3575,5 & 0,203 \\
\hline 10 & 2 & 529,4 & 4096,5 & 0,129 \\
\hline 10 & 3 & 1777,9 & 7424,8 & 0,239 \\
\hline 10 & 4 & 423 & 4855,6 & 0,087 \\
\hline 10 & 5 & 810,9 & 4263,9 & 0,190 \\
\hline 10 & 6 & 530,8 & 4381,5 & 0,121 \\
\hline 10 & 7 & 377,4 & 4559,4 & 0,083 \\
\hline 10 & 8 & 287,1 & 3924,9 & 0,073 \\
\hline 10 & 9 & 564,4 & 2920,8 & 0,193 \\
\hline 10 & 10 & 3320,6 & 10305,7 & 0,322 \\
\hline 10 & 11 & 1759 & 10220,9 & 0,172 \\
\hline 10 & 12 & 866,9 & 3389,2 & 0,256 \\
\hline 10 & 13 & 1406,1 & 6977,3 & 0,202 \\
\hline 10 & 14 & 903,3 & 4260,4 & 0,212 \\
\hline 10 & 15 & 546,9 & 3153,3 & 0,173 \\
\hline
\end{tabular}


Anexo E - Medidas de área preenchida por colágeno $\left(\mu \mathrm{m}^{2}\right)$, área total dos espaços-porta $\left(\mu \mathrm{m}^{2}\right)$ e fração de área de colágeno - grupo PENTOXIFILINA 15 dias

\begin{tabular}{|c|c|c|c|c|}
\hline Lâmina & Espaço-porta & Área de colágeno & Área total & Fração de área de colágeno \\
\hline 1 & 1 & 21945,3 & 124409,5 & 0,176 \\
\hline 1 & 2 & 15675,9 & 181952,3 & 0,086 \\
\hline 1 & 3 & 13677,4 & 168226 & 0,081 \\
\hline 1 & 4 & 4951,5 & 47384,2 & 0,104 \\
\hline 1 & 5 & 14752,3 & 75435,7 & 0,196 \\
\hline 1 & 6 & 17263,4 & 84179,8 & 0,205 \\
\hline 1 & 7 & 11864,4 & 68871,5 & 0,172 \\
\hline 1 & 8 & 8714,7 & 67469,6 & 0,129 \\
\hline 1 & 9 & 8575,3 & 57890,1 & 0,148 \\
\hline 1 & 10 & 12835,7 & 106800,2 & 0,120 \\
\hline 1 & 11 & 11171,2 & 107264,5 & 0,104 \\
\hline 1 & 12 & 20739,5 & 118316,6 & 0,175 \\
\hline 1 & 13 & 20842,4 & 131727,2 & 0,158 \\
\hline 1 & 14 & 6697,9 & 60889,3 & 0,110 \\
\hline 1 & 15 & 7484,3 & 87824 & 0,085 \\
\hline 2 & 1 & 8412,2 & 45340,8 & 0,186 \\
\hline 2 & 2 & 6379,3 & 58192,6 & 0,110 \\
\hline 2 & 3 & 37032,3 & 132325,9 & 0,280 \\
\hline 2 & 4 & 36301,9 & 155029,6 & 0,234 \\
\hline 2 & 5 & 18479,7 & 104297,5 & 0,177 \\
\hline 2 & 6 & 12671,8 & 73716,6 & 0,172 \\
\hline 2 & 7 & 4993,5 & 29758,1 & 0,168 \\
\hline 2 & 8 & 12378,4 & 81611,3 & 0,152 \\
\hline 2 & 9 & 12689,3 & 104712,7 & 0,121 \\
\hline 2 & 10 & 13715,9 & 67730,8 & 0,203 \\
\hline 2 & 11 & 7102 & 44810,8 & 0,158 \\
\hline 2 & 12 & 8293,1 & 68758,1 & 0,121 \\
\hline 2 & 13 & 9979,3 & 50398,8 & 0,198 \\
\hline 2 & 14 & 12667,6 & 61864,8 & 0,205 \\
\hline 2 & 15 & 8726,6 & 65586,6 & 0,133 \\
\hline 3 & 1 & 15166,8 & 54361,5 & 0,279 \\
\hline 3 & 2 & 7204,2 & 45292,5 & 0,159 \\
\hline 3 & 3 & 9463,3 & 80955,1 & 0,117 \\
\hline 3 & 4 & 4071,3 & 43553,8 & 0,093 \\
\hline 3 & 5 & 6072,6 & 59198,2 & 0,103 \\
\hline 3 & 6 & 15341,9 & 121640 & 0,126 \\
\hline 3 & 7 & 3473,3 & 46088,7 & 0,075 \\
\hline 3 & 8 & 8139,1 & 35937,1 & 0,226 \\
\hline 3 & 9 & 8649,6 & 37016,2 & 0,234 \\
\hline
\end{tabular}


Anexo E - Medidas de área preenchida por colágeno $\left(\mu \mathrm{m}^{2}\right)$, área total dos espaços-porta $\left(\mu \mathrm{m}^{2}\right)$ e fração de área de colágeno - grupo PENTOXIFILINA 15 dias (continuação)

\begin{tabular}{|c|c|c|c|c|}
\hline Lâmina & Espaço-porta & Área de colágeno & Área total & Fração de área de colágeno \\
\hline 3 & 10 & 8498,3 & 31562,6 & 0,269 \\
\hline 3 & 11 & 8513,7 & 36553,3 & 0,233 \\
\hline 3 & 12 & 12294,4 & 76145,1 & 0,161 \\
\hline 3 & 13 & 9847,7 & 45149 & 0,218 \\
\hline 3 & 14 & 6237,2 & 54336,3 & 0,115 \\
\hline 3 & 15 & 7864,6 & 85994,2 & 0,091 \\
\hline 4 & 1 & 11750,3 & 94137,5 & 0,125 \\
\hline 4 & 2 & 15437,1 & 116927,3 & 0,132 \\
\hline 4 & 3 & 10298 & 88793,1 & 0,116 \\
\hline 4 & 4 & 1406,8 & 21501,3 & 0,065 \\
\hline 4 & 5 & 7394 & 110554,3 & 0,067 \\
\hline 4 & 6 & 4165,8 & 47069,1 & 0,089 \\
\hline 4 & 7 & 2612 & 64629,4 & 0,040 \\
\hline 4 & 8 & 8003,9 & 99307,4 & 0,081 \\
\hline 4 & 9 & 10058,5 & 143191,8 & 0,070 \\
\hline 4 & 10 & 27296,7 & 172914,1 & 0,158 \\
\hline 4 & 11 & 4871 & 74809 & 0,065 \\
\hline 4 & 12 & 5120,3 & 105068,5 & 0,049 \\
\hline 4 & 13 & 2740,1 & 39854,3 & 0,069 \\
\hline 4 & 14 & 10741,9 & 114272,6 & 0,094 \\
\hline 4 & 15 & 14831,4 & 157521,8 & 0,094 \\
\hline 5 & 1 & 4793,2 & 64583,9 & 0,074 \\
\hline 5 & 2 & 4438,9 & 45438,2 & 0,098 \\
\hline 5 & 3 & 7400,3 & 103221,2 & 0,072 \\
\hline 5 & 4 & 10914,9 & 117263,4 & 0,093 \\
\hline 5 & 5 & 10072,5 & 138623,3 & 0,073 \\
\hline 5 & 6 & 7943,7 & 97442,7 & 0,082 \\
\hline 5 & 7 & 1620,4 & 27873 & 0,058 \\
\hline 5 & 8 & 15313,2 & 114225 & 0,134 \\
\hline 5 & 9 & 14726,4 & 144401,1 & 0,102 \\
\hline 5 & 10 & 8668,5 & 78979 & 0,110 \\
\hline 5 & 11 & 10784,6 & 100817,9 & 0,107 \\
\hline 5 & 12 & 27239,9 & 161455,1 & 0,169 \\
\hline 5 & 13 & 5015,2 & 98275,3 & 0,051 \\
\hline 5 & 14 & 11844,8 & 99162,5 & 0,119 \\
\hline 5 & 15 & 7239,9 & 107806,5 & 0,067 \\
\hline 6 & 1 & 8759,5 & 106763,1 & 0,082 \\
\hline
\end{tabular}


Anexo E - Medidas de área preenchida por colágeno $\left(\mu \mathrm{m}^{2}\right)$, área total dos espaços-porta $\left(\mu \mathrm{m}^{2}\right)$ e fração de área de colágeno - grupo PENTOXIFILINA 15 dias (continuação)

\begin{tabular}{|c|c|c|c|c|}
\hline Lâmina & Espaço-porta & Área de colágeno & Área total & Fração de área de colágeno \\
\hline 6 & 2 & 5543,2 & 98234 & 0,056 \\
\hline 6 & 3 & 9531,2 & 107724,5 & 0,088 \\
\hline 6 & 4 & 7601,3 & 75379 & 0,101 \\
\hline 6 & 5 & 3686,9 & 85292,5 & 0,043 \\
\hline 6 & 6 & 7976,6 & 78958,7 & 0,101 \\
\hline 6 & 7 & 14945,6 & 145419,3 & 0,103 \\
\hline 6 & 8 & 5913,7 & 129371,5 & 0,046 \\
\hline 6 & 9 & 9407,2 & 127234,3 & 0,074 \\
\hline 6 & 10 & 5064,2 & 131569,6 & 0,038 \\
\hline 6 & 11 & 3340,2 & 84748,4 & 0,039 \\
\hline 6 & 12 & 3410,9 & 86912,2 & 0,039 \\
\hline 6 & 13 & 3115,4 & 87814,1 & 0,035 \\
\hline 6 & 14 & 23922,8 & 166410,8 & 0,144 \\
\hline 6 & 15 & 12527,6 & 96533 & 0,130 \\
\hline 7 & 1 & 16730,5 & 141062,3 & 0,119 \\
\hline 7 & 2 & 15081,4 & 101343,8 & 0,149 \\
\hline 7 & 3 & 9308,5 & 91905 & 0,101 \\
\hline 7 & 4 & 10866,6 & 132211,8 & 0,082 \\
\hline 7 & 5 & 5338 & 64016,7 & 0,083 \\
\hline 7 & 6 & 9328,8 & 56382,5 & 0,165 \\
\hline 7 & 7 & 5860,4 & 96386 & 0,061 \\
\hline 7 & 8 & 9325,3 & 61552,5 & 0,152 \\
\hline 7 & 9 & 9475,2 & 61357,8 & 0,154 \\
\hline 7 & 10 & 7068,4 & 35958,8 & 0,197 \\
\hline 7 & 11 & 8279,8 & 68791,7 & 0,120 \\
\hline 7 & 12 & 23123,1 & 113860,9 & 0,203 \\
\hline 7 & 13 & 8702,1 & 132440,7 & 0,066 \\
\hline 7 & 14 & 6227,4 & 112617,9 & 0,055 \\
\hline 7 & 15 & 7626,5 & 93895,9 & 0,081 \\
\hline 8 & 1 & 5613,2 & 47604,1 & 0,118 \\
\hline 8 & 2 & 14690,7 & 121801,1 & 0,121 \\
\hline 8 & 3 & 7177,6 & 53969,4 & 0,133 \\
\hline 8 & 4 & 7929,7 & 56054,8 & 0,141 \\
\hline 8 & 5 & 8284,7 & 73462,4 & 0,113 \\
\hline 8 & 6 & 6753,3 & 65466,9 & 0,103 \\
\hline 8 & 7 & 12641,1 & 90597 & 0,140 \\
\hline 8 & 8 & 7045,3 & 36731,2 & 0,192 \\
\hline
\end{tabular}


Anexo E - Medidas de área preenchida por colágeno $\left(\mu \mathrm{m}^{2}\right)$, área total dos espaços-porta $\left(\mu \mathrm{m}^{2}\right)$ e fração de área de colágeno - grupo PENTOXIFILINA 15 dias (conclusão)

\begin{tabular}{|c|c|c|c|c|}
\hline Lâmina & Espaço-porta & Área de colágeno & Área total & Fração de área de colágeno \\
\hline 8 & 9 & 8645,4 & 51935,2 & 0,166 \\
\hline 8 & 10 & 12781,1 & 118856,5 & 0,108 \\
\hline 8 & 11 & 9499,7 & 86931,8 & 0,109 \\
\hline 8 & 12 & 20697,5 & 124574,1 & 0,166 \\
\hline 8 & 13 & 13970,1 & 91122,2 & 0,153 \\
\hline 8 & 14 & 21264 & 97440,6 & 0,218 \\
\hline 8 & 15 & 8024,9 & 70701,3 & 0,114 \\
\hline 9 & 1 & 11085,7 & 90577,4 & 0,122 \\
\hline 9 & 2 & 15451,1 & 92902,9 & 0,166 \\
\hline 9 & 3 & 20639,3 & 130376,4 & 0,158 \\
\hline 9 & 4 & 11131,3 & 77682,1 & 0,143 \\
\hline 9 & 5 & 7151 & 92289,5 & 0,077 \\
\hline 9 & 6 & 13727,1 & 51893,1 & 0,265 \\
\hline 9 & 7 & 6585,9 & 91006,6 & 0,072 \\
\hline 9 & 8 & 19628,9 & 68378,6 & 0,287 \\
\hline 9 & 9 & 11870,7 & 89239,9 & 0,133 \\
\hline 9 & 10 & 11148,8 & 85854,8 & 0,130 \\
\hline 9 & 11 & 12631,2 & 103068,5 & 0,123 \\
\hline 9 & 12 & 5191,7 & 37425,9 & 0,139 \\
\hline 9 & 13 & 19222 & 93633,3 & 0,205 \\
\hline 9 & 14 & 6500,5 & 84959,2 & 0,077 \\
\hline 9 & 15 & 11272,7 & 69258,8 & 0,163 \\
\hline 10 & 1 & 8282,6 & 80763,3 & 0,103 \\
\hline 10 & 2 & 8775,6 & 106319,8 & 0,083 \\
\hline 10 & 3 & 7546 & 85375,2 & 0,088 \\
\hline 10 & 4 & 5251,2 & 54271,2 & 0,097 \\
\hline 10 & 5 & 9940,1 & 86836,6 & 0,114 \\
\hline 10 & 6 & 13718,7 & 128681,8 & 0,107 \\
\hline 10 & 7 & 6773,6 & 81301,1 & 0,083 \\
\hline 10 & 8 & 7163,6 & 79137,3 & 0,091 \\
\hline 10 & 9 & 8665,7 & 87945,8 & 0,099 \\
\hline 10 & 10 & 19409 & 80808,1 & 0,240 \\
\hline 10 & 11 & 12489,8 & 93257,2 & 0,134 \\
\hline 10 & 12 & 14680,9 & 110739,8 & 0,133 \\
\hline 10 & 13 & 8596,3 & 73099 & 0,118 \\
\hline 10 & 14 & 9527,7 & 65927,7 & 0,145 \\
\hline 10 & 15 & 8798,7 & 86276,4 & 0,102 \\
\hline
\end{tabular}


Anexo F - Medidas de área preenchida por colágeno $\left(\mu \mathrm{m}^{2}\right)$, área total dos espaços-porta $\left(\mu \mathrm{m}^{2}\right)$ e fração de área de colágeno - grupo PENTOXIFILINA 30 dias

\begin{tabular}{|c|c|c|c|c|}
\hline Lâmina & Espaço-porta & Área de colágeno & Área total & Fração de área de colágeno \\
\hline 1 & 1 & 1479,6 & 8408,7 & 0,176 \\
\hline 1 & 2 & 534,3 & 5331,7 & 0,100 \\
\hline 1 & 3 & 7022,2 & 20004,2 & 0,351 \\
\hline 1 & 4 & 17209,5 & 41251,4 & 0,417 \\
\hline 1 & 5 & 1352,2 & 6394 & 0,211 \\
\hline 1 & 6 & 2329,8 & 21220,5 & 0,110 \\
\hline 1 & 7 & 2797,5 & 10692,9 & 0,262 \\
\hline 1 & 8 & 8077,4 & 27570,5 & 0,293 \\
\hline 1 & 9 & 1372,5 & 17059,6 & 0,080 \\
\hline 1 & 10 & 3656,7 & 15090,5 & 0,242 \\
\hline 1 & 11 & 1972,6 & 21294,1 & 0,093 \\
\hline 1 & 12 & 1341 & 10952,7 & 0,122 \\
\hline 1 & 13 & 1165,9 & 5847,8 & 0,199 \\
\hline 1 & 14 & 2687,6 & 10946,4 & 0,246 \\
\hline 1 & 15 & 1250,7 & 7968,2 & 0,157 \\
\hline 2 & 1 & 7389,8 & 60444 & 0,122 \\
\hline 2 & 2 & 18621,9 & 140472 & 0,133 \\
\hline 2 & 3 & 20801,8 & 142199,5 & 0,146 \\
\hline 2 & 4 & 10810,5 & 78341,1 & 0,138 \\
\hline 2 & 5 & 22014,6 & 119545,5 & 0,184 \\
\hline 2 & 6 & 16196,9 & 101738,7 & 0,159 \\
\hline 2 & 7 & 11160 & 113628,4 & 0,098 \\
\hline 2 & 8 & 18300,5 & 108593,5 & 0,169 \\
\hline 2 & 9 & 10022,1 & 83661,6 & 0,120 \\
\hline 2 & 10 & 3430,6 & 42710 & 0,080 \\
\hline 2 & 11 & 4320,6 & 101437,6 & 0,043 \\
\hline 2 & 12 & 9117,3 & 80144,3 & 0,114 \\
\hline 2 & 13 & 9853,3 & 128033,3 & 0,077 \\
\hline 2 & 14 & 7457,7 & 83878 & 0,089 \\
\hline 2 & 15 & 19650,2 & 134923,1 & 0,146 \\
\hline 3 & 1 & 18584,1 & 108880 & 0,171 \\
\hline 3 & 2 & 11279 & 128978 & 0,087 \\
\hline 3 & 3 & 16012,7 & 96183,6 & 0,166 \\
\hline 3 & 4 & 18666,7 & 114448,4 & 0,163 \\
\hline 3 & 5 & 16779,5 & 163298,2 & 0,103 \\
\hline 3 & 6 & 15741,7 & 146349,2 & 0,108 \\
\hline 3 & 7 & 14895,1 & 117283 & 0,127 \\
\hline 3 & 8 & 14327,2 & 142627,4 & 0,100 \\
\hline 3 & 9 & 8374,4 & 112972,2 & 0,074 \\
\hline
\end{tabular}


Anexo F - Medidas de área preenchida por colágeno $\left(\mu \mathrm{m}^{2}\right)$, área total dos espaços-porta $\left(\mu \mathrm{m}^{2}\right)$ e fração de área de colágeno - grupo PENTOXIFILINA 30 dias (continuação)

\begin{tabular}{|c|c|c|c|c|}
\hline Lâmina & Espaço-porta & Área de colágeno & Área total & Fração de área de colágeno \\
\hline 3 & 10 & 23642,7 & 145079 & 0,163 \\
\hline 3 & 11 & 11508 & 108951,4 & 0,106 \\
\hline 3 & 12 & 12184,4 & 115553,4 & 0,105 \\
\hline 3 & 13 & 9164,2 & 144037 & 0,064 \\
\hline 3 & 14 & 18877,5 & 160885,8 & 0,117 \\
\hline 3 & 15 & 17815,2 & 115368,5 & 0,154 \\
\hline 4 & 1 & 18112,8 & 102845,8 & 0,176 \\
\hline 4 & 2 & 14910,5 & 89587,2 & 0,166 \\
\hline 4 & 3 & 21114,8 & 151231,4 & 0,140 \\
\hline 4 & 4 & 16493,1 & 105812,1 & 0,156 \\
\hline 4 & 5 & 22502,7 & 158069,4 & 0,142 \\
\hline 4 & 6 & 23553,8 & 119056,8 & 0,198 \\
\hline 4 & 7 & 18776 & 102075,6 & 0,184 \\
\hline 4 & 8 & 21086,8 & 151451,3 & 0,139 \\
\hline 4 & 9 & 8467,5 & 92958,2 & 0,091 \\
\hline 4 & 10 & 17001,5 & 146427,6 & 0,116 \\
\hline 4 & 11 & 17991,7 & 130071,8 & 0,138 \\
\hline 4 & 12 & 14876,2 & 92566,8 & 0,161 \\
\hline 4 & 13 & 12081,5 & 85250,5 & 0,142 \\
\hline 4 & 14 & 18087,6 & 130930,3 & 0,138 \\
\hline 4 & 15 & 11937,3 & 109545,9 & 0,109 \\
\hline 5 & 1 & 7932,5 & 131594,1 & 0,060 \\
\hline 5 & 2 & 13082,2 & 138215,1 & 0,095 \\
\hline 5 & 3 & 4996,3 & 108211,9 & 0,046 \\
\hline 5 & 4 & 13393,8 & 171155,1 & 0,078 \\
\hline 5 & 5 & 11100,5 & 101004,9 & 0,110 \\
\hline 5 & 6 & 11888,2 & 155283,8 & 0,077 \\
\hline 5 & 7 & 8719,6 & 122807,3 & 0,071 \\
\hline 5 & 8 & 8461,2 & 129830,9 & 0,065 \\
\hline 5 & 9 & 13526,8 & 161845,2 & 0,084 \\
\hline 5 & 10 & 8980,8 & 133981,3 & 0,067 \\
\hline 5 & 11 & 9970,2 & 84195,2 & 0,118 \\
\hline 5 & 12 & 19925,1 & 158243,1 & 0,126 \\
\hline 5 & 13 & 11556,3 & 113627 & 0,102 \\
\hline 5 & 14 & 13299,3 & 97263,4 & 0,137 \\
\hline 5 & 15 & 12909,2 & 158772,5 & 0,081 \\
\hline 6 & 1 & 9131,3 & 115662,6 & 0,079 \\
\hline
\end{tabular}


Anexo F - Medidas de área preenchida por colágeno $\left(\mu \mathrm{m}^{2}\right)$, área total dos espaços-porta $\left(\mu \mathrm{m}^{2}\right)$ e fração de área de colágeno - grupo PENTOXIFILINA 30 dias (continuação)

\begin{tabular}{|c|c|c|c|c|}
\hline Lâmina & Espaço-porta & Área de colágeno & Área total & Fração de área de colágeno \\
\hline 6 & 2 & 15371,3 & 135463,7 & 0,113 \\
\hline 6 & 3 & 7742 & 134276,8 & 0,058 \\
\hline 6 & 4 & 19233,9 & 113414,1 & 0,170 \\
\hline 6 & 5 & 6300,2 & 43922,1 & 0,143 \\
\hline 6 & 6 & 18441,9 & 137056,1 & 0,135 \\
\hline 6 & 7 & 19456,6 & 144402,5 & 0,135 \\
\hline 6 & 8 & 5969,7 & 83060,1 & 0,072 \\
\hline 6 & 9 & 14897,9 & 114667,6 & 0,130 \\
\hline 6 & 10 & 10505,2 & 123610,5 & 0,085 \\
\hline 6 & 11 & 22584,6 & 114131,2 & 0,198 \\
\hline 6 & 12 & 13038,8 & 126269,4 & 0,103 \\
\hline 6 & 13 & 19160,4 & 109058,5 & 0,176 \\
\hline 6 & 14 & 14594 & 140629,5 & 0,104 \\
\hline 6 & 15 & 4945,9 & 138959,4 & 0,036 \\
\hline 7 & 1 & 6450,1 & 101701,6 & 0,063 \\
\hline 7 & 2 & 13655 & 167950 & 0,081 \\
\hline 7 & 3 & 17568 & 169903 & 0,103 \\
\hline 7 & 4 & 10897,4 & 150119,4 & 0,073 \\
\hline 7 & 5 & 23726,1 & 141612,7 & 0,168 \\
\hline 7 & 6 & 10335,8 & 118424,4 & 0,087 \\
\hline 7 & 7 & 12762,2 & 171563,3 & 0,074 \\
\hline 7 & 8 & 9756,7 & 126108,3 & 0,077 \\
\hline 7 & 9 & 15351,7 & 119897,1 & 0,128 \\
\hline 7 & 10 & 11863,7 & 126241,4 & 0,094 \\
\hline 7 & 11 & 22308 & 105801,6 & 0,211 \\
\hline 7 & 12 & 7872,3 & 95957,4 & 0,082 \\
\hline 7 & 13 & 11878,4 & 154898,6 & 0,077 \\
\hline 7 & 14 & 13697,7 & 138273,9 & 0,099 \\
\hline 7 & 15 & 10379,9 & 145506,1 & 0,071 \\
\hline 8 & 1 & 15511,4 & 147942,3 & 0,105 \\
\hline 8 & 2 & 12188,6 & 110393,9 & 0,110 \\
\hline 8 & 3 & 29281,2 & 142086,1 & 0,206 \\
\hline 8 & 4 & 5564,2 & 105231,6 & 0,053 \\
\hline 8 & 5 & 34300,6 & 138733,9 & 0,247 \\
\hline 8 & 6 & 11131,3 & 144941 & 0,077 \\
\hline 8 & 7 & 15853,1 & 105297,4 & 0,151 \\
\hline 8 & 8 & 14179,5 & 83038,4 & 0,171 \\
\hline
\end{tabular}


Anexo F - Medidas de área preenchida por colágeno $\left(\mu \mathrm{m}^{2}\right)$, área total dos espaços-porta $\left(\mu \mathrm{m}^{2}\right)$ e fração de área de colágeno - grupo PENTOXIFILINA 30 dias (conclusão)

\begin{tabular}{|c|c|c|c|c|}
\hline Lâmina & Espaço-porta & Área de colágeno & Área total & Fração de área de colágeno \\
\hline 8 & 9 & 14485,5 & 103607,7 & 0,140 \\
\hline 8 & 10 & 11988,4 & 143220,5 & 0,084 \\
\hline 8 & 11 & 11316,1 & 133391 & 0,085 \\
\hline 8 & 12 & 10270,6 & 116115 & 0,088 \\
\hline 8 & 13 & 12149,4 & 129653,7 & 0,094 \\
\hline 8 & 14 & 15372 & 115514,2 & 0,133 \\
\hline 8 & 15 & 17656,2 & 104888,5 & 0,168 \\
\hline 9 & 1 & 14554,1 & 139328,5 & 0,104 \\
\hline 9 & 2 & 11440,8 & 134586,3 & 0,085 \\
\hline 9 & 3 & 8037,5 & 97439,2 & 0,082 \\
\hline 9 & 4 & 10963,9 & 135256,5 & 0,081 \\
\hline 9 & 5 & 14984,8 & 132229,3 & 0,113 \\
\hline 9 & 6 & 16358 & 132143,1 & 0,124 \\
\hline 9 & 7 & 8802,9 & 125001,2 & 0,070 \\
\hline 9 & 8 & 7573,3 & 132665,5 & 0,057 \\
\hline 9 & 9 & 5684,7 & 96378,3 & 0,059 \\
\hline 9 & 10 & 9714 & 123877,3 & 0,078 \\
\hline 9 & 11 & 12642,4 & 110472,3 & 0,114 \\
\hline 9 & 12 & 6738,6 & 91934,5 & 0,073 \\
\hline 9 & 13 & 16359,4 & 132271,3 & 0,124 \\
\hline 9 & 14 & 12993,9 & 134622,7 & 0,097 \\
\hline 9 & 15 & 10029,8 & 140150,6 & 0,072 \\
\hline 10 & 1 & 7975,2 & 47237,1 & 0,169 \\
\hline 10 & 2 & 9156,5 & 71811,9 & 0,128 \\
\hline 10 & 3 & 19687 & 85472,5 & 0,230 \\
\hline 10 & 4 & 6184 & 129134,8 & 0,048 \\
\hline 10 & 5 & 13663,4 & 129583,7 & 0,105 \\
\hline 10 & 6 & 4044,7 & 42677,8 & 0,095 \\
\hline 10 & 7 & 11280,4 & 102425,7 & 0,110 \\
\hline 10 & 8 & 12596,9 & 73907,8 & 0,170 \\
\hline 10 & 9 & 10959,7 & 94481,3 & 0,116 \\
\hline 10 & 10 & 11508 & 42474 & 0,271 \\
\hline 10 & 11 & 3333,2 & 46594,3 & 0,072 \\
\hline 10 & 12 & 13118,6 & 108716,8 & 0,121 \\
\hline 10 & 13 & 23920 & 116376,2 & 0,206 \\
\hline 10 & 14 & 14134 & 127959,8 & 0,110 \\
\hline 10 & 15 & 12487,7 & 75793,6 & 0,165 \\
\hline
\end{tabular}


Anexo G - Medidas de área preenchida por colágeno $\left(\mu \mathrm{m}^{2}\right)$, área total dos espaços-porta $\left(\mu \mathrm{m}^{2}\right)$ e fração de área de colágeno - grupo PREDNISOLONA 15 dias

\begin{tabular}{|c|c|c|c|c|}
\hline Lâmina & Espaço-porta & Área de colágeno & Área total & Fração de área de colágeno \\
\hline 1 & 1 & 11651,6 & 76603,1 & 0,152 \\
\hline 1 & 2 & 34694,2 & 154318,8 & 0,225 \\
\hline 1 & 3 & 30040,3 & 107115,3 & 0,280 \\
\hline 1 & 4 & 10784,6 & 64756,8 & 0,167 \\
\hline 1 & 5 & 27550,2 & 104670,7 & 0,263 \\
\hline 1 & 6 & 9875 & 32366,5 & 0,305 \\
\hline 1 & 7 & 20223,4 & 103108,4 & 0,196 \\
\hline 1 & 8 & 11510,1 & 30343,5 & 0,379 \\
\hline 1 & 9 & 17171,7 & 81672,2 & 0,210 \\
\hline 1 & 10 & 34062,5 & 124854,2 & 0,273 \\
\hline 1 & 11 & 10202 & 67457,7 & 0,151 \\
\hline 1 & 12 & 9329,5 & 66224,6 & 0,141 \\
\hline 1 & 13 & 11830,1 & 73296,5 & 0,161 \\
\hline 1 & 14 & 12414,1 & 47599,9 & 0,261 \\
\hline 1 & 15 & 6037,6 & 22441,1 & 0,269 \\
\hline 2 & 1 & 5935,4 & 41086,8 & 0,144 \\
\hline 2 & 2 & 4492,8 & 28881,3 & 0,156 \\
\hline 2 & 3 & 3687,5 & 28679 & 0,129 \\
\hline 2 & 4 & 5021,5 & 31884 & 0,157 \\
\hline 2 & 5 & 17224,2 & 75337 & 0,229 \\
\hline 2 & 6 & 2397 & 15456 & 0,155 \\
\hline 2 & 7 & 2324,8 & 20300,4 & 0,115 \\
\hline 2 & 8 & 5223,2 & 35423,1 & 0,147 \\
\hline 2 & 9 & 12225,1 & 54312,5 & 0,225 \\
\hline 2 & 10 & 5881,4 & 38604,4 & 0,152 \\
\hline 2 & 11 & 6779,2 & 42884,4 & 0,158 \\
\hline 2 & 12 & 1801,8 & 11870,7 & 0,152 \\
\hline 2 & 13 & 662,4 & 7961,9 & 0,083 \\
\hline 2 & 14 & 2717 & 32338,5 & 0,084 \\
\hline 2 & 15 & 5240 & 47102,7 & 0,111 \\
\hline 3 & 1 & 15776,8 & 70505,2 & 0,224 \\
\hline 3 & 2 & 10745,4 & 74351 & 0,145 \\
\hline 3 & 3 & 17091,8 & 80600,1 & 0,212 \\
\hline 3 & 4 & 14387,5 & 54594,7 & 0,264 \\
\hline 3 & 5 & 19904,1 & 73603,2 & 0,270 \\
\hline 3 & 6 & 20833,3 & 75992,4 & 0,274 \\
\hline 3 & 7 & 5683,3 & 49423,3 & 0,115 \\
\hline 3 & 8 & 3896,9 & 21387,9 & 0,182 \\
\hline 3 & 9 & 13500,2 & 47195,8 & 0,286 \\
\hline
\end{tabular}


Anexo G - Medidas de área preenchida por colágeno $\left(\mu \mathrm{m}^{2}\right)$, área total dos espaços-porta $\left(\mu \mathrm{m}^{2}\right)$ e fração de área de colágeno - grupo PREDNISOLONA 15 dias (continuação)

\begin{tabular}{|c|c|c|c|c|}
\hline Lâmina & Espaço-porta & Área de colágeno & Área total & Fração de área de colágeno \\
\hline 3 & 10 & 5628,7 & 72421,1 & 0,078 \\
\hline 3 & 11 & 2860,5 & 28674,8 & 0,100 \\
\hline 3 & 12 & 12036,7 & 110557,8 & 0,109 \\
\hline 3 & 13 & 9382 & 81354,3 & 0,115 \\
\hline 3 & 14 & 8773,5 & 87743,4 & 0,100 \\
\hline 3 & 15 & 11874,2 & 66998,4 & 0,177 \\
\hline 4 & 1 & 15334,9 & 75781,7 & 0,202 \\
\hline 4 & 2 & 19055,4 & 82757,6 & 0,230 \\
\hline 4 & 3 & 20187 & 93517 & 0,216 \\
\hline 4 & 4 & 15175,9 & 76931,5 & 0,197 \\
\hline 4 & 5 & 24403,9 & 78715 & 0,310 \\
\hline 4 & 6 & 22620,4 & 70975,1 & 0,319 \\
\hline 4 & 7 & 15873,4 & 80455,2 & 0,197 \\
\hline 4 & 8 & 24811,5 & 117319,4 & 0,211 \\
\hline 4 & 9 & 11641,5 & 47917,1 & 0,243 \\
\hline 4 & 10 & 9522,1 & 38503,5 & 0,247 \\
\hline 4 & 11 & 17301,9 & 83093,7 & 0,208 \\
\hline 4 & 12 & 12832,2 & 71792,3 & 0,179 \\
\hline 4 & 13 & 12643,8 & 67426,9 & 0,188 \\
\hline 4 & 14 & 10500,3 & 53811,8 & 0,195 \\
\hline 4 & 15 & 10379,9 & 75141,6 & 0,138 \\
\hline 5 & 1 & 12258 & 67411,5 & 0,182 \\
\hline 5 & 2 & 4394,8 & 31619,3 & 0,139 \\
\hline 5 & 3 & 1483,1 & 19283,6 & 0,077 \\
\hline 5 & 4 & 5202,2 & 63726,1 & 0,082 \\
\hline 5 & 5 & 3955,7 & 45027,8 & 0,088 \\
\hline 5 & 6 & 3148,3 & 38126,8 & 0,083 \\
\hline 5 & 7 & 5477,4 & 54728,4 & 0,100 \\
\hline 5 & 8 & 1528 & 25385,7 & 0,060 \\
\hline 5 & 9 & 14900,7 & 89279,1 & 0,167 \\
\hline 5 & 10 & 13816,7 & 73294,4 & 0,189 \\
\hline 5 & 11 & 7434,6 & 42128,8 & 0,176 \\
\hline 5 & 12 & 18608,6 & 92342 & 0,202 \\
\hline 5 & 13 & 9040,3 & 68931,1 & 0,131 \\
\hline 5 & 14 & 3894,1 & 33547,8 & 0,116 \\
\hline 5 & 15 & 10127,8 & 70288,2 & 0,144 \\
\hline 6 & 1 & 7999 & 22697,4 & 0,352 \\
\hline
\end{tabular}


Anexo G - Medidas de área preenchida por colágeno $\left(\mu \mathrm{m}^{2}\right)$, área total dos espaços-porta $\left(\mu \mathrm{m}^{2}\right)$ e fração de área de colágeno - grupo PREDNISOLONA 15 dias (continuação)

\begin{tabular}{|c|c|c|c|c|}
\hline Lâmina & Espaço-porta & Área de colágeno & Área total & Fração de área de colágeno \\
\hline 6 & 2 & 13050 & 46090,8 & 0,283 \\
\hline 6 & 3 & 7021,5 & 35533,8 & 0,198 \\
\hline 6 & 4 & 6065,6 & 26681,1 & 0,227 \\
\hline 6 & 5 & 18605,1 & 110017,9 & 0,169 \\
\hline 6 & 6 & 29667,7 & 115499,5 & 0,257 \\
\hline 6 & 7 & 18549,8 & 54977,8 & 0,337 \\
\hline 6 & 8 & 14984,1 & 55699 & 0,269 \\
\hline 6 & 9 & 14862,9 & 78371,2 & 0,190 \\
\hline 6 & 10 & 12502,4 & 87218,2 & 0,143 \\
\hline 6 & 11 & 35371,3 & 124224,6 & 0,285 \\
\hline 6 & 12 & 8600,5 & 54059,7 & 0,159 \\
\hline 6 & 13 & 13589,9 & 75895,1 & 0,179 \\
\hline 6 & 14 & 11580,1 & 52437,2 & 0,221 \\
\hline 6 & 15 & 18048,4 & 111234,2 & 0,162 \\
\hline 7 & 1 & 3845,8 & 28820,4 & 0,133 \\
\hline 7 & 2 & 11163,5 & 92534,6 & 0,121 \\
\hline 7 & 3 & 22955,1 & 114456,1 & 0,201 \\
\hline 7 & 4 & 18138 & 121176,4 & 0,150 \\
\hline 7 & 5 & 9641,8 & 56981,2 & 0,169 \\
\hline 7 & 6 & 8587,2 & 66822,6 & 0,129 \\
\hline 7 & 7 & 6062,8 & 48493,4 & 0,125 \\
\hline 7 & 8 & 2933,4 & 26625,1 & 0,110 \\
\hline 7 & 9 & 8082,3 & 33544,3 & 0,241 \\
\hline 7 & 10 & 2460,7 & 14748,8 & 0,167 \\
\hline 7 & 11 & 8117,4 & 40079,1 & 0,203 \\
\hline 7 & 12 & 13639,6 & 59800,4 & 0,228 \\
\hline 7 & 13 & 14900 & 83421,4 & 0,179 \\
\hline 7 & 14 & 7431,8 & 39869,1 & 0,186 \\
\hline 7 & 15 & 15218 & 69533,3 & 0,219 \\
\hline 8 & 1 & 2161,7 & 23024,4 & 0,094 \\
\hline 8 & 2 & 6310,7 & 45200,8 & 0,140 \\
\hline 8 & 3 & 7097,8 & 61698,1 & 0,115 \\
\hline 8 & 4 & 2044,7 & 23981,7 & 0,085 \\
\hline 8 & 5 & 8401 & 55752,9 & 0,151 \\
\hline 8 & 6 & 7906,6 & 83850,7 & 0,094 \\
\hline 8 & 7 & 12547,2 & 67019,4 & 0,187 \\
\hline 8 & 8 & 12715,2 & 85908,8 & 0,148 \\
\hline
\end{tabular}


Anexo G - Medidas de área preenchida por colágeno $\left(\mu \mathrm{m}^{2}\right)$, área total dos espaços-porta $\left(\mu \mathrm{m}^{2}\right)$ e fração de área de colágeno - grupo PREDNISOLONA 15 dias (conclusão)

\begin{tabular}{ccccc}
\hline Lâmina & Espaço-porta & Área de colágeno & Área total & Fração de área de colágeno \\
\hline 8 & 9 & 13071,7 & 63955 & 0,204 \\
\hline 8 & 10 & 22235,2 & 122544 & 0,181 \\
\hline 8 & 11 & 8394,7 & 69602,6 & 0,121 \\
\hline 8 & 12 & 13484,1 & 97780,2 & 0,138 \\
\hline 8 & 13 & 10463,2 & 115510 & 0,091 \\
\hline 8 & 14 & 3972,5 & 38883,1 & 0,102 \\
\hline 8 & 15 & 7927,6 & 74105,3 & 0,107 \\
\hline 9 & 1 & 16620,6 & 43750,6 & 0,380 \\
\hline 9 & 2 & 16396,5 & 69098,4 & 0,237 \\
\hline 9 & 3 & 13402,9 & 84590,2 & 0,158 \\
\hline 9 & 4 & 6558,6 & 30001,8 & 0,219 \\
\hline 9 & 5 & 17301,9 & 89328,8 & 0,194 \\
\hline 9 & 6 & 3238,7 & 26277,1 & 0,123 \\
\hline 9 & 7 & 4172,8 & 40955,1 & 0,102 \\
\hline 9 & 8 & 1448,1 & 17085,5 & 0,085 \\
\hline 9 & 9 & 2740,1 & 48903,8 & 0,056 \\
\hline 9 & 10 & 2067,2 & 39838,2 & 0,052 \\
\hline 9 & 11 & 2566,4 & 14320,2 & 0,179 \\
\hline 9 & 12 & 2962,8 & 31987 & 0,093 \\
\hline 9 & 13 & 6849,2 & 27441,6 & 0,250 \\
\hline 9 & 14 & 7679 & 83897,6 & 0,092 \\
\hline 9 & 15 & 10387,6 & 49475,9 & 0,210 \\
\hline 10 & 1 & 4246,3 & 25348,6 & 0,168 \\
\hline 10 & 2 & 5149,7 & 29168,4 & 0,177 \\
\hline 10 & 3 & 11996,1 & 94568,1 & 0,127 \\
\hline 10 & 4 & 8988,5 & 66397,5 & 0,135 \\
\hline 10 & 5 & 7431,1 & 71799,3 & 0,103 \\
\hline 10 & 6 & 4457,1 & 48663,6 & 0,092 \\
\hline 10 & 7 & 5812,1 & 31349 & 0,185 \\
\hline 10 & 8 & 20710,1 & 88755,3 & 0,233 \\
\hline 10 & 9 & 8207 & 83538,4 & 0,098 \\
\hline 10 & 10 & 15125,5 & 66078,9 & 0,229 \\
\hline 10 & 11 & 3400,4 & 39647,1 & 0,086 \\
\hline 10 & 12 & 5333,1 & 43022,3 & 0,124 \\
\hline 10 & 13 & 8207 & 51229,3 & 0,160 \\
\hline 10 & 14 & 19930 & 63481 & 0,314 \\
\hline & 15 & 9183,9 & 84839,5 & 0,108 \\
\hline
\end{tabular}


Anexo H - Medidas de área preenchida por colágeno $\left(\mu \mathrm{m}^{2}\right)$, área total dos espaços-porta $\left(\mu \mathrm{m}^{2}\right)$ e fração de área de colágeno - grupo PREDNISOLONA 30 dias

\begin{tabular}{|c|c|c|c|c|}
\hline Lâmina & Espaço-porta & Área de colágeno & Área total & Fração de área de colágeno \\
\hline 1 & 1 & 34271,2 & 109125,7 & 0,314 \\
\hline 1 & 2 & 10182,4 & 25000,5 & 0,407 \\
\hline 1 & 3 & 32297,9 & 84065 & 0,384 \\
\hline 1 & 4 & 21627,4 & 89023,5 & 0,243 \\
\hline 1 & 5 & 21038,5 & 127681,1 & 0,165 \\
\hline 1 & 6 & 22478,2 & 123101,4 & 0,183 \\
\hline 1 & 7 & 17023,9 & 72209 & 0,236 \\
\hline 1 & 8 & 7802,9 & 49627,8 & 0,157 \\
\hline 1 & 9 & 26816,3 & 107074 & 0,250 \\
\hline 1 & 10 & 15187,8 & 60646,3 & 0,250 \\
\hline 1 & 11 & 6546 & 31613,7 & 0,207 \\
\hline 1 & 12 & 16225,6 & 92022,7 & 0,176 \\
\hline 1 & 13 & 10277,7 & 64325,5 & 0,160 \\
\hline 1 & 14 & 22977,5 & 69737,8 & 0,329 \\
\hline 1 & 15 & 18219,9 & 55338,4 & 0,329 \\
\hline 2 & 1 & 13220,1 & 51777,6 & 0,255 \\
\hline 2 & 2 & 24069,9 & 92935,1 & 0,259 \\
\hline 2 & 3 & 16748,7 & 85209,9 & 0,197 \\
\hline 2 & 4 & 10441,5 & 74302 & 0,141 \\
\hline 2 & 5 & 13645,2 & 64698 & 0,211 \\
\hline 2 & 6 & 8245,5 & 49111,7 & 0,168 \\
\hline 2 & 7 & 11195,7 & 63756,9 & 0,176 \\
\hline 2 & 8 & 13288,8 & 40656,8 & 0,327 \\
\hline 2 & 9 & 10949,9 & 50443,6 & 0,217 \\
\hline 2 & 10 & 13036 & 57603 & 0,226 \\
\hline 2 & 11 & 11877,7 & 69719,5 & 0,170 \\
\hline 2 & 12 & 9027 & 26249,1 & 0,344 \\
\hline 2 & 13 & 17014,8 & 63448,1 & 0,268 \\
\hline 2 & 14 & 25230,9 & 83616,8 & 0,302 \\
\hline 2 & 15 & 6740,7 & 23965,5 & 0,281 \\
\hline 3 & 1 & 22137,2 & 91993,3 & 0,241 \\
\hline 3 & 2 & 17578,5 & 68842,1 & 0,255 \\
\hline 3 & 3 & 12619,3 & 73493,2 & 0,172 \\
\hline 3 & 4 & 4401,8 & 29020 & 0,152 \\
\hline 3 & 5 & 5662,3 & 31443,6 & 0,180 \\
\hline 3 & 6 & 21535,7 & 114408,5 & 0,188 \\
\hline 3 & 7 & 9195,1 & 75639,5 & 0,122 \\
\hline 3 & 8 & 11324,5 & 87046 & 0,130 \\
\hline 3 & 9 & 10146 & 59607,9 & 0,170 \\
\hline
\end{tabular}


Anexo H - Medidas de área preenchida por colágeno $\left(\mu \mathrm{m}^{2}\right)$, área total dos espaços-porta $\left(\mu \mathrm{m}^{2}\right)$ e fração de área de colágeno - grupo PREDNISOLONA 30 dias (continuação)

\begin{tabular}{|c|c|c|c|c|}
\hline Lâmina & Espaço-porta & Área de colágeno & Área total & Fração de área de colágeno \\
\hline 3 & 10 & 5735,8 & 53104,6 & 0,108 \\
\hline 3 & 11 & 1616,2 & 36189,9 & 0,045 \\
\hline 3 & 12 & 3197,4 & 29938 & 0,107 \\
\hline 3 & 13 & 6087,3 & 52595,5 & 0,116 \\
\hline 3 & 14 & 6887,7 & 40583,3 & 0,170 \\
\hline 3 & 15 & 9835,1 & 62044,7 & 0,159 \\
\hline 4 & 1 & 5135,7 & 41438,3 & 0,124 \\
\hline 4 & 2 & 3001,3 & 36348,9 & 0,083 \\
\hline 4 & 3 & 8204,2 & 56622 & 0,145 \\
\hline 4 & 4 & 6583,1 & 47840,8 & 0,138 \\
\hline 4 & 5 & 6599,2 & 49758,1 & 0,133 \\
\hline 4 & 6 & 3448,1 & 41106,4 & 0,084 \\
\hline 4 & 7 & 15063,2 & 89501,8 & 0,168 \\
\hline 4 & 8 & 20706,6 & 103305,2 & 0,200 \\
\hline 4 & 9 & 22697,4 & 117130,4 & 0,194 \\
\hline 4 & 10 & 21049 & 109325,3 & 0,193 \\
\hline 4 & 11 & 12909,9 & 103301 & 0,125 \\
\hline 4 & 12 & 18411,8 & 96253,6 & 0,191 \\
\hline 4 & 13 & 7790,3 & 37505 & 0,208 \\
\hline 4 & 14 & 25159,5 & 114872 & 0,219 \\
\hline 4 & 15 & 13310,5 & 47364,6 & 0,281 \\
\hline 5 & 1 & 27438,1 & 107609,7 & 0,255 \\
\hline 5 & 2 & 14982 & 52485,6 & 0,285 \\
\hline 5 & 3 & 6329,6 & 31847,6 & 0,199 \\
\hline 5 & 4 & 6460,6 & 44228,1 & 0,146 \\
\hline 5 & 5 & 12258 & 44859,8 & 0,273 \\
\hline 5 & 6 & 7303,7 & 32620,7 & 0,224 \\
\hline 5 & 7 & 7677,6 & 43037 & 0,178 \\
\hline 5 & 8 & 18194,7 & 47547,4 & 0,383 \\
\hline 5 & 9 & 20997,2 & 89306,4 & 0,235 \\
\hline 5 & 10 & 7744,8 & 42261,1 & 0,183 \\
\hline 5 & 11 & 26480,9 & 125489,3 & 0,211 \\
\hline 5 & 12 & 14180,9 & 54278,2 & 0,261 \\
\hline 5 & 13 & 8816,2 & 38771,8 & 0,227 \\
\hline 5 & 14 & 5246,3 & 25180,5 & 0,208 \\
\hline 5 & 15 & 10157,9 & 78047 & 0,130 \\
\hline 6 & 1 & 22252 & 96596,8 & 0,230 \\
\hline
\end{tabular}


Anexo H - Medidas de área preenchida por colágeno $\left(\mu \mathrm{m}^{2}\right)$, área total dos espaços-porta $\left(\mu \mathrm{m}^{2}\right)$ e fração de área de colágeno - grupo PREDNISOLONA 30 dias (continuação)

\begin{tabular}{|c|c|c|c|c|}
\hline Lâmina & Espaço-porta & Área de colágeno & Área total & Fração de área de colágeno \\
\hline 6 & 2 & 8908,7 & 43909,5 & 0,203 \\
\hline 6 & 3 & 21816,5 & 91094,8 & 0,239 \\
\hline 6 & 4 & 31577,3 & 126189,6 & 0,250 \\
\hline 6 & 5 & 20348,7 & 73816,7 & 0,276 \\
\hline 6 & 6 & 20085,4 & 80806 & 0,249 \\
\hline 6 & 7 & 10556,4 & 74525,4 & 0,142 \\
\hline 6 & 8 & 13913,4 & 81027,3 & 0,172 \\
\hline 6 & 9 & 10631,3 & 57706 & 0,184 \\
\hline 6 & 10 & 13669,7 & 55718,6 & 0,245 \\
\hline 6 & 11 & 13818,8 & 77395,8 & 0,179 \\
\hline 6 & 12 & 28667,1 & 117374 & 0,244 \\
\hline 6 & 13 & 20275,9 & 90353,3 & 0,224 \\
\hline 6 & 14 & 13652,9 & 82558,7 & 0,165 \\
\hline 6 & 15 & 7820,5 & 46106,2 & 0,170 \\
\hline 7 & 1 & 5528,5 & 36425,2 & 0,152 \\
\hline 7 & 2 & 16480,5 & 80280,8 & 0,205 \\
\hline 7 & 3 & 17576,4 & 118801,9 & 0,148 \\
\hline 7 & 4 & 8355,4 & 44740,7 & 0,187 \\
\hline 7 & 5 & 6408,7 & 40165,3 & 0,160 \\
\hline 7 & 6 & 6173,5 & 45550,2 & 0,136 \\
\hline 7 & 7 & 14626,9 & 87141,9 & 0,168 \\
\hline 7 & 8 & 5588,7 & 36601 & 0,153 \\
\hline 7 & 9 & 8413,6 & 64907,4 & 0,130 \\
\hline 7 & 10 & 5018 & 31928,2 & 0,157 \\
\hline 7 & 11 & 16548,4 & 82847,2 & 0,200 \\
\hline 7 & 12 & 10460,4 & 48982,2 & 0,214 \\
\hline 7 & 13 & 13872,8 & 61492,9 & 0,226 \\
\hline 7 & 14 & 3833,2 & 30344,9 & 0,126 \\
\hline 7 & 15 & 8629,2 & 52272,7 & 0,165 \\
\hline 8 & 1 & 10150,9 & 61648,4 & 0,165 \\
\hline 8 & 2 & 17997,3 & 129800,8 & 0,139 \\
\hline 8 & 3 & 11641,7 & 62667,3 & 0,186 \\
\hline 8 & 4 & 17641,5 & 87914,3 & 0,201 \\
\hline 8 & 5 & 5981,6 & 38135,9 & 0,157 \\
\hline 8 & 6 & 10356,8 & 68727,3 & 0,151 \\
\hline 8 & 7 & 20495,8 & 119916,7 & 0,171 \\
\hline 8 & 8 & 22089,6 & 110779 & 0,199 \\
\hline
\end{tabular}


Anexo H - Medidas de área preenchida por colágeno $\left(\mu \mathrm{m}^{2}\right)$, área total dos espaços-porta $\left(\mu \mathrm{m}^{2}\right)$ e fração de área de colágeno - grupo PREDNISOLONA 30 dias (conclusão)

\begin{tabular}{|c|c|c|c|c|}
\hline Lâmina & Espaço-porta & Área de colágeno & Área total & Fração de área de colágeno \\
\hline 8 & 9 & 20843,8 & 111157,2 & 0,188 \\
\hline 8 & 10 & 19287,8 & 73793,6 & 0,261 \\
\hline 8 & 11 & 20880,9 & 110840,7 & 0,188 \\
\hline 8 & 12 & 19521 & 74804,1 & 0,261 \\
\hline 8 & 13 & 7469,6 & 40495,1 & 0,184 \\
\hline 8 & 14 & 10975,8 & 79553,9 & 0,138 \\
\hline 8 & 15 & 32599 & 175721,4 & 0,186 \\
\hline 9 & 1 & 27124,4 & 105758,9 & 0,256 \\
\hline 9 & 2 & 11950,6 & 55760,7 & 0,214 \\
\hline 9 & 3 & 10717,4 & 42147 & 0,254 \\
\hline 9 & 4 & 12959,6 & 49927,5 & 0,260 \\
\hline 9 & 5 & 19182,1 & 69335,1 & 0,277 \\
\hline 9 & 6 & 22720,5 & 63458,6 & 0,358 \\
\hline 9 & 7 & 12409,9 & 34540,1 & 0,359 \\
\hline 9 & 8 & 34650,7 & 121075,6 & 0,286 \\
\hline 9 & 9 & 20820,7 & 83875,9 & 0,248 \\
\hline 9 & 10 & 44432,6 & 140777,3 & 0,316 \\
\hline 9 & 11 & 33688,6 & 107977,3 & 0,312 \\
\hline 9 & 12 & 11122,2 & 30605,4 & 0,363 \\
\hline 9 & 13 & 9417 & 29980 & 0,314 \\
\hline 9 & 14 & 20039,9 & 53213,1 & 0,377 \\
\hline 9 & 15 & 17116,3 & 49543,8 & 0,345 \\
\hline 10 & 1 & 18816,6 & 83641,3 & 0,225 \\
\hline 10 & 2 & 16856,6 & 86201,5 & 0,196 \\
\hline 10 & 3 & 8961,2 & 48507,4 & 0,185 \\
\hline 10 & 4 & 15705,3 & 65539,7 & 0,240 \\
\hline 10 & 5 & 14894,4 & 51952,7 & 0,287 \\
\hline 10 & 6 & 13930,2 & 53933 & 0,258 \\
\hline 10 & 7 & 12743,3 & 69683,8 & 0,183 \\
\hline 10 & 8 & 22313,6 & 96290 & 0,232 \\
\hline 10 & 9 & 12069,6 & 54961,7 & 0,220 \\
\hline 10 & 10 & 14083,5 & 59568,6 & 0,236 \\
\hline 10 & 11 & 11319,6 & 49337,2 & 0,229 \\
\hline 10 & 12 & 30265 & 117949,7 & 0,257 \\
\hline 10 & 13 & 25445,9 & 138702,4 & 0,183 \\
\hline 10 & 14 & 23420 & 86235,8 & 0,272 \\
\hline 10 & 15 & 15779,6 & 101404,7 & 0,156 \\
\hline
\end{tabular}


Anexo I - Medidas de área preenchida por colágeno $\left(\mu \mathrm{m}^{2}\right)$, área total dos espaços-porta $\left(\mu \mathrm{m}^{2}\right)$ e fração de área de colágeno - grupo PENTOXIFILINA + PREDNISOLONA 15 dias

\begin{tabular}{|c|c|c|c|c|}
\hline Lâmina & Espaço-porta & Área de colágeno & Área total & Fração de área de colágeno \\
\hline 1 & 1 & 12454 & 67433,2 & 0,185 \\
\hline 1 & 2 & 8938,8 & 30477,9 & 0,293 \\
\hline 1 & 3 & 17164,7 & 61246,5 & 0,280 \\
\hline 1 & 4 & 14615,7 & 121032,9 & 0,121 \\
\hline 1 & 5 & 17133,2 & 79000,7 & 0,217 \\
\hline 1 & 6 & 14120 & 57905,5 & 0,244 \\
\hline 1 & 7 & 22369 & 98624 & 0,227 \\
\hline 1 & 8 & 19135,2 & 95717,9 & 0,200 \\
\hline 1 & 9 & 16199,7 & 108359,7 & 0,149 \\
\hline 1 & 10 & 8635,6 & 68567,6 & 0,126 \\
\hline 1 & 11 & 18937 & 122040,5 & 0,155 \\
\hline 1 & 12 & 19562,3 & 112906,4 & 0,173 \\
\hline 1 & 13 & 19367 & 99268,9 & 0,195 \\
\hline 1 & 14 & 4994,2 & 29021,4 & 0,172 \\
\hline 1 & 15 & 18626,1 & 94603,8 & 0,197 \\
\hline 2 & 1 & 5971,8 & 23985,2 & 0,249 \\
\hline 2 & 2 & 2606,4 & 24266,7 & 0,107 \\
\hline 2 & 3 & 6059,3 & 51496,1 & 0,118 \\
\hline 2 & 4 & 6359,7 & 47935,3 & 0,133 \\
\hline 2 & 5 & 4604,9 & 35866,4 & 0,128 \\
\hline 2 & 6 & 11069,6 & 109646 & 0,101 \\
\hline 2 & 7 & 9496,2 & 30050,1 & 0,316 \\
\hline 2 & 8 & 7245,5 & 89537,5 & 0,081 \\
\hline 2 & 9 & 7683,2 & 45938,9 & 0,167 \\
\hline 2 & 10 & 7817 & 73861,6 & 0,106 \\
\hline 2 & 11 & 1946,7 & 17586,2 & 0,111 \\
\hline 2 & 12 & 3335,3 & 46396,1 & 0,072 \\
\hline 2 & 13 & 4240,7 & 23583,2 & 0,180 \\
\hline 2 & 14 & 6025,7 & 24865,4 & 0,242 \\
\hline 2 & 15 & 9102,6 & 75622,7 & 0,120 \\
\hline 3 & 1 & 8756 & 40019,6 & 0,219 \\
\hline 3 & 2 & 7700,7 & 31215,3 & 0,247 \\
\hline 3 & 3 & 4534,2 & 27089,4 & 0,167 \\
\hline 3 & 4 & 13907,1 & 62367,6 & 0,223 \\
\hline 3 & 5 & 10468,1 & 47675,5 & 0,220 \\
\hline 3 & 6 & 12319,6 & 55346,8 & 0,223 \\
\hline 3 & 7 & 19125,4 & 58326,4 & 0,328 \\
\hline 3 & 8 & 2457,9 & 8453,5 & 0,291 \\
\hline 3 & 9 & 6203,6 & 25413,7 & 0,244 \\
\hline
\end{tabular}


Anexo I - Medidas de área preenchida por colágeno $\left(\mu \mathrm{m}^{2}\right)$, área total dos espaços-porta $\left(\mu \mathrm{m}^{2}\right)$ e fração de área de colágeno - grupo PENTOXIFILINA + PREDNISOLONA 15 dias (continuação)

\begin{tabular}{|c|c|c|c|c|}
\hline Lâmina & Espaço-porta & Área de colágeno & Área total & Fração de área de colágeno \\
\hline 3 & 10 & 6034,8 & 18295,6 & 0,330 \\
\hline 3 & 11 & 5249,1 & 40039,2 & 0,131 \\
\hline 3 & 12 & 2708,6 & 9719,5 & 0,279 \\
\hline 3 & 13 & 8281,9 & 25151,1 & 0,329 \\
\hline 3 & 14 & 10559,9 & 32562,6 & 0,324 \\
\hline 3 & 15 & 12351,8 & 43349,3 & 0,285 \\
\hline 4 & 1 & 10214,6 & 46657,3 & 0,219 \\
\hline 4 & 2 & 8608,9 & 50139 & 0,172 \\
\hline 4 & 3 & 9527,7 & 40963,6 & 0,233 \\
\hline 4 & 4 & 6498,4 & 34520,5 & 0,188 \\
\hline 4 & 5 & 3452,3 & 11356 & 0,304 \\
\hline 4 & 6 & 4651,1 & 25723,2 & 0,181 \\
\hline 4 & 7 & 5763,1 & 31573,8 & 0,183 \\
\hline 4 & 8 & 4489,3 & 24177,7 & 0,186 \\
\hline 4 & 9 & 14448,4 & 71350,4 & 0,202 \\
\hline 4 & 10 & 6569,1 & 30213,9 & 0,217 \\
\hline 4 & 11 & 7886,3 & 40876,7 & 0,193 \\
\hline 4 & 12 & 6741,4 & 27739,2 & 0,243 \\
\hline 4 & 13 & 3390,6 & 17009,9 & 0,199 \\
\hline 4 & 14 & 8048 & 51735,6 & 0,156 \\
\hline 4 & 15 & 6773,6 & 37453,9 & 0,181 \\
\hline 5 & 1 & 13238,3 & 45133,6 & 0,293 \\
\hline 5 & 2 & 15309 & 62852,1 & 0,244 \\
\hline 5 & 3 & 14051,3 & 62866,8 & 0,224 \\
\hline 5 & 4 & 4187,5 & 19787,8 & 0,212 \\
\hline 5 & 5 & 18037,2 & 68994,8 & 0,261 \\
\hline 5 & 6 & 11653 & 56326,5 & 0,207 \\
\hline 5 & 7 & 15119,9 & 58984,6 & 0,256 \\
\hline 5 & 8 & 25789,7 & 139995,1 & 0,184 \\
\hline 5 & 9 & 4472,5 & 27116 & 0,165 \\
\hline 5 & 10 & 4113,3 & 13578 & 0,303 \\
\hline 5 & 11 & 4902,5 & 19233,2 & 0,255 \\
\hline 5 & 12 & 5067 & 18328,5 & 0,276 \\
\hline 5 & 13 & 16687,8 & 97582,7 & 0,171 \\
\hline 5 & 14 & 15584,2 & 41221,9 & 0,378 \\
\hline 5 & 15 & 21346,6 & 66955,6 & 0,319 \\
\hline 6 & 1 & 13097,6 & 63805,2 & 0,205 \\
\hline
\end{tabular}


Anexo I - Medidas de área preenchida por colágeno $\left(\mu \mathrm{m}^{2}\right)$, área total dos espaços-porta $\left(\mu \mathrm{m}^{2}\right)$ e fração de área de colágeno - grupo PENTOXIFILINA + PREDNISOLONA 15 dias (continuação)

\begin{tabular}{|c|c|c|c|c|}
\hline Lâmina & Espaço-porta & Área de colágeno & Área total & Fração de área de colágeno \\
\hline 6 & 2 & 18761,9 & 58065,9 & 0,323 \\
\hline 6 & 3 & 4766,6 & 20329,1 & 0,234 \\
\hline 6 & 4 & 22654 & 98970,6 & 0,229 \\
\hline 6 & 5 & 2581,8 & 15134,6 & 0,171 \\
\hline 6 & 6 & 4640,6 & 17848,8 & 0,260 \\
\hline 6 & 7 & 6975,2 & 33532,4 & 0,208 \\
\hline 6 & 8 & 11403 & 35400,7 & 0,322 \\
\hline 6 & 9 & 13578 & 33384,7 & 0,407 \\
\hline 6 & 10 & 9474,5 & 50996,1 & 0,186 \\
\hline 6 & 11 & 9219,6 & 36384,6 & 0,253 \\
\hline 6 & 12 & 2348,6 & 14087,7 & 0,167 \\
\hline 6 & 13 & 3186,9 & 19573,5 & 0,163 \\
\hline 6 & 14 & 18265,5 & 86828,2 & 0,210 \\
\hline 6 & 15 & 8524,9 & 32663,4 & 0,261 \\
\hline 7 & 1 & 34069,5 & 113504,4 & 0,300 \\
\hline 7 & 2 & 8061,3 & 35365 & 0,228 \\
\hline 7 & 3 & 13246 & 43936,1 & 0,301 \\
\hline 7 & 4 & 20184,2 & 74105,3 & 0,272 \\
\hline 7 & 5 & 6542,2 & 21096,6 & 0,310 \\
\hline 7 & 6 & 14554,1 & 57044,2 & 0,255 \\
\hline 7 & 7 & 3259 & 15399,3 & 0,212 \\
\hline 7 & 8 & 10347,7 & 43417,9 & 0,238 \\
\hline 7 & 9 & 9680,3 & 50099,1 & 0,193 \\
\hline 7 & 10 & 13746 & 50791,6 & 0,271 \\
\hline 7 & 11 & 12206,9 & 57395,7 & 0,213 \\
\hline 7 & 12 & 5607,6 & 17262,7 & 0,325 \\
\hline 7 & 13 & 10463,9 & 39303,9 & 0,266 \\
\hline 7 & 14 & 25326,1 & 97575 & 0,260 \\
\hline 7 & 15 & 9236,4 & 53932,3 & 0,171 \\
\hline 8 & 1 & 9124,3 & 41570 & 0,219 \\
\hline 8 & 2 & 13491,1 & 50866,6 & 0,265 \\
\hline 8 & 3 & 8381,4 & 49478 & 0,169 \\
\hline 8 & 4 & 5401,8 & 30628,5 & 0,176 \\
\hline 8 & 5 & 4359,8 & 21324,9 & 0,204 \\
\hline 8 & 6 & 17395,7 & 69700,6 & 0,250 \\
\hline 8 & 7 & 6230,9 & 41735,2 & 0,149 \\
\hline 8 & 8 & 15142,3 & 65646,2 & 0,231 \\
\hline
\end{tabular}


Anexo I - Medidas de área preenchida por colágeno $\left(\mu \mathrm{m}^{2}\right)$, área total dos espaços-porta $\left(\mu \mathrm{m}^{2}\right)$ e fração de área de colágeno - grupo PENTOXIFILINA + PREDNISOLONA 15 dias (conclusão)

\begin{tabular}{|c|c|c|c|c|}
\hline Lâmina & Espaço-porta & Área de colágeno & Área total & Fração de área de colágeno \\
\hline 8 & 9 & 10306,4 & 43177,6 & 0,239 \\
\hline 8 & 10 & 10065,5 & 47347,8 & 0,213 \\
\hline 8 & 11 & 16564,5 & 93452,6 & 0,177 \\
\hline 8 & 12 & 6878,6 & 29267,9 & 0,235 \\
\hline 8 & 13 & 19062,4 & 90376,4 & 0,211 \\
\hline 8 & 14 & 16726,3 & 76773,2 & 0,218 \\
\hline 8 & 15 & 10637,6 & 61346,6 & 0,173 \\
\hline 9 & 1 & 10211,1 & 54610,1 & 0,187 \\
\hline 9 & 2 & 10674 & 37848,1 & 0,282 \\
\hline 9 & 3 & 11374,3 & 38794,9 & 0,293 \\
\hline 9 & 4 & 14795 & 40969,9 & 0,361 \\
\hline 9 & 5 & 6286,2 & 23693,1 & 0,265 \\
\hline 9 & 6 & 19410,4 & 60004,2 & 0,323 \\
\hline 9 & 7 & 20346,6 & 59585,4 & 0,341 \\
\hline 9 & 8 & 8464,7 & 50487 & 0,168 \\
\hline 9 & 9 & 8230,8 & 49820,4 & 0,165 \\
\hline 9 & 10 & 6125,8 & 23284,2 & 0,263 \\
\hline 9 & 11 & 20576,3 & 101034,3 & 0,204 \\
\hline 9 & 12 & 14975,7 & 53675,3 & 0,279 \\
\hline 9 & 13 & 20965,6 & 79691,9 & 0,263 \\
\hline 9 & 14 & 11263,6 & 44810,8 & 0,251 \\
\hline 9 & 15 & 5098,6 & 27412,9 & 0,186 \\
\hline 10 & 1 & 10531,1 & 56617,8 & 0,186 \\
\hline 10 & 2 & 5701,5 & 35139,5 & 0,162 \\
\hline 10 & 3 & 8048 & 54337 & 0,148 \\
\hline 10 & 4 & 8866,6 & 41647,7 & 0,213 \\
\hline 10 & 5 & 7127,2 & 35126,9 & 0,203 \\
\hline 10 & 6 & 5520,8 & 29029,1 & 0,190 \\
\hline 10 & 7 & 33939,3 & 115535,2 & 0,294 \\
\hline 10 & 8 & 6884,2 & 33687,2 & 0,204 \\
\hline 10 & 9 & 26269,3 & 110399,5 & 0,238 \\
\hline 10 & 10 & 7822,6 & 47868,1 & 0,163 \\
\hline 10 & 11 & 12728,5 & 61153,3 & 0,208 \\
\hline 10 & 12 & 10053,6 & 44504,7 & 0,226 \\
\hline 10 & 13 & 22314,3 & 85284,1 & 0,262 \\
\hline 10 & 14 & 23755,5 & 83225,4 & 0,285 \\
\hline 10 & 15 & 22545,4 & 105635,7 & 0,213 \\
\hline
\end{tabular}


Anexo $\mathbf{J}$ - Medidas de área preenchida por colágeno $\left(\mu \mathrm{m}^{2}\right)$, área total dos espaços-porta $\left(\mu \mathrm{m}^{2}\right)$ e fração de área de colágeno - grupo PENTOXIFILINA + PREDNISOLONA 30 dias

\begin{tabular}{|c|c|c|c|c|}
\hline Lâmina & Espaço-porta & Área de colágeno & Área total & Fração de área de colágeno \\
\hline 1 & 1 & 4458,5 & 15383,2 & 0,290 \\
\hline 1 & 2 & 28165,7 & 82660,3 & 0,341 \\
\hline 1 & 3 & 23926,3 & 77479,8 & 0,309 \\
\hline 1 & 4 & 25962 & 92297,2 & 0,281 \\
\hline 1 & 5 & 15407 & 58237,5 & 0,265 \\
\hline 1 & 6 & 37230,5 & 82725,4 & 0,450 \\
\hline 1 & 7 & 33482,7 & 127581,7 & 0,262 \\
\hline 1 & 8 & 21345,2 & 99836,1 & 0,214 \\
\hline 1 & 9 & 21496,4 & 70330,9 & 0,306 \\
\hline 1 & 10 & 24529,2 & 68226,6 & 0,360 \\
\hline 1 & 11 & 27417,1 & 82284,2 & 0,333 \\
\hline 1 & 12 & 24539,8 & 94645,1 & 0,259 \\
\hline 1 & 13 & 24375,2 & 99231,8 & 0,246 \\
\hline 1 & 14 & 19537,8 & 53118,6 & 0,368 \\
\hline 1 & 15 & 18424,4 & 79411,1 & 0,232 \\
\hline 2 & 1 & 5665,1 & 40350,8 & 0,140 \\
\hline 2 & 2 & 15490,4 & 65821,2 & 0,235 \\
\hline 2 & 3 & 9069,7 & 29037,5 & 0,312 \\
\hline 2 & 4 & 16236,8 & 75871,3 & 0,214 \\
\hline 2 & 5 & 18911,8 & 67072,6 & 0,282 \\
\hline 2 & 6 & 18524,6 & 76456 & 0,242 \\
\hline 2 & 7 & 25086 & 79074,3 & 0,317 \\
\hline 2 & 8 & 15881,1 & 64971,8 & 0,244 \\
\hline 2 & 9 & 16958,1 & 93830 & 0,181 \\
\hline 2 & 10 & 14414,1 & 54806,2 & 0,263 \\
\hline 2 & 11 & 29885,5 & 111591,3 & 0,268 \\
\hline 2 & 12 & 31760,8 & 73012,8 & 0,435 \\
\hline 2 & 13 & 29597,7 & 98063,8 & 0,302 \\
\hline 2 & 14 & 22665,2 & 113610,2 & 0,199 \\
\hline 2 & 15 & 18963,6 & 90123,6 & 0,210 \\
\hline 3 & 1 & 34721,5 & 84831,8 & 0,409 \\
\hline 3 & 2 & 18843,9 & 62492,9 & 0,302 \\
\hline 3 & 3 & 18885,2 & 52961 & 0,357 \\
\hline 3 & 4 & 23050,3 & 100317,9 & 0,230 \\
\hline 3 & 5 & 3682,6 & 22393,5 & 0,164 \\
\hline 3 & 6 & 16138,8 & 60653,3 & 0,266 \\
\hline 3 & 7 & 9326,7 & 37848,8 & 0,246 \\
\hline 3 & 8 & 7758,8 & 28691,6 & 0,270 \\
\hline 3 & 9 & 15990,3 & 64780,6 & 0,247 \\
\hline
\end{tabular}


Anexo $\mathbf{J}$ - Medidas de área preenchida por colágeno $\left(\mu \mathrm{m}^{2}\right)$, área total dos espaços-porta $\left(\mu \mathrm{m}^{2}\right)$ e fração de área de colágeno - grupo PENTOXIFILINA + PREDNISOLONA 30 dias (continuação)

\begin{tabular}{|c|c|c|c|c|}
\hline Lâmina & Espaço-porta & Área de colágeno & Área total & Fração de área de colágeno \\
\hline 3 & 10 & 7990,6 & 33216,6 & 0,241 \\
\hline 3 & 11 & 14612,9 & 38186,3 & 0,383 \\
\hline 3 & 12 & 17243,8 & 53073,1 & 0,325 \\
\hline 3 & 13 & 21103,6 & 76487,5 & 0,276 \\
\hline 3 & 14 & 11245,4 & 43349,3 & 0,259 \\
\hline 3 & 15 & 11516,4 & 47054,4 & 0,245 \\
\hline 4 & 1 & 14390,3 & 58449,6 & 0,246 \\
\hline 4 & 2 & 8352,6 & 48786,8 & 0,171 \\
\hline 4 & 3 & 12816,8 & 42541,9 & 0,301 \\
\hline 4 & 4 & 7581,7 & 38278,8 & 0,198 \\
\hline 4 & 5 & 8336,5 & 42647 & 0,195 \\
\hline 4 & 6 & 13082,2 & 65201,5 & 0,201 \\
\hline 4 & 7 & 21011,9 & 93262,1 & 0,225 \\
\hline 4 & 8 & 15207,5 & 68457,7 & 0,222 \\
\hline 4 & 9 & 14517,7 & 60929,2 & 0,238 \\
\hline 4 & 10 & 17357,9 & 61300,4 & 0,283 \\
\hline 4 & 11 & 7647,5 & 39393,6 & 0,194 \\
\hline 4 & 12 & 5599,2 & 27171,3 & 0,206 \\
\hline 4 & 13 & 11668,4 & 38277,4 & 0,305 \\
\hline 4 & 14 & 12984,1 & 43990,1 & 0,295 \\
\hline 4 & 15 & 7460,5 & 26927,6 & 0,277 \\
\hline 5 & 1 & 39406,9 & 105356,3 & 0,374 \\
\hline 5 & 2 & 21871,8 & 77300,5 & 0,283 \\
\hline 5 & 3 & 33020,6 & 94821,6 & 0,348 \\
\hline 5 & 4 & 26842,2 & 82614,1 & 0,325 \\
\hline 5 & 5 & 20591,7 & 63722,6 & 0,323 \\
\hline 5 & 6 & 20467,1 & 77581,3 & 0,264 \\
\hline 5 & 7 & 16255 & 44598,6 & 0,364 \\
\hline 5 & 8 & 16659,1 & 48482,2 & 0,344 \\
\hline 5 & 9 & 22038,4 & 69766,5 & 0,316 \\
\hline 5 & 10 & 24016,7 & 72687,9 & 0,330 \\
\hline 5 & 11 & 17290,7 & 74190 & 0,233 \\
\hline 5 & 12 & 20072,8 & 73239 & 0,274 \\
\hline 5 & 13 & 19974,8 & 58158,3 & 0,343 \\
\hline 5 & 14 & 19951 & 77264,8 & 0,258 \\
\hline 5 & 15 & 24941,7 & 128248,3 & 0,194 \\
\hline 6 & 1 & 36008,5 & 132017,1 & 0,273 \\
\hline
\end{tabular}


Anexo $\mathbf{J}$ - Medidas de área preenchida por colágeno $\left(\mu \mathrm{m}^{2}\right)$, área total dos espaços-porta $\left(\mu \mathrm{m}^{2}\right)$ e fração de área de colágeno - grupo PENTOXIFILINA + PREDNISOLONA 30 dias (continuação)

\begin{tabular}{|c|c|c|c|c|}
\hline Lâmina & Espaço-porta & Área de colágeno & Área total & Fração de área de colágeno \\
\hline 6 & 2 & 27803 & 100334 & 0,277 \\
\hline 6 & 3 & 13092 & 81025,2 & 0,162 \\
\hline 6 & 4 & 17949 & 90080,2 & 0,199 \\
\hline 6 & 5 & 13580,8 & 80287,8 & 0,169 \\
\hline 6 & 6 & 25392,7 & 115802,7 & 0,219 \\
\hline 6 & 7 & 15853,1 & 96609,4 & 0,164 \\
\hline 6 & 8 & 12248,2 & 70861,7 & 0,173 \\
\hline 6 & 9 & 14794,3 & 79753,5 & 0,186 \\
\hline 6 & 10 & 9667 & 44700,1 & 0,216 \\
\hline 6 & 11 & 15112,2 & 84418,6 & 0,179 \\
\hline 6 & 12 & 7610,4 & 56833,4 & 0,134 \\
\hline 6 & 13 & 16923,8 & 78348,8 & 0,216 \\
\hline 6 & 14 & 13546,4 & 56906,3 & 0,238 \\
\hline 6 & 15 & 8124,4 & 45877,2 & 0,177 \\
\hline 7 & 1 & 15143,7 & 55875,5 & 0,271 \\
\hline 7 & 2 & 3168 & 19486 & 0,163 \\
\hline 7 & 3 & 2773 & 11899,4 & 0,233 \\
\hline 7 & 4 & 6861,1 & 37572,2 & 0,183 \\
\hline 7 & 5 & 16235,4 & 80649,1 & 0,201 \\
\hline 7 & 6 & 46247 & 147069,1 & 0,314 \\
\hline 7 & 7 & 17385,9 & 92998,8 & 0,187 \\
\hline 7 & 8 & 1985,9 & 25824 & 0,077 \\
\hline 7 & 9 & 4461,3 & 36423,8 & 0,122 \\
\hline 7 & 10 & 7613,9 & 71503,8 & 0,106 \\
\hline 7 & 11 & 6819,8 & 63908,8 & 0,107 \\
\hline 7 & 12 & 5848,5 & 46936,7 & 0,125 \\
\hline 7 & 13 & 17312,4 & 57222,8 & 0,303 \\
\hline 7 & 14 & 25802,3 & 105826,8 & 0,244 \\
\hline 7 & 15 & 10244,7 & 52986,2 & 0,193 \\
\hline 8 & 1 & 12846,2 & 99286,4 & 0,129 \\
\hline 8 & 2 & 10108,9 & 87307,2 & 0,116 \\
\hline 8 & 3 & 18222,1 & 79516,1 & 0,229 \\
\hline 8 & 4 & 7898,2 & 50437,3 & 0,157 \\
\hline 8 & 5 & 12541,6 & 76718,6 & 0,163 \\
\hline 8 & 6 & 11892,4 & 66465,5 & 0,179 \\
\hline 8 & 7 & 9233,6 & 50466 & 0,183 \\
\hline 8 & 8 & 15465,8 & 65467,6 & 0,236 \\
\hline
\end{tabular}


Anexo $\mathbf{J}$ - Medidas de área preenchida por colágeno $\left(\mu \mathrm{m}^{2}\right)$, área total dos espaços-porta $\left(\mu \mathrm{m}^{2}\right)$ e fração de área de colágeno - grupo PENTOXIFILINA + PREDNISOLONA 30 dias (conclusão)

\begin{tabular}{|c|c|c|c|c|}
\hline Lâmina & Espaço-porta & Área de colágeno & Área total & Fração de área de colágeno \\
\hline 8 & 9 & 3682,6 & 31224,4 & 0,118 \\
\hline 8 & 10 & 9372,9 & 54872,7 & 0,171 \\
\hline 8 & 11 & 7279,2 & 47054,4 & 0,155 \\
\hline 8 & 12 & 6633,5 & 36640,2 & 0,181 \\
\hline 8 & 13 & 2153,3 & 15367,1 & 0,140 \\
\hline 8 & 14 & 14021,9 & 73904,3 & 0,190 \\
\hline 8 & 15 & 12578,7 & 65706,4 & 0,191 \\
\hline 9 & 1 & 14465,2 & 98867 & 0,146 \\
\hline 9 & 2 & 19482,5 & 103604,2 & 0,188 \\
\hline 9 & 3 & 16957,4 & 107216,8 & 0,158 \\
\hline 9 & 4 & 3336,7 & 36285,1 & 0,092 \\
\hline 9 & 5 & 7178,3 & 50523,4 & 0,142 \\
\hline 9 & 6 & 3736,6 & 37019 & 0,101 \\
\hline 9 & 7 & 3710 & 31883,3 & 0,116 \\
\hline 9 & 8 & 6721,1 & 47494,1 & 0,142 \\
\hline 9 & 9 & 5043,9 & 44119,6 & 0,114 \\
\hline 9 & 10 & 5901,1 & 49357,5 & 0,120 \\
\hline 9 & 11 & 5614,6 & 52655 & 0,107 \\
\hline 9 & 12 & 9679,6 & 88443,7 & 0,109 \\
\hline 9 & 13 & 5989,3 & 34619,9 & 0,173 \\
\hline 9 & 14 & 31980 & 99009,1 & 0,323 \\
\hline 9 & 15 & 18913,9 & 55329,3 & 0,342 \\
\hline 10 & 1 & 11752,4 & 51473,7 & 0,228 \\
\hline 10 & 2 & 7952,1 & 39567,2 & 0,201 \\
\hline 10 & 3 & 13222,9 & 50725,1 & 0,261 \\
\hline 10 & 4 & 28943 & 85221,1 & 0,340 \\
\hline 10 & 5 & 16242,4 & 70056,4 & 0,232 \\
\hline 10 & 6 & 11478,6 & 68699,3 & 0,167 \\
\hline 10 & 7 & 10704,1 & 51895,9 & 0,206 \\
\hline 10 & 8 & 11750,3 & 48026,3 & 0,245 \\
\hline 10 & 9 & 2950,2 & 33889,6 & 0,087 \\
\hline 10 & 10 & 11553,5 & 66222,5 & 0,174 \\
\hline 10 & 11 & 2975,4 & 18783 & 0,158 \\
\hline 10 & 12 & 18851,6 & 69155,1 & 0,273 \\
\hline 10 & 13 & 12790,2 & 58719,2 & 0,218 \\
\hline 10 & 14 & 8947,9 & 37110 & 0,241 \\
\hline 10 & 15 & 11239,8 & 42351,5 & 0,265 \\
\hline
\end{tabular}


Anexo L - Médias e desvios-padrão das medidas de área preenchida por colágeno $\left(\mu \mathrm{m}^{2}\right)$, área total dos espaços-porta $\left(\mu \mathrm{m}^{2}\right)$ e fração de área de colágeno

\begin{tabular}{lccc}
\hline \multicolumn{1}{c}{ Grupos } & Área de colágeno & Área total & $\begin{array}{c}\text { Fração de área de } \\
\text { colágeno }\end{array}$ \\
\hline LDBC 15 dias & $27818,7 \pm 5889,6$ & $90560,6 \pm 17877,3$ & $0,316 \pm 0,073$ \\
\hline SHAM 15 dias & $1786,9 \pm 1339,7$ & $11501,9 \pm 3997,8$ & $0,129 \pm 0,041$ \\
\hline PTX 15 dias & $10650,4 \pm 1908,4$ & $87702,4 \pm 14617$ & $0,126 \pm 0,034$ \\
\hline PRED 15 dias & $10959,3 \pm 3999$ & $61032,1 \pm 13274,8$ & $0,175 \pm 0,038$ \\
\hline PTX + PRED 15 dias & $11131,9 \pm 3044,5$ & $51447,7 \pm 13996,3$ & $0,223 \pm 0,035$ \\
\hline LDBC 30 dias & $21956,3 \pm 3515$ & $71086,2 \pm 22576,7$ & $0,344 \pm 0,116$ \\
\hline SHAM 30 dias & $1811 \pm 1066,2$ & $10269,5 \pm 4566,3$ & $0,138 \pm 0,030$ \\
\hline PTX 30 dias & $12466,9 \pm 3675,9$ & $107934,6 \pm 35651$ & $0,125 \pm 0,034$ \\
\hline PRED 30 dias & $14922,7 \pm 3680$ & $70125,2 \pm 11153,7$ & $0,213 \pm 0,046$ \\
\hline PTX + PRED 30 dias & $15483,6 \pm 4909,2$ & $65172,8 \pm 11705,2$ & $0,232 \pm 0,053$ \\
\hline
\end{tabular}

Anexo M - Descrição da técnica de coloração pelo picrossírius:

1. Desparafinização a quente com xilol.

2. Hidratação: banhos sucessivos em etanol $100^{\circ}, 95^{\circ}, 80^{\circ}$ e lavagens em água corrente e água destilada.

3. Imersão no corante específico ("sirius red" + solução saturada de ácido pícrico) por 1 hora.

4. Lavagens em água corrente e água destilada.

5. Imersão em hematoxilina de Carazzi por 5 minutos (coloração de fundo dos núcleos).

6. Lavagens em água corrente e água destilada.

7. Desidratação: banhos sucessivos em etanol $80^{\circ}, 95^{\circ}, 100^{\circ}$ e xilol.

8. Montagem das lâminas com bálsamo. 
8. REFERÊNCIAS 
1. Colégio Brasileiro de Experimentação (COBEA). Princípios éticos para o uso de animais de laboratório. [citado 12 set 2007]. Disponível em: http://www.cobea.org.br.

2. Rojkind M. The liver as a bioecological system. In: Arias IM, Jakoby WB, Popper H, Schachter D, Shafritz DA. The liver: biology and pathobiology. $2^{\text {nd }}$ ed. New York: Raven Press; 1988. p.1269-85.

3. Parise ER. Matriz extracellular: fibrogênese. In: Gayotto LCC, Alves VAF. Doenças do figado e vias biliares. São Paulo: Atheneu; 2001. p.41-9.

4. Porta G, Pugliese RSP. Síndrome colestática do recém-nascido e do lactente. In: Gayotto LCC, Alves VAF, editores. Doenças do fígado e vias biliares. São Paulo: Atheneu; 2001. p.239-52.

5. Silva MM, Maksoud JG. Atresia das vias biliares. In: Maksoud JG. Cirurgia pediátrica. $2^{\mathrm{a} e d . ~ R i o ~ d e ~ J a n e i r o: ~ R e v i n t e r ; ~ 2003 . ~ p .904-22 . ~}$

6. Chapchap P. Atresia das vias biliares e outras alterações dos ductos biliares extra-hepáticos. In: Gayotto LCC, Alves VAF, editores. Doenças do figado e vias biliares. São Paulo: Atheneu; 2001. p. 267-81. 
7. Karrer FM, Lilly JR. Corticosteroid therapy in biliary atresia. J Pediatr Surg. $1985 ; 20: 693-5$.

8. Muraji T, Higashimoto Y. The improved outlook for biliary atresia with corticosteroid therapy. J Pediatr Surg. 1997;32:1103-7.

9. Kobayashi H, Yamataka A, Koga H, Okazaki T, Tamura T, Urao M, Yanai T, Lane GJ, Miyano T. Optimum prednisolone usage in patients with biliary atresia postportoenterostomy. J Pediatr Surg. 2005;40:327-30.

10. Escobar MA, Jay CL, Brooks RM, West KW, Rescorla FJ, Molleston JP, Grosfeld JL. Effect of corticosteroid therapy on outcomes in biliary atresia after Kasai portoenterostomy. J Pediatr Surg. 2006;41:99-103.

11. Stringer MD, Davison SM, Rajwal SR, McClean P. Kasai portoenterostomy: 12-year experience with a novel adjuvant therapy regimen. J Pediatr Surg. 2007;42:1324-8.

12. Albanis E, Friedman SL. Antifibrotic agents for liver disease. Am $J$ Transplant. 2006;6:12-9.

13. Li X, Meng Y, Wu P, Zhang Z, Yang X. Angiotensin II and aldosterone stimulating NF- $\kappa \beta$ and AP-1 activation in hepatic fibrosis of rat. Regul Pept. 2007;138:15-25. 
14. Oberti F, Pilette C, Rifflet H, Maïga MY, Moreau A, Gallois Y, Girault A, Bouil A, Le Jeune JJ, Saumet JL, Feldmann G, Calès P. Effects of simvastatin, pentoxifylline and spironolactone on hepatic fibrosis and portal hypertension in rats with bile duct ligation. J Hepatol. 1997;26:1363-71.

15. Hsu YC, Chiu YT, Cheng CC, Wu CF, Lin YL, Huang YT. Antifibrotic effects of tetrandrine on hepatic stellate cells and rats with liver fibrosis. Hepatology. 2007;22:99-111.

16. Peterson TC, Neumeister M. Effect of pentoxifylline in rat and swine models of hepatic fibrosis: role of fibroproliferation in its mechanism. Immunopharmacology. 1996;31:183-93.

17. Ward A, Clissold SP. Pentoxifylline: a review of its pharmacodynamic and pharmacokinetic properties and its therapeutic efficacy. Drugs. 1987;34:50-97.

18. Raetsch C, Jia JD, Boigk G, Bauer M, Hahn EG, Riecken EO, Schuppan D. Pentoxifylline downregulates profibrogenic cytokines and procollagen I expression in rat secondary biliary fibrosis. Gut. 2002;50:241-7.

19. Schandené L, Vandenbussche P, Crusiaux A, Alègre ML, Abramowicz D, Dupont E, Content J, Goldman M. Differential effects of pentoxifylline on the production of tumour necrosis factor-alpha (TNFa) and interleukin-6 (IL-6) by monocytes and T cells. Immunology. 1992;76:30-4. 
20. Tarçin O, Avsar K, Demirtürk L, Gültepe M, Oktar BK, Ozdogan OC, Tarçin O, Baloglu H, Gürbüz AK. In vivo inefficiency of pentoxifylline an interferon-alpha on hepatic fibrosis in biliary-obstructed rats: assessment by tissue collagen content and prolidase activity. $J$ Gastroenterol Hepatol. 2003;18:437-44.

21. Neuner P, Klosner G, Pourmojib M, Knobler R, Schwarz T. Pentoxifylline in vivo and in vitro down-regulates the expression of intercellular adhesion molecule-1 in monocytes. Immunology. 1997;90:435-9.

22. Kumar V, Abbas AK, Fausto N, editors. Robbins and Cotran pathologic basis of disease. $7^{\text {th }}$ ed. Philadelphia: Elsevier; 2005.

23. Riepenhoff-Talty M, Schaekel K, Clark HF, Mueller W, Uhnoo I, Rossi T, Fisher J, Ogra PL. Group A rotaviruses produce extrahepatic biliary obstruction in orally inoculated newborn mice. Pediatr Res. 1993;33:394-9.

24. Cameron GR, Oakley CL. Ligation of the common bile duct. J Pathol Bact. 1932;35:769-98.

25. Medeiros MVMJ, Freitas LAR, Andrade ZA. Differences in hepatic pathology resulting from bile duct obstruction in young and old rats. Braz $J$ Med Biol Res. 1988;21:75-83. 
26. Omori M, Evarts RP, Omori N, Hu Z, Marsden ER, Thorgeirsson SS. Expression of $\alpha$-fetoprotein and stem cell factor/ c-kit system in bile duct ligated young rats. Hepatology. 1997;25:1115-22.

27. Gibelli NEM. Fibrose portal e periportal na obstrução extra-hepática experimental em ratos jovens e adultos: contribuição para o estudo da atresia das vias biliares [tese]. São Paulo: Faculdade de Medicina, Universidade de São Paulo; 2003.

28. Gibelli NE, Tannuri U, de Mello ES, Rodrigues CJ. Bile duct ligation in neonatal rats: Is it a valid experimental model for biliary atresia studies? Pediatr Transplant. 2008 Apr 28. [Epub ahead of print]

29. Kisseleva T, Brenner DA. Role of hepatic cells in fibrogenesis and the reversal of fibrosis. J Gastroenterol Hepatol. 2007;22:S73-8.

30. Bucuvalas JC, Ryckman FC, Atherton H. Predictors of cost of liver transplantation in children: a single center study. J Pediatr. 2001;139:66-74.

31. Demirbilek S, Tas E, Gurunluoglu K, Akin M, Aksoy RT, Emre MH, Aydin NE, Ay S, Ozatay N. Fluvastatin reduced liver injury in rat model of extrahepatic cholestasis. Pediatr Surg Int. 2007;23:155-62. 
32. Schreiber RA, Kleinman RE. Genetic, immunology, and biliary atresia: an opening or a diversion? J Pediatr Gastroenterol Nutr. 1993;16:111-3.

33. Raweily EA, Gibson AAM, Burt AD. Abnormalities of intrahepatic bile ducts in extrahepatic biliary atresia. Histopathology. 1990;27:521-7.

34. Sokol RJ, Mack C. Ethiopathogenesis of biliary atresia. Semin Liver Dis. $2001 ; 21: 517-24$

35. Ahmed AFKU, Ohtani H, Nio M, Funaki N, Iwami D, Kumagai S, Sato E, Nagura H, Ohi R. In situ expression of fibrogenic growth factors and their receptors in biliary atresia: comparison between early and late stages. $J$ Pathol. 2000;192:73-80.

36. Froh M, Conzelmann L, Walbrun P, Netter S, Wiest R, Wheeler MD, Lehnert M, Uesugi T, Scholmerich J, Thurman RG. Heme oxygenase-1 overexpression increases liver injury after bile duct ligation in rats. World $J$ Gastroenterol. 2007;13:3478-86.

37. Guyot C, Lepreux S, Combe C, Doudnikoff E, Bioulac-Sage P, Balabaud C, Desmoulière A. Hepatic fibrosis and cirrhosis: the (myo)fibroblastic cell subpopulations involved. Int J Biochem Cell Biol. 2006;38:135-51. 
38. Meyers RL, Book LS, O'Gorman MA, Jackson WD, Black RE, Johnson DG, Matlak ME. High dose steroids, ursodeoxycholic acid, and chronic intravenous antibiotics improve bile flow after Kasai procedure in infants with biliary atresia. J Pediatr Surg. 2003;38:406-11.

39. Miner PB, Gaito JM. Bile flow in response to pharmacologic agents. Biochem Pharmacol. 1979;28:1063-6.

40. Simon FR, Sutherland E, Accatino L. Stimulation of hepatic sodium and potassium-activated adenosine triphosphatase activity by Phenobarbital - its possible role in regulation of bile flow. J Clin Invest. 1977;59:849-61.

41. Rhen T, Cidlowski JA. Mechanisms of disease: anti-inflammatory action of glucocorticoids - new mechanisms for old drugs. $N$ Engl $J$ Med. $2005 ; 353: 1711-23$.

42. Muraji T, Nio M, Ohhama Y, Hashimoto T, Iwanaka T, Takamatsu H, Ohnuma N, Kato T, Ohi R. Postoperative corticosteroid therapy for bile drainage in biliary atresia: a nationwide survey. $J$ Pediatr Surg. 2004;39:1803-5.

43. Davenport M, Stringer MD, Tizzard SA, McClean P, Mieli-Vergani G, Hadzic N. Randomized, double-blind, placebo-controlled trial of corticosteroids after Kasai portoenterostomy for biliary atresia. Hepatology. 2007;46:1821-7. 
44. Washburn LK, Nixon PA, O'Shea TM. Follow-up of a randomized, placebocontrolled trial of postnatal dexamethasone: blood pressure and anthropometric measurements at school age. Pediatrics. 2006;118:1592-9.

45. Iuchi T, Akaike M, Mitsui T, Ohshima Y, Shintani Y, Azuma H, Matsumoto T. Glucocorticoid excess induces superoxide production in vascular endothelial cells and elicits vascular endothelial dysfunction. Circ Res. 2003;92:81-7.

46. Windmeier C, Gressner AM. Pharmacological aspects of pentoxifylline with emphasis on its inhibitory actions on hepatic fibrosis. Gen Pharmacol. 1997;29:181-96.

47. Bender AT, Beavo JA. Cyclic nucleotide phosphodiesterases: molecular regulation to clinical use. Pharmacol Rev. 2006;58:488-520.

48. Conti M, Beavo JA. Biochemistry and physiology of cyclic nucleotide phosphodiesterases: essential components in cyclic nucleotide signaling. Annu Rev Biochem. 2007;76:481-511.

49. Omori K, Kotera J. Overview of PDEs and their regulation. Circ Res. 2007;100:306-27. 
50. Lee KS, Cottam HB, Houglum K, Wasson DB, Carson D, Chojkier M. Pentoxifylline blocks hepatic stellate cell activation independently of phosphodiesterase inhibitory activity. Am J Physiol Gastrointest Liver Physiol. 1997;273:1094-100.

51. Peterson T. Pentoxifylline prevents fibrosis in an animal model and inhibits platelet-derived growth factor driven proliferation of fibroblast. Hepatology. 1993; 17:486-93.

52. Preaux A, Mallat A, Rosenbaum J, Zafrani E, Mavier P. Pentoxifylline inhibits growth and collagen synthesis of cultured human hepatic myofibroblast cells. Hepatology. 1997;26:315-22.

53. Anania F, Potter J, Rennie-Tankersley L, Mezey E. Activation by acetaldehyde of the promoter of the mouse alpha- 2 collagen gene when transfected into rat activated stellate cells. Arch Biochem Biophys. 1996;331:187-93.

54. Stark AR, Carol WA, Tyson JE, Papile LA, Wright LL, Shankaran S. Adverse effects of early dexamethasone in extremely-low-birth-weight infants. N Engl J Med. 2001;344:95-101. 